\title{
Feasibility and Design Considerations of Emergency Evacuation by Elevators
}

John H. Klote

Daniel M. Alvord

Bernard M. Levin

Norman E. Groner
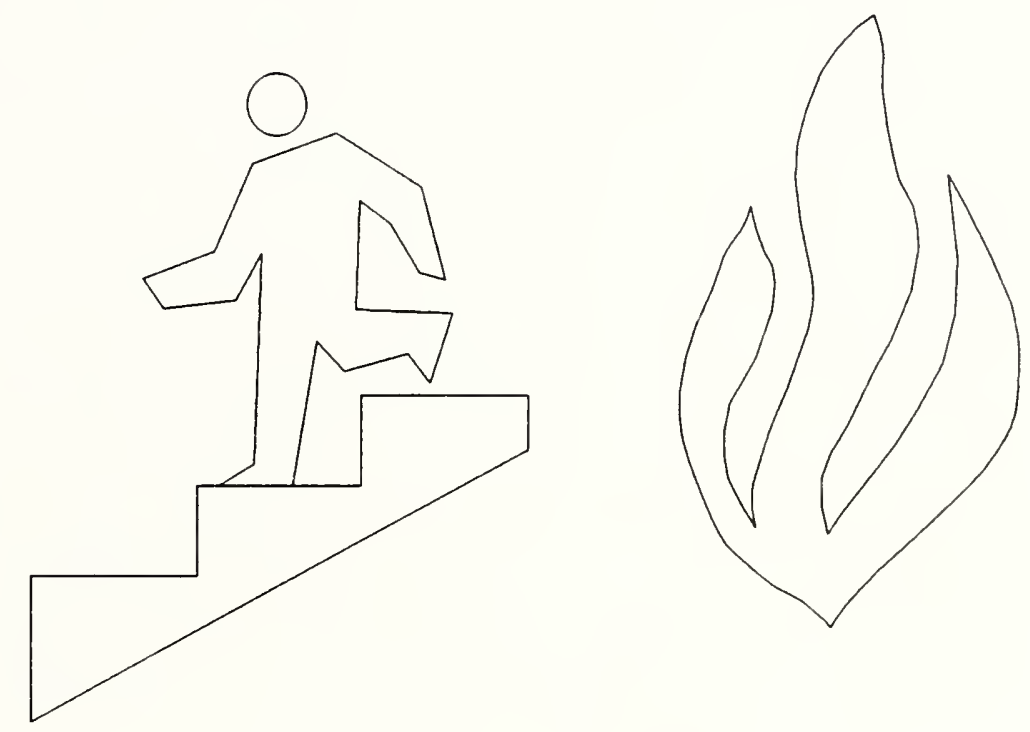

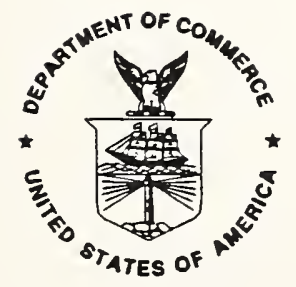

U.S. Department of Commerce Technology Administration

National Institute of Standards and Technology Gaithersburg, MD 20899

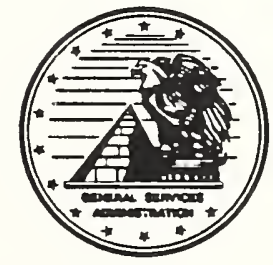

Prepared for:

General Services Administration

Public Buildings Service

Office of Real Property Management and Safety Washington, DC 20405 



\section{Feasibility and Design Considerations of Emergency Evacuation by Elevators}

John H. Klote

Daniel M. Alvord

Building and Fire Research Laboratory

Gaithersburg, Maryland 20899

Bernard M. Levin

Norman E. Groner

George Mason University

Fairfax, Virginia 22030

September 1992

U.S. Department of Commerce

Barbara Hackman Franklin, Secretary

Technology Administration

Robert M. White, Under Secretary for Technology

National Institute of Standards and Technology

John W. Lyons, Director
Prepared for:

General Services Administration Richard G. Austin, Administrator Public Buildings Service Milton Herson, Commissioner Office of Real Property Management and Safety Washington, D.C. 20405 



\section{Table of Contents}

Page

List of Figures $\ldots \ldots \ldots \ldots \ldots \ldots \ldots \ldots \ldots \ldots \ldots \ldots \ldots \ldots \ldots \ldots \ldots \ldots$

List of Tables $\ldots \ldots \ldots \ldots \ldots \ldots \ldots \ldots \ldots \ldots \ldots \ldots \ldots \ldots \ldots \ldots \ldots$

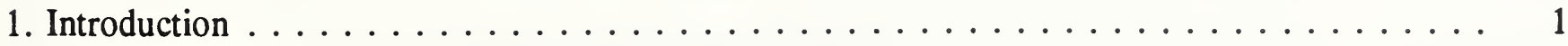

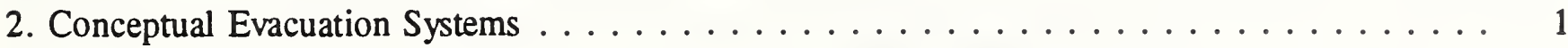

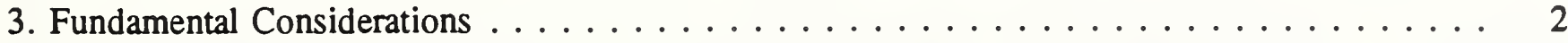

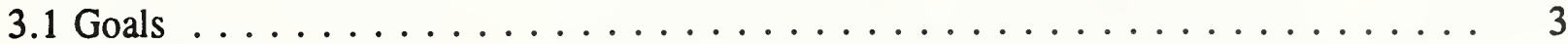

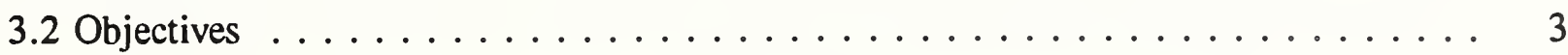

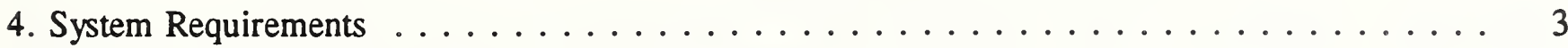

5. Manual and Automatic Control .......................... 4

6. Calculation of Evacuation Time ........................ 5

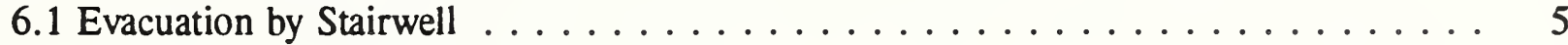

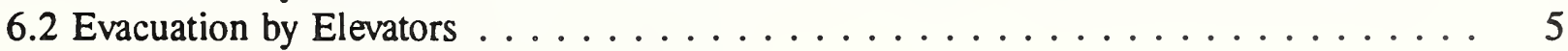

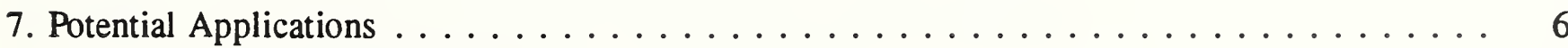

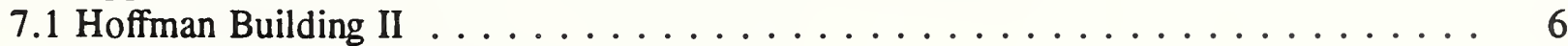

7.2 White Flint North Building . . . . . . . . . . . . . . . . . 7

7.3 Jackson Federal (Seattle) Building $\ldots \ldots \ldots \ldots \ldots \ldots$

7.4 General Services Building $\ldots \ldots \ldots \ldots \ldots \ldots \ldots$

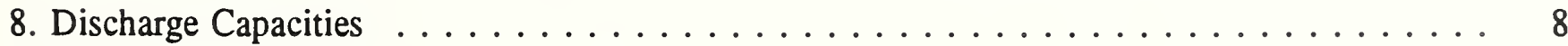

9. Other Evacuation Concepts $\ldots \ldots \ldots \ldots \ldots \ldots \ldots \ldots \ldots$

10. Engineering Considerations $\ldots \ldots \ldots \ldots \ldots \ldots \ldots \ldots \ldots \ldots \ldots \ldots \ldots \ldots \ldots$

10.1 Doors Opening Onto the Fire . . . . . . . . . . . . . . . . . 10

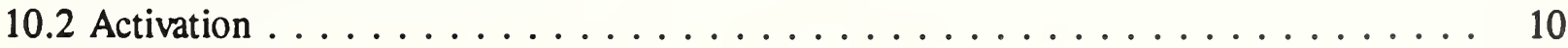

10.3 Elevator Doors Jamming Open . . . . . . . . . . . . . . . . . 11

10.4 Fire Resistance $\ldots \ldots \ldots \ldots \ldots \ldots \ldots \ldots \ldots \ldots \ldots$

10.5 Water Damage . . . . . . . . . . . . . . . . . . . . . . . 11

10.6 Reliability of Electrical Power . . . . . . . . . . . . . . . . . . 12

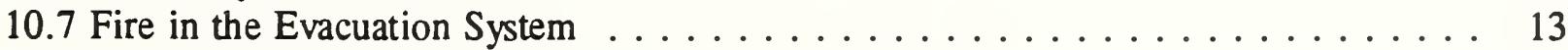

10.8 Smoke and the Evacuation System . . . . . . . . . . . . . . . . 14

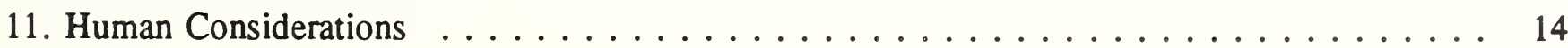

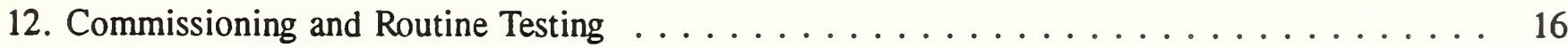

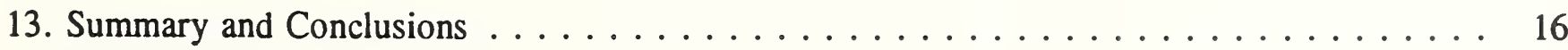




\section{Table of Contents (continued)}

14. Acknowledgements . . . . . . . . . . . . . . . . . . . . 17

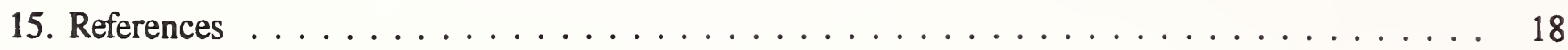

Appendix A Design of Elevator Smoke Control Systems $\ldots \ldots \ldots \ldots \ldots \ldots \ldots$

Appendix B Calculation of the People Movement Time for Elevator Evacuation . . . . . . . 62

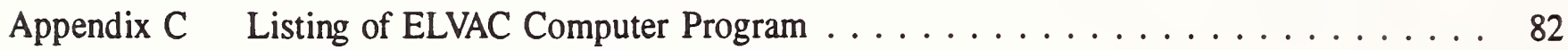

Appendix D ELVAC Example of an 11 story building $\ldots \ldots \ldots \ldots \ldots \ldots \ldots$

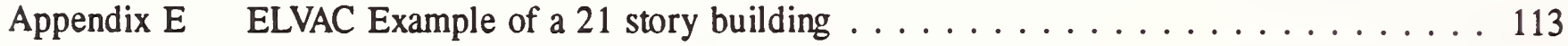

Appendix $F \quad$ ELVAC Example of a building with multiple rises $\ldots \ldots \ldots \ldots \ldots$ 


\section{List of Figures}

Page

Figure 1. Typical sign currently used to indicate that elevators should not to be used during

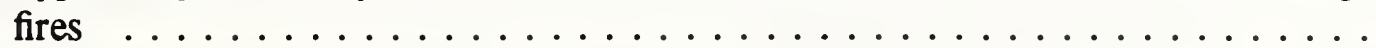

Figure 2. Diagram of physical systems and people flow for emergency use of both stairs

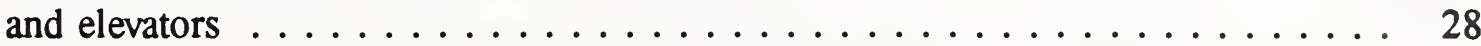

Figure 3. Diagram of system interaction for emergency use of both stairs and elevators . . . 29

Figure 4. Ground floor plan of Hoffman Building II . . . . . . . . . . . . . . . . 30

Figure 5. Typical plan for floors 1 through 12 of Hoffman Building II . . . . . . . . . . 30

Figure 6. Time for combinations of stair and elevator evacuation for Hoffman Building

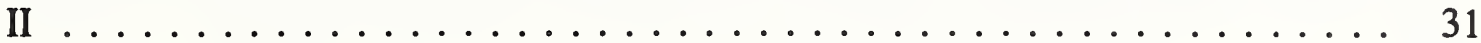

Figure 7. Typical plan of floors 2 through 16 of the White Flint North Building . . . . . . 32

Figure 8. Time for combinations of stair and elevator evacuation for White Flint North

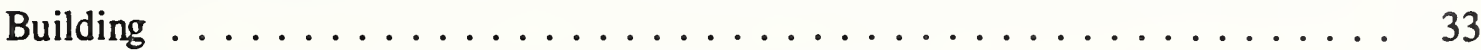

Figure 9. Diagram of the elevator rises at the Seattle Building . . . . . . . . . . . . 34

Figure 10. Fourth floor plan of the Seattle Building . . . . . . . . . . . . 35

Figure 11. Typical low rise elevator plan of the Seattle Building (floors 5-13) . . . . . . . 36

Figure 12. Typical mid rise elevator plan of the Seattle Building (floors 15-25) . . . . . . 37

Figure 13. Typical high rise elevator plan of the Seattle Building (floors 27-35) . . . . . . . 38

Figure 14. Time for different combinations of stair and elevator evacuation of the mid and high rise floors of the Seattle Building $\ldots \ldots \ldots \ldots \ldots$

Figure 15. First floor plan of the GSA Building . . . . . . . . . . . . . . . 40

Figure 16. Typical plan of floors 2 through 6 of the GSA Building . . . . . . . . . . 41

Figure 17. Seventh floor plan of the GSA Building . . . . . . . . . . . . . . 42 


\section{List of Tables}

Table 1.

Data used for evacuation calculations of the Hoffman Building II

Table 2. Evacuation times for combinations of Elevator and Stairwell Use for evacuation of the Hoffman Building II . . . . . . . . . . . . . . . 21

Table 3. Data used for evacuation calculations of the White Flint North Building

Table 4. Evacuation times for combinations of Elevator and Stairwell Use for evacuation of the White Flint North Building . . . . . . . . . . . . . . 23

Table 5. Data used for evacuation calculations of the Seattle Building

Table 6. Evacuation times for combinations of Elevator and Stairwell Use for evacuation

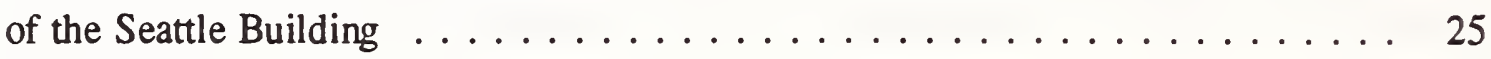

Table 7. Data used for evacuation calculations of the GSA Building 


\section{Feasibility and Design Considerations of Emergency Evacuation by Elevators}

\section{Introduction}

Throughout most of the world, warning signs next to elevators indicate they should not be used in fire situations (figure 1). These elevators are not intended as means of fire egress, and they should not be used for fire evacuation (Sumka 1987). The idea of using elevators to speed up fire evacuation and to evacuate persons with disabilities has gained considerable attention (Bazjanac 1974, Bazjanac 1977, Pauls 1977, Pauls, Gatfield and Juillet 1991, Gatfield 1991, Degenkolb 1991, and Fox 1991).

A joint project of the National Institute of Standards and Technology (NIST) in the United States and the National Research Council of Canada (NRCC) was formed to evaluate the feasibility of smoke control by pressurization for elevator evacuation systems. Full-scale fire experiments were conducted at the NRCC's ten story fire research tower near Ottawa (Tamura and Klote, 1988, 1987a, 1987b, 1987c). These experiments verified that pressurization can provide smoke protection for the elevator system. Additionally, the joint NIST/NRCC project addressed the impact of pressure disturbances caused by elevator car motion on smoke control (Klote and Tamura, 1987, 1986; Klote, 1988). Such piston effect is a concern, because it can pull smoke into a normally pressurized elevator lobby. While smoke control of elevator systems by pressurization may not be necessary in some applications, a summary of the findings of the joint project that are relevant to the design of elevator smoke control is presented in Appendix A.

The potential of elevator evacuation is so significant that the U.S. General Services Administration (GSA) has sponsored a research project at NIST to develop techniques for occupant use of elevators during building evacuations. This paper is the final report of that project, and it addresses fundamental system considerations, engineering design considerations, design analysis, and human behavior. This paper shows that use of elevators in addition to stairs during a fire emergency allows occupants and firefighters an additional system of vertical transportation. Even though the focus of this paper is fire evacuation, much of the information is also applicable to evacuation for other emergencies.

\section{Conceptual Evacuation Systems}

The extent to which elevator use speeds up evacuation depends on the specific building and the Occupant Emergency Plan $^{1}$ (OEP) and the impact of the fire on vertical transportation systems and other building systems. For combined stair and elevator use, the OEP should assign a specific stairwell or a specific group of elevators for occupants to use based on the location of the occupants in the building. The OEP should assign alternate means (elevators or stairs) of vertical travel in the event that the primary means can not be used because of the fire. Of course, persons who can not use stairs or have great difficulty using stairs should use elevators regardless of their location. Pauls (1988) estimates that about $3 \%$ of the population have such mobility limitations.

\footnotetext{
${ }^{1}$ All GSA buildings are required to have an Occupant Emergency Plan including a system of warden or monitors to implement the plan. Further, all GSA buildings have two fire drills a year.
} 
Even though an OEP and routine fire drills are valuable, they generally do not incorporate fire related conditions and the wide range of resulting people movement. Figure 2 is a diagram of the stair and elevator systems illustrating the possible kinds of movement. The arrow heads on this figure indicate possible flow of occupants and firefighters into and out of each floor, to and from the roof, and to and from the outside. In addition to the movement described in the OEP, this figure represents deviations from that movement. Routes can be blocked by fire or smoke, resulting in alternate routes or trapped occupants. It is well known that travel differing from the OEP includes rescue by fire fighters, fire fighting mobilization, occupants searching for loved ones, occupants investigating the fire, and occupants fighting the fire. Further, much of the actual movement in fire emergencies is bidirectional. A person may have difficulty walking down the stairs, and after a going down a number of flights, they may leave the stairs and go to an elevator.

Elevator and stair systems interact with other systems in the building as illustrated in figure 3 . The occupants can choose to use stairs or elevators based on information they get about the fire, smoke, stair system, elevator system, utilities system, and fire protection system. Fire and smoke can threaten the utilities system and the fire protection system. For example, fire can damage electrical distribution to the fire protection system or fire can damage water supply to sprinklers. Further, smoke can infiltrate stairwells and elevator shafts. Occupants can get information by observation or from a communication system. For example, occupants may see smoke in a corridor blocking their way to a stair and use another means of vertical transportation. Another example is people who are waiting for elevator evacuation keeping in two way communication with a central control station.

An elevator evacuation system needs to be able to operate under a wide range of people movement patterns, smoke movement and fire spread. Because there are so many combinations of conditions possible, it is difficult to be sure that a conventional design will operate. A computer program for simulating elevator and stair evacuation would provide a means for evaluating system performance under numerous conditions of operation. Such a program could be used to evaluate various control approaches and to train people to operate the elevator system. However, such simulation software is beyond the scope of this paper.

\section{Fundamental Considerations}

The fundamental reasons for having any safety related system are to save lives and reduce property damage. These reasons apply to elevator evacuation as well. Additionally, an elevator evacuation might be installed with the intent of cost reduction. If elevators become a totally accepted means of fire evacuation, society could allow a reduction in stair capacity in new buildings with elevator evacuation. However, cost reduction is not addressed further in this paper.

Because more specific details are needed about how an elevator evacuation system should operate, goals and objectives need to be considered. For the purposes of this paper, the meanings of the terms goals and objectives are consistent with those of Churchman (1979). Goals are abstract statements describing the purposes for providing a system. Objectives are succinct statements that clarify the goal statements by describing the desired performance in terms of engineering parameters that can be measured. Ideally all parties (designers, local authorities, owner, etc.) should be involved in the selection of goals and objectives for a particular system. Additionally, all these parties should develop an agreement as to the purpose and capabilities of the system. 


\subsection{Goals}

Some possible goals of an elevator evacuation system are:

- to move occupants from locations of potential danger to the outside,

- to move occupants with mobility limitations from locations of potential danger to the outside,

- to move occupants from locations of potential danger to locations of safety inside the building,

- to move occupants with mobility limitations from locations of potential danger to locations of safety inside the building,

to move fire service personnel and equipment to fight fires,

to move fire service personnel to rescue occupants,

to minimize occupant time on the fire floor,

to maintain operation of the elevator system during evacuation, and

to maintain operation of the elevator system during both evacuation and fire service operations.

Usually, elevator evacuation systems would be designed to accomplish a number of these goals. Alternatively, a goal or goals not on this list might be selected. The goals above are abstract statements in that they do not provide specific guidance and specific information about the desired performance of the system. The objectives include specific information.

\subsection{Objectives}

Some possible objectives of an elevator evacuation system are:

- move occupants from the fire floor within $x$ minutes,

- to move occupants from locations of potential danger to the outside within $x$ minutes,

- to move occupants with mobility limitations from locations of potential danger to the outside within $x$ minutes,

- to move occupants from locations of potential danger to locations of safety inside the building within $x$ minutes,

- to move occupants with mobility limitations from locations of potential danger to locations of safety inside the building within $x$ minutes,

- $\quad$ to move $x$ firefighters and their equipment to fight fires within $y$ minutes,

- to move $x$ firefighters within the building to rescue $y$ occupants within $z$ minutes,

- to maintain operation of the elevator system for the $x$ minutes required for evacuation, and

- to maintain operation of the elevator system for the $x$ minutes required for both evacuation and fire service operations.

Determination of the quantities above is difficult without a computer simulation of combined stair and elevator evacuation.

\section{System Requirements}

For discussion, a system will be considered with the following objectives:

- move occupants from the fire floor within $x$ minutes,

- to move occupants from locations of potential danger to the outside within $x$ minutes, 
- to move occupants with mobility limitations from locations of potential danger to the outside within $x$ minutes,

- to move $x$ firefighters and their equipment to fight fires within $y$ minutes,

- to move $x$ firefighters within the building to rescue $y$ occupants within $z$ minutes,

- to maintain operation of the elevator system for the $x$ minutes required for both evacuation and fire service operations.

For a conceptual system with these objectives, the requirements for elevator evacuation systems are:

- people must accept the system,

- the system must be usable by people,

- people and the system must be protected from heat, smoke, water, etc.,

- system components must be reliable,

- elevator evacuation controls (manual or automatic) must be provided,

- elevator fire service controls (manual or automatic) must be provided,

- communications to and from a command center (for example from telephones, intercoms, call buttons, detectors, water flow, etc.) must be available,

- protected lobbies must be sized to be big enough for the number of people waiting, and

- discharge lobbies and floors must be able to handle the flow of people.

\section{Manual and Automatic Control}

Elevator evacuation systems can be considered to fall into one of the following system types:

- Manual control with total building evacuation

- Manual control with partial building evacuation

- Automatic control with total building evacuation

- Automatic control with partial building evacuation

In a manual control system, a person inside the elevator car manually controls the operation of the car. This person may be a building security officer, a member of the fire service, or some other person. It could be considered that this manual operation is a rescue function, because the occupants need the intervention of other people to get to safety. However, one generally thinks of rescue as being unplanned. For this paper the planned use of elevators under manual control for the people movement to locations of safety is considered to be evacuation.

Automatic control consists of a special emergency mode of automatic elevator control. The occupants provide input to the system indicating that they are waiting in an elevator lobby on a particular floor. This input could be in the form of pushing a call button. The elevator evacuates the occupants according to a predetermined logic for this emergency taking into account data from various sensors in the elevator system and in the building.

Both manual and automatic systems can be used for total or partial evacuation, and this will have an effect on the details of the elevator system. Numerous variations of these four systems are possible, but it is not feasible to discuss all these variations in this paper. However, all of the systems should have the same goals and requirements discussed above.

Automatic control has a time advantage in that there are no human operators who need to get to the elevators before evacuation can start. Manual control has the advantage that people can adjust their 
actions to situations not anticipated in an automatic control program. However, the development of a computer evacuation simulation program could allow detailed computer testing of an automatic control program to minimize the potential for unforseen problems.

\section{Calculation of Evacuation Time}

The evacuation time addressed in this paper is an idealized time for people movement of the OEP. As previously stated, this time does not account for the complex human behavior that often occurs during emergencies. It is believed that the estimates of evacuation time by elevators in this paper are about as accurate as those for evacuation by stairs. There is little guidance available regarding the extent to which actual evacuation time is greater than the idealized times for stairs or elevators. Nelson and MacLennan (1988) indicate that, for stair evacuation, actual evacuation time can be two or even three times as long. However, for a building with regular fire drills, the difference between the calculated evacuation time and the actual time may be much smaller. While an OEP and fire drills are the rule for GSA buildings, they occur less often in the private sector.

\subsection{Evacuation by Stairwell}

The stair evacuation times used in this paper were based on idealized flow such as that described by Nelson and MacLennan (1988). The effective width concept of Pauls (1988) was used to calculate all flows as is illustrated by the example problem presented by Nelson and MacLennan.

\subsection{Evacuation by Elevators}

Analysis of the time for people movement during elevator evacuation must take into account the number and arrangement of elevators in a building. Generally elevators are located in groups of up to eight elevators. Elevators in a group are located near each other and are controlled together to efficiently move people. Ideally the time to evacuate a number of people using one group of elevators consists of the sum of all the round trip times divided by the number of elevators plus the time needed to start up the elevator evacuation and the travel time from the elevator lobby to the outside (or to another safe location). Inefficiencies of elevator operation must also be addressed.

The round trip starts at the discharge floor and consists of the following sequence: elevator doors close, car travels to another floor, elevator doors open, passengers enter the car, doors close, car travels to discharge floor, doors open, and passengers leave the car. Travel time consists of acceleration, constant velocity and deceleration.

The elevator evacuation start up time is the time from activation to the start of the round trips that evacuate people. For automatic elevator operation during evacuation, a simple approach is to start elevator evacuation after all of the elevators have been moved to the discharge floor. An alternative to this simple approach consists of starting the evacuation operation individually for each elevator when it reaches the discharge floor. While this alternative can result in slightly reduced evacuation time, it is not discussed in this paper due to its limited benefit and added complexity. For manual elevator operation, the time for elevator operators to be alerted and then get to the elevators must be included in the estimate of start up time. The start up time for manual operation can be considerably greater than that for automatic operation. 
More detailed information about evacuation time by elevators is provided in appendix B including relevant information about elevator engineering. An interactive computer program, ELVAC, was written specifically for the analyses of this paper, and a copy of this program is listed in appendix C. ELVAC calculates the evacuation time for people using one group of elevators. For buildings with multiple groups of elevators including multiple elevator rises, ELVAC is be applied separately to each group of elevators in order to calculate the elevator evacuation time for the building. It is believed that this computer program may be helpful to others interested in elevator evacuation. Example applications of ELVAC to various buildings are provided in appendices $D, E$ and $F$.

\section{Potential Applications}

Four GSA buildings were selected to be analyzed as potential applications of elevator evacuation. These buildings were selected in an attempt to study buildings of different heights, elevator capabilities, and architectural characteristics. For each of the buildings, the advantages of combined stair and elevator evacuation are:
a. reduction of estimated building evacuation time,
b. people with disabilities can use elevators to evacuate the building in the same way that they entered,
c. the fire service can use the elevators to rescue occupants, and
d. the fire service can use the elevators to move men and equipment for fire fighting.

These building and the extent to which elevators can reduce evacuation time are described below. The following sections address total building evacuation, and other evacuation concepts are addressed later.

\subsection{Hoffman Building II}

The Hoffman Building II, located in Alexandria, VA, is an office building leased by GSA and used primarily by the US Army and US Navy. This 13 story building is unsprinklered and has four stairwells and two groups of 6 elevators. Figure 4 shows the plan of the ground floor of Hoffman building II, and figure 5 shows a typical plan of the upper floors. The building has an office population of 3506. The number of people at work on a particular day will differ, because some people will be on travel or vacation and there will be some visitors. It is estimated that on a typical day the total number of people will be about $85 \%$ of the office population. The number of evacuees were estimated by proportioning them on a floor area basis, resulting in 230 people per floor. A similar approach was used for the other buildings.

The data used for calculation of evacuation times for the Hoffman Building are listed in table 1. Only five elevators in each group were used for the calculations, because use of all six elevators resulted in congestion and restricted flow in the discharge lobby at the ground floor. This restricted flow is discussed in more detail later. Estimated time for total evacuation by stairs is about 15 minutes, and estimated time for total evacuation by elevators is 24 minutes.

Various approaches for combined stair and elevator evacuation were considered. An appropriate approach that seems particularly advantageous is elevator evacuation for the upper floors and of the people with mobility limitations on other floors, and stair evacuation for the rest of the occupants. The number of persons with mobility limitations were taken to be $3 \%$ of the evacuees for this and the other buildings analyzed. Table 2 lists the results of evacuation calculations that were made for different combinations 
of floors evacuated by elevator. This information is also shown in figure 6. The optimum was found to be elevator evacuation of the upper four floors. The building evacuation time for this combination was estimated at about 11 minutes. Thus combined stair and elevator evacuation is about $20 \%$ faster than stair only evacuation.

\subsection{White Flint North Building}

The White Flint North Building is located in Bethesda, MD and is an office building which was speculatively built and then purchased by GSA. This 18 story building has one group of six elevators and two stairwells as illustrated in figure 7. The building has an office population of 1425 people, and the number of evacuees were estimated at 68 people per floor.

Table 3 lists data for the analysis of this building. The same stair and elevator approach was used for this building as for the Hoffman Building. The results of the calculations are summarized in table 4 and shown graphically in figure 8. Only four elevators were used for the calculations, because use of all six elevators resulted in congestion and restricted flow in the discharge lobby at the ground floor. This restricted flow is discussed in more detail later. Elevator evacuation of the top 4 floors resulted in the optimum combination of stair and elevator usage at about 12 minutes for total building evacuation. This is a reduction of about $15 \%$ compared to stair only evacuation.

\subsection{Jackson Federal (Seattle) Building}

The Jackson Federal Building which is located in Seattle was designed by GSA and constructed in 1971. In this report the building is referred to as the Seattle Building. GSA pioneered a number of fire protection features in this building including smoke control and emergency voice communications (GSA 1971). The Seattle Building is totally protected by sprinklers. This building has 36 stories plus a basement and two mechanical penthouse floors. The building has two stairwells that serve all floors. There are three rises of passenger elevators, freight elevators, and shuttle elevators serving the floors shown in figure 9. Each rise has six elevator cars. For simplicity, only the three rises of passenger elevators were considered for evacuation in the calculations of this paper. This is not to indicate that the other elevators could not be used as well.

The first and fourth floors both have exits to the outside. Plans of various floors of the Seattle Building are shown in figures 10 through 13. The building has an office population of 3021 people, and the evacuees were estimated at 76 people per flocr. Floor 15 is a mechanical floor and it does not have any occupants.

The data used for evacuation calculations are listed in table 5. The estimated time for total evacuation by stairs is about 26 minutes, and the estimated time for total evacuation by elevators is 17 minutes. Various approaches for combined stair and elevator evacuation were considered. Calculations showed that optimum elevator use for the particular approach analyzed was:

a. elevator evacuation for the upper 4 floors of the low rise,

b. elevator evacuation for people with mobility limitations on other low rise floors,

c. Stair evacuation for the rest of the occupants of the low rise,

d. use of stairs for evacuation of $35 \%$ of evacuees from each floor in both mid and high rise, and 
e. use of elevators for evacuation of $65 \%$ of evacuees from each floor in both mid and high rise.

For the mid and high rise, persons with mobility limitations are included in the $65 \%$ of evacuees from each floor. Of course, achieving the desired split between elevator and stair evacuation will require considerable organizational effort including an OEP and fire drills. The results of the evacuation calculations are listed in table 6 and shown in figure 14. It is apparent that the mid and high rise elevators take almost the same time to evacuate. Further, the results of the calculations show the optimum elevator use for mid and high rise was about $65 \%$ of evacuees. This resulted in an estimated evacuation time of about 13 minutes. This is a reduction of evacuation time of $50 \%$ over stair only evacuation.

\subsection{General Services Building}

The GSA Building, located in Washington, DC, was built in 1914. This building has 7 stories plus a basement and ground floor. It is a sprawling building with six groups of 2 elevators and six stairwells as illustrated in figures 15,16 and 17. The basement, ground floor and first floor all have exits directly to the outside. The GSA Building is unsprinklered. The office population of this building is 3621 people, and number of evacuees is estimated at 453 per floor for floors 2 through 6 and 362 for floor 7 .

Data used in the analysis of this building is listed in table 7. The estimated time for total evacuation by stairs is about 7 minutes, and estimated time for total evacuation by elevator is 17 minutes. The approach for combination stair and elevator evacuation is the same as for the other two single rise buildings above (Hoffman and White Flint). Combined stair and elevator usage amounts to less than $10 \%$ time saving over stair only evacuation. Thus reduced evacuation time is not a significant benefit for this building.

\section{Discharge Capacities}

As previously stated, discharge lobbies and floors must be able to handle the flow of people. A rough method of evaluating the capacity of the elevator lobby is described below. The people density in the elevator lobby is based on a number of elevators in a group discharging at the same time. This density is evaluated by the methods presented by Nelson and MacLennan (1988) to determine the walking speed. Taking into account the width of the exits from the lobby, the maximum flow rate of people per unit time from the lobby can be estimated. This flow is compared to the flow of people from the elevators.

This approach is outlined below for the Hoffman Building. With 6 elevators emptying 16 people each into the $25.3 \mathrm{~m}^{2}\left(272 \mathrm{ft}^{2}\right)$ lobby, a density of 0.033 people per $\mathrm{m}^{2}\left(.35\right.$ people per foot $\left.{ }^{2}\right)$. Nelson and MacLennan indicate that at this density, the walking speed is zero. This means that when six elevators are used for evacuation of this building, major congestion in the elevator is likely to occur. If there is no room in the lobby, people will wait in the elevator. Thus the evacuation capacity of the elevators is restricted by the size of the elevator lobby.

To see if the discharge capacity of the Hoffman Building is adequate for 5 elevators operating, calculations were made for that number. This resulted in a density of 0.027 people per $\mathrm{m}^{2}(.29$ people per foot $^{2}$ ) and a people movement speed of $13.4 \mathrm{~m} / \mathrm{min}(44 \mathrm{fpm})$. The time for the people from 5 elevators to leave the lobby is about 19 seconds. The round trip time for 5 cars is one minute or more. Thus there is sufficient discharge capacity for the operation of 5 elevators but probably not 6 elevators. 
The ground floor doors of the Hoffman Building are divided into entrances and exits for security. This reduces exit capacity of the exterior doors by nearly half. During a fire emergency, it is possible for occupants to leave through the normal entrance ways. If provisions are made for this, there is sufficient discharge capacity at the exterior doors. A similar situation was found for most of the other buildings. It is believed that the capacity of the elevator lobbies and exterior doors must be carefully evaluated for any building where elevator evacuation is used.

Appling the above approach to the White Flint North Building shows that the density in the ground floor elevator lobby is well above 0.033 people per $\mathrm{m}^{2}$ ( .35 people per foot ${ }^{2}$ ), if all six elevators were to unload at the same time. Thus this lobby cannot accomodate the people from six full elevators. Five cars empting into the lobby results in a people movement speed of about $4.0 \mathrm{~m} / \mathrm{min}$ (13 fpm). This spped is insufficient to get the people out of the lobby before the next five cars would arrive. Thus the evacuation calculations for this building were based on four elevators.

\section{Other Evacuation Concepts}

The above discussion was focused on total building evacuation, but other possible approaches include partial evacuation, vertical evacuation, and horizontal evacuation. During partial evacuation, the occupants of the fire area and possibly some other spaces move to the outside. During vertical evacuation, the occupants of the fire area and possibly some other spaces move to locations of relative safety on other floors. During horizontal evacuation, the occupants of the fire area and possibly some other spaces move to locations of relative safety on the fire floor. The times involved with these other approaches is small in comparison to total evacuation, but many or all of the occupants remain in the building.

The OEP's for the White Flint Building and the Seattle Building use partial evacuation for fires. It is believed that total sprinkler protection was a major factor for selecting partial evacuation of these buildings. The OEP's for the other two buildings, which were both unsprinklered, call for total building evacuation during fires. However, OEP's consider other emergencies (such as bomb threats) where the appropriate response is total building evacuation.

\section{Engineering Considerations}

There are a number of considerations about elevator fire evacuation that are not readily dealt with by analytical methods. However, many of these considerations can be of extreme importance in any practical implementation of elevator evacuation. The considerations discussed in this paper are:

1. doors opening into the fire,

2. elevator system activation,

3. elevator doors jamming open,

4. fire or heat penetration of elevator system barriers,

5. water damage of elevator system components,

6. reliability of electrical power,

7. fire in the evacuation system, and

8. smoke and the evacuation system.

The items above do not include smoke protection for elevator systems or people movement by elevator systems, because these issues will be addressed in detail elsewhere. It is believed that the following 
discussion of these considerations may be helpful to those considering the use of elevators for fire evacuation and to any designers of such systems.

\subsection{Doors Opening Onto the Fire}

The concern about fatalities inside elevator cars due to elevator doors opening into a fire are well known. Even if there are no people in the car, opening these doors into fire still results in damage to the elevator car including the elevator door mechanism. The elevator doors can warp so that they do not open and close freely resulting in loss of the elevator for fire evacuation. Thus the elevator evacuation systems must be designed to prevent opening of elevator cars into fire.

The conventional approach to the problem is very different from that envisioned for elevator evacuation. Currently elevator doors are not allowed to open onto a lobby from which there is a fire detection signal. This conventional approach seems to be based on the idea that elevator cars should never go to floors on which there is a fire. Generally elevator lobbies are not enclosed, and smoke and fire can flow into the lobby uninhibited. Exposure to high temperature gases can cause warpage of elevator doors even when they are closed, but this is not a life safety concern for conventional systems because the elevators are taken out of service during a fire.

The conventional approach described above is not appropriate when elevators are to be used for evacuation of people from the fire floor. If an elevator evacuation system is to support people who can not use stairs because of physical disabilities, then elevator cars must be able to go to floors where there are fires. To prevent elevator cars from opening into fire, an approach consisting of an enclosed elevator lobby and elevator lobby detection is envisioned. In this approach the lobby is enclosed by walls, floors and automatically closing doors with fire resistance sufficient to assure that the elevator system is protected during evacuation. This enclosure provides protection from fires outside the elevator lobby. Fires inside the elevator lobby would activate detectors inside the elevator lobby with the objective of preventing cars from going to this lobby.

\subsection{Activation}

The problems of activating the elevator evacuation system include the following:

1. minimizing false alarms,

2. maximizing safe evacuation time,

3. warning occupants,

4. notifying the fire service, and

5. identification of the location of the hazard.

All of these problems occur for conventional vertical evacuation by stairwells only. The impact of the first four items is probably not much different for elevator evacuation than it is for conventional evacuation. In general, approaches for dealing with these four problems with conventional systems can be applied to elevator based systems. Identification of the fire location is important for elevator evacuation to the extent that the elevator system must respond differently to the fire floor. 


\subsection{Elevator Doors Jamming Open}

Elevator door closing forces are limited by the elevator code A17.1 (ASME 1987). Sometimes elevator doors can not close because of pressure differences across the doors. In non-fire situations, this problem is commonly caused by pressure differences due to seasonal stack effect in high rise buildings, requiring adjustment of door closer mechanisms by elevator mechanics. However, pressure differences are possible during building fires that could also cause door jamming (for example, elevator shaft pressurization or a broken fire floor window). This problem is significant because, when elevator doors are jammed open, the car will not move and elevator evacuation by that car is stopped.

People can be taught to help close such jammed doors. Only a small amount of added force is needed for these doors to close. One of the authors has encountered such a pair of jammed elevator doors. He closed them by putting the palm of a hand against each door and pushing the two doors together. This was successful because the coefficient of friction between the hands and the door was high enough to allow the necessary added closing force. To facilitate the closing of jammed doors, the use of grips, indentations or high coefficient surfaces can be used.

\subsection{Fire Resistance}

The use of elevators during a significant building fire requires elevator system barriers that are able to withstand the exposure to fire. These barriers consist of partitions, floors, doors, and other construction assembly surrounding the elevator shaft, elevator machinery room, elevator lobby, and any other spaces that are part of the elevator system.

The commercially accepted method for determining the fire resistance of an assembly is with the "standard time-temperature" fire test. The standard fire is defined by a number of time and temperature data points. The endurance rating of the assembly is the time (rounded down to the last $1 / 2$ hour) for which the assembly maintains its integrity while exposed to the standard fire. The time that an assembly will withstand exposure to a real fire may differ from this rated endurance because of differences in fire intensity and construction.

One approach for selection of the fire endurance rating of these assemblies is that the elevator evacuation system should be able to withstand fire exposure for long enough to allow for relocating or evacuating people to safety and for time needed by the fire service for fire fighting plus some safety factor. This approach seems applicable to unsprinklered fires. However, water spray from sprinklers reduces fire growth and intensity. Thus it seems reasonab!e that the fire endurance rating of elevator system barriers in sprinklered buildings need not be as large as to those in nonsprinklered buildings.

\subsection{Water Damage}

During a building fire water from sprinklers and fire hoses can damage electronic, electrical, and mechanical components of an elevator evacuation system. The two major locations of concern for this damage are inside the mechanical room and inside the elevator shaft. The extent of the water damage problem is very different for these locations.

Frequently elevator machinery rooms are located such that water from fires outside of the machinery room will not flow into the machinery room. For fires in the machinery room, the most appropriate action seems to be to take the elevators served by that room out of service. Because of the limited fuel 
load, relatively small compartment size and the fire resistive construction, fires in machinery rooms are not believed to have as high a potential for hazard as fires in many other building spaces. If any evacuation is needed, other vertical paths (elevators and stairs) can be used.

The problem of water damage to components inside the elevator shaft is a more significant problem. Water from fires away from the elevator system can flow into the shaft and damage system components when the elevator system is needed for evacuation. Two potential solutions to the elevator shaft water problem are:

1. use elevator system components that can function in a wet environment, and

2. prevent water from entering the shaft.

Currently many elevators operate outdoors on exterior walls of buildings with many of the system components exposed to rain, wind and extremes of temperature. These outdoor conditions are believed to be much more severe than those associated with water flow inside an elevator shaft due to a building fire. Thus it is technically feasible to build elevators with water protected components which will operate during a fire. However, maintenance of such water resistive components is a concern. For example, inadvertent system repair with non-water resistive components can operate properly under normal conditions without indication of the improper parts. To assure that the water resistive features operate properly, special inspection and repair efforts will be needed.

Elevators can be constructed to prevent water entering the shaft by use of floors sloping away from the elevator door. Floor drains can be part of such an approach. This approach has the advantage of requiring almost no maintenance. One approach is to slope the floors outside the elevator lobby and have them level inside the lobby. This approach would accommodate lobby doors with small undercuts opening into the lobby. The use of automatically opening, folding doors would allow a greater variety of floor slope arrangements. However, retrofit involving sloping floors has the disadvantage of requiring that elevator doors be removed and reinstalled. The new floor at the elevator door would be 0.08 to $0.16 \mathrm{~m}(3$ to 6 inches) above the original floor.

Further research is needed to determine which approach to water protection for the elevator shaft is the most practical and cost effective.

\subsection{Reliability of Electrical Power}

Reliability of electric power consists of:

a. assuring a source of power and

b. assuring continued distribution of power to where it is used.

Considerable experience exists in assuring the supply of electrical power for critical functions in hospitals, communication facilities, computer facilities and the like. However, elevator evacuation is a unique application, and the approach to assure reliability of electric power must be appropriate to the application. While it is beyond the scope of this paper to determine what components are needed to assure reliable power for elevator evacuation, the following discussion should be helpful for those making such determinations.

Some components that can be used to ensure reliability of power are fire protected distribution, redundant feeds, power from multiple substations outside the building, and emergency generator sets. Because 
elevator evacuation can tolerate short duration power loss, uninterruptable power supplies are not necessary. Any consideration of reliability of electric power should consider potential causes of power failure and the consequences of that failure.

Concern about interruption of power supplied by the local utility is not as important for elevator evacuation as it is for many other applications. Applications such as hospitals and many communication facilities operate most or all of the time, and they need highly reliable power for all the time that they operate. Fire evacuation by elevators is different in that this mode of elevator operation is only needed during a building fire. At most, the fire evacuation mode of an elevator would be expected to operate during a fire situation for a few hours over the life of the building. The probability of simultaneously having a fire and having the utility company power interrupted is relatively small, provided that the fire and power failure do not have the same cause (for example an earthquake). However, the probability of having a power distribution failure during a fire is relatively high. This is because fire frequently damages electrical distribution within buildings. Therefore, the power distribution to the elevator system should be such that it is highly unlikely that a fire could interrupt electrical power.

The consequences of loss of electric power to an elevator evacuation system depends on the redundancy of the evacuation systems. If there are multiple banks of elevators and several stairwells in a building, the loss of one bank of elevators may not delay evacuation significantly. However, if a system has few redundant vertical paths of egress, the loss of one may result in a significant extension of the evacuation time. Evaluation of what amounts to a dangerous extension depends on the available safe egress time. This time can be estimated by use of fire models.

The location of electrical components has an impact on reliability of electrical power as is illustrated by the following discussion of feeders in hoistways and emergency generator sets. Electrical feeders located inside a hoistway are protected by the fire endurance of the hoistway. Further, loss of these feeders due to fire exposure in the hoistway has no impact on evacuation, because fire in the hoistway would have already rendered the elevator system useless. Thus, feeders inside the hoistway do not need any special fire protection. If an emergency generator set is at a location remote from the elevator mechanical room, the power feeders from the generator will need fire protection. However, if the generator set is inside the mechanical room, the power feeders will not need any special fire protection for the same reason as the feeders inside a hoistway.

The level of reliability and the appropriate components needed to achieve that reliability depend on the particular evacuation system and on the total level of fire protection in the building. Some buildings may only need fire protection for the power distribution system, and other buildings may need emergency generator sets.

\subsection{Fire in the Evacuation System}

Fires are possible inside elevator evacuation systems, as well as, inside stairwells. It is possible that combustible materials are stored in stairwells, elevator machinery rooms, elevator pits, elevator lobbies, and elevator cars. Generally, these spaces are not intended for storage and there should be little or no fuel inside them. Service elevator lobbies are an exception, because they frequently are used for short term storage of trash or other materials. With the exception of service elevators, it is believed that fires in stairwells and elevators are much less likely than in many other building locations. Possibly, service elevators without sprinklered lobbies should not be used for fire evacuation. 
As previously discussed, if there are multiple banks of elevators and several stairwells in a building, the loss of one bank of elevators may not delay evacuation significantly. The compartmentation of elevator systems and stairwells provides some level of protection against the spread of smoke and fire to other parts of the building. Sprinklers can be used to provide additional protection. Any determination of the extent of protection against fire in parts of the evacuation system should be within the context of total building fire protection.

\subsection{Smoke and the Evacuation System}

Ideally elevator systems should be not operate when significant levels of smoke are in an elevator lobby, hoistway or machinery room. However, conventional smoke detectors will be activated by low levels of smoke that would not adversely effect performance of an elevator evacuation system. The use of analog smoke detectors may be a solution to this problem. Another approach is pressurization of these spaces to prevent smoke infiltration. As previously stated, appendix A presents design information for such elevator smoke control systems. Design fires for similar applications are discussed by Klote, Nelson, Deal and Levin (1992).

\section{Human Considerations}

Designing and constructing elevators that can be safely used for evacuation during a fire emergency is only half of the job. The building occupants must also be willing to use the elevators and able to use them in the manner prescribed in the OEP. The tasks assigned to the building security staff and to the monitors and wardens must be designed so that they can be properly performed in an emergency situation.

There should be no problem getting those occupants who cannot descend stairs to use elevators. However, it is important to teach them about the fire safety features in the elevator system so that they will support the fire safety plan and use the elevators with confidence. The evacuation system cannot be deemed a success if occupants with mobility limitations, who should rely on the elevators, have serious doubts about their own safety in fire emergencies.

There are several obstacles to getting mobile building occupants to use elevators in fire emergencies. First, there has been a twenty year campaign to teach people not to use elevators in fires. Secondly, occupants in many buildings may not have sufficient confidence in the building management to entrust their safety to a mechanical device that is designed and maintained by current building management. Also, people have strong needs to exert control ove: their own fate and relying on elevators in fire emergency evacuations decreases such control.

On the other hand, the use of elevators should be appealing for several reasons. People tend to leave buildings by the same route they used for entering: those who used elevators to arrive at their desired destination will tend to return by the same means. If the occupants are on an upper floor, the physical effort required to leave the building by stairs might encourage elevator use. The congestion on the stairs, especially if the evacuation is not phased by floor, might be very unpleasant.

In a well run and well maintained building, a good training program should be able to overcome obstacles to occupant acceptance of elevator use for fire evacuations. This training program should include:

An explanation and discussion regarding why most buildings prohibit the use of elevators in fire emergencies and how their building has been designed to permit fire safe elevator evacuations 
in fire emergencies. This will help overcome the previous training which encouraged people not to use elevators in fire situations.

An explanation of how the use of elevators decreases the time to evacuate the building (or portion of the building).

A discussion of congestion problems on the stairs.

An explanation of how the system works including who gets priority use of the elevators (or stairs if there is a phased evacuation), how the communication system works, how the system assures that no one is left behind in an elevator lobby, etc.

Fire drills where the occupants can practice their evacuation assignments and obtain a more concrete understanding of how the system works.

It is clear that fully mobile occupants from the fire floor should always be assigned to use stairs rather than elevators: this should satisfy some of the concerns regarding controlling one's own fate, and help make the system appear reasonable. Alerting occupants to the availability of stairs as a backup that can be used before a floor becomes dangerous--and informing occupants that they would be alerted well before conditions become dangerous--should satisfy some of the other concerns regarding controlling one's own fate.

Occupants will have more confidence that the fire safety features were properly designed and installed and are being properly maintained if the building, in general, is well run and well maintained. This confidence is important in getting occupant acceptance for the OEP and for the use of elevators.

It is generally accepted that there should be a written Occupant Emergency Plan. This written plan can serve at least three purposes. It can be a management tool, assuring management that the emergency evacuation system has been well designed and implemented. It can also serve to provide information to the emergency team (including the monitors and wardens) regarding their assignments and responsibilities. Finally, it can inform the occupants about the plan, that is, it can supplement the formal training or even be used as a textbook for the training. The written plan, which can be printed as several documents, should meet all these functions. It should be revised frequently, as appropriate, to assure the occupants that the system is not falling into disrepair.

Some of the occupants will be required to wait for a considerable time in or near the elevator lobby before the first elevator arrives, perhaps in a few cases more than the approximate 10 minutes in the Hoffman and Seattle Buildings analyzed above. Even with a good training program, people are unlikely to wait that long before deciding to use the stairs unless information is provided to them about the progress of the fire and the progress of the elevator evacuation. A good two-way communications system, including both a control center and the elevator lobbies, is vital. (Fire drills can be conducted where only part of the building is evacuated so that the maximum wait at the elevator would be shorter. This would decrease the time that the drill interferes with work and avoids a tedious wait. The occupants should be told that in a real fire the wait might be longer.)

It may appear obvious to some, but it cannot be emphasized too strongly, that all the tasks assigned to the emergency team (and the associated equipment and computer programs) be carefully designed from a human factors engineering standpoint. The emergency team should be thoroughly trained, including drills where they can practice their assignments. 
Each building will need to have a command center or control room where the priorities for assigning elevators to floors are made and controlled, and from where information is sent to the elevator lobbies. The design of this center, and the training of the security staff manning it, is of special importance.

Large systems often have operating problems that only become apparent after the system is installed. For example, fire alarms may interfere with communicating using an intercom system. After installation, it is vital to have thorough testing and evaluation from a human factors standpoint. One way of avoiding some of the problems is to provide the designers with guidelines. The first version of such guidelines could be based in part on the Human Factor Guidelines for the Design and Use of Staging Areas (Levin and Groner, 1992) and should be modified as experts gain experience in designing and installing fire safe elevator systems.

Groner and Levin (1992) have prepared a report, as part of this research project, that discusses additional human factors considerations and elaborates on some of the considerations discussed in this section.

\section{Commissioning and Routine Testing}

Commissioning and routine testing are needed to assure that elevator evacuation systems will function as intended during fire situations. With any building system, many of the problems, encountered during acceptance testing, stem from misconceptions about the reasons for the system and the system's capabilities. General agreement about goals and objectives should help reduce such problems. As a minimum, commissioning procedures for new systems should include:

a. inspection of the system components,

b. testing of the system operation,

c. adjustment of the system to assure performance,

Commissioning might also include development of the Occupant Emergency Plan (OEP) and plans for training occupants and building owners about the functioning of the all building's evacuation systems.

Some designs such as smoke control incorporate the capability of field adjustment. Such adjustments need to be a formal part of any commissioning.

Acceptable performance for a new system does not assure that, years later, the system will perform acceptably during a fire. Components deteriorate with age and can be inadvertently damaged during building modifications. For these reasons, anrual testing of elevator evacuation systems is recommended to provide a level of assurance that the system will function as desired in the event of a fire. The methods of routine testing should be the same as those of acceptance testing. Deficiencies encountered during routine testing should be corrected as soon as possible.

\section{Summary and Conclusions}

1. Elevator evacuation of buildings is feasible, but it involves significant organizational and engineering challenges.

2. Elevator evacuation can have significant benefits. These depend on the particular building and the type of elevator evacuation system, and some possible benefits are: 

a. reduction of estimated building evacuation time,
b. people with disabilities can use elevators to evacuate the building in the same way that they entered,
c. the fire service can use the elevators to rescue occupants, and
d. the fire service can use the elevators to move men and equipment for fire fighting.

3. The potential for reduced evacuation time is generally greater for tall buildings than for shorter buildings.

4. Elevator evacuation should have two-way communication between operators in a control center and people in the elevator lobbies.

5. Operators of a control center for elevator evacuation need to be well trained.

6. Elevator evacuation can be either automatically controlled or manually controlled, and it is not clear which approach is most advantageous. Automatic control has a time advantage in that there are no human operators who need to get to the elevators before evacuation can start. Manual control has the advantage that people can adjust their actions to situations not anticipated in an automatic control program.

7. To evaluate combined elevator and stair evacuation under a wide range of people movement patterns, smoke movement and fire spread; a computer program for simulating elevator and stair evacuation would need to be developed. Such a simulation model could allow detailed computer testing of an automatic control program to minimize the potential for situations that are not anticipated in an automatic control program. Further, such simulation software could be used as part of the training program for control room operators.

8. The discharge lobbies and floors must be sufficient to handle the flow of people from elevators during building evacuation.

9. The potential for water damage to elevator equipment in the hoistway is a significant problem. However, floor drains, sloping floors, and water resistant elevator components are possible solutions.

\section{Acknowledgements}

The authors acknowledge the support and encouragement of David Frable of the General Services Administration concerning many aspects of this research. Harold Nelson of NIST provided valuable insight about almost every aspect of this study. Jake Pauls of Hughes Associates also provided valuable advice and comments particularly about people movement. Elmer Chapman, retired Fire Chief from New York City, provided insight into fire service use of elevators. Special thanks are due to George Strakosch of Elevator World Magazine, for his advice and guidance concerning almost every aspect of elevator engineering. 


\section{References}

ASME 1987. American Standard Safety Code for Elevators, Escalators, Dumbwaiters and Moving Walks, A17.1, American Society of Mechanical Engineers, New York.

Bazjanac, V. 1977. Simulation of Elevator Performance in High-Rise Buildings Under Conditions of Emergency, Human Response to Tall Buildings, Ed by D.J. Conway. Dowden, Hutchinson \& Ross, Stroudsburg, PA, pp 316-328.

Bazjanac, V. 1974. Another Way Out? Progressive Architecture, April, pp 88-89.

Churchman, C.W. 1979. The Systems Approach, New York, Delta.

Degenkolb, J. 1991. Elevator Usage During a Building Fire, ASME Symposium on Fire and Elevators, Baltimore, MD, February 19-20, 1991, American Society of Mechanical Engineers, New York, NY, pp 76-79.

Fox C.C. 1991. Handicapped Use of Elevators, ASME Symposium on Fire and Elevators, Baltimore, MD, February 19-20, 1991, American Society of Mechanical Engineers, New York, NY, pp 80-82.

Gatfield, A.J. 1991. Elevators and Fire: Designing for Safety, ASME Symposium on Fire and Elevators, Baltimore, MD, February 19-20, 1991, American Society of Mechanical Engineers, New York, NY, pp 95-107.

Groner, N.E. and Levin, B.M. 1992. Human Factors Considerations in the Potential for Using Elevators in Building Emergency Evacuation Plans, National Institute of Standards and Technology, NIST-GCR-92-615.

GSA 1971. Proceedings: Reconvened International Conference on Firesafety in High-Rise Buildings, Generals Services Administration, Washington, DC.

Klote, J.H. 1988. An Analysis of the Influence of Piston Effect on Elevator Smoke Control, Nat. Bur. Stand. (U. S.), NBSIR 88-3751.

Klote, J.H., Nelson, H.E., Deal, S., Levin, B.M. 1992. Staging Areas for Persons with Mobility Limitations, National Institute of Standards and Technology, NISTIR 4770.

Klote, J.H. and Tamura, G.T. 1986. Elevator Piston Effect and the Smoke Problem, Fire Safety Journal, Vol 11, No 3, May, pp 227-233.

Klote, J.H. and Tamura, G.T. 1987. Experiments of Piston Effect on Elevator Smoke Control, ASHRAE Transactions, Vol 93, Part 2, pp 2217-2228.

Levin, B.M. and Groner, N.E. 1992. Human Behavior Aspects of Staging Areas for Fire Safety in GSA Buildings, National Institute of Standards and Technology, NIST-GCR-92-606.

Nelson, H.E. and MacLennan, H.A. 1988. Emergency Movement, SFPE Handbook of Fire Protection Engineering, Society of Fire Protection Engineers, Boston, MA. 
Pauls, J. 1977. Management and Movement of Building Occupants in Emergencies, DBR Paper No. 788, National Research Council, Ottawa, Canada.

Pauls, J. 1988. People Movement, SFPE Handbook of Fire Protection Engineering, Society of Fire Protection Engineers, Boston, MA.

Pauls, J., Gatfield A.J., Juillet, E. 1991. Elevator Use for Egress: The Human-Factors Problems and Prospects, ASME Symposium on Fire and Elevators, Baltimore, MD, February 19-20, 1991, American Society of Mechanical Engineers, New York, NY, pp 63-75.

Sumka, E.H.. 1987. Presently, elevators are not safe in fire emergencies, ASHRAE Transactions, Vol. 93, Part 2, pp. 2229-2234.

Tamura, G.T. and Klote, J.H. 1987c. Experimental Fire Tower Studies on Elevator Pressurization Systems for Smoke Control, ASHRAE Transactions, Vol 93, Part 2, pp 2235-2257.

Tamura, G.T. and Klote, J.H. 1987b. Experimental Fire Tower Studies on Mechanical Pressurization to Control Smoke Movement Caused by Fire Pressures, Proceedings of the 2nd International Symposium on Fire Safety Science, Tokyo, Japan.

Tamura, G.T. and Klote, J.H. 1988. Experimental Fire Tower Studies on Adverse Pressures Caused by Stack and Wind Action: Studies on Smoke Movement and Control, ASTM International Symposium on Characterization and Toxicity of Smoke, December 5, Phoenix, AZ.

Tamura, G.T. and Klote, J.H. 1987a. Experimental Fire Tower Studies on Elevator Pressurization Systems for Smoke Control, ASHRAE Transactions, Vol 93, Part 2, pp 2235-2257. 
Table 1. Data used for evacuation calculations of the Hoffman Building II

\begin{tabular}{|lc||}
\hline Item & Quantity \\
\hline Floor to Floor Height & $3.10 \mathrm{~m}(10.17 \mathrm{ft})$ \\
People per Floor & 230 \\
Width of Elevator Doors & $1.07 \mathrm{~m}(42 \mathrm{in})$ \\
Elevator Car Velocity & $1.78 \mathrm{~m} / \mathrm{s}(350 \mathrm{fpm})$ \\
Elevator Car Acceleration & $0.61 \mathrm{~m} / \mathrm{s}^{2}\left(2 \mathrm{ft} / \mathrm{s}^{2}\right)$ \\
Number of People in a Full Elevator Car & 16 \\
Stair Riser & $0.19 \mathrm{~m}(7.5 \mathrm{in})$ \\
Stair Tread & $0.25 \mathrm{~m}(10 \mathrm{in})$ \\
Stair Width & $1.42 \mathrm{~m}(56 \mathrm{in})$ \\
Stair Door Width & $1.01 \mathrm{~m}(40 \mathrm{in})$ \\
\hline \hline
\end{tabular}


Table 2. Evacuation times for combinations of Elevator and Stairwell Use for evacuation of the Hoffman Building II

\begin{tabular}{||cc|cc|c||}
\hline $\begin{array}{c}\text { Floors } \\
\text { Stairs }\end{array}$ & $\begin{array}{c}\text { Time } \\
\text { Required } \\
\text { (min) }\end{array}$ & $\begin{array}{c}\text { Floors } \\
\text { Evacuated by } \\
\text { Elevators }\end{array}$ & $\begin{array}{c}\text { Time } \\
\text { Required } \\
\text { (min) }\end{array}$ & $\begin{array}{c}\text { Building } \\
\text { Evacuation } \\
\text { Time (min) }\end{array}$ \\
\hline $12-1$ & 14.9 & none & 4.8 & 14.9 \\
$11-1$ & 13.7 & 12 & 7.0 & 13.7 \\
$10-1$ & 12.6 & $12-11$ & 9.1 & 12.6 \\
$9-1$ & 11.4 & $12-10$ & 11.2 & 11.4 \\
\hline $8-1$ & 10.3 & $12-9$ & 13.1 & $11.2 *$ \\
\hline $7-1$ & 9.1 & $12-8$ & 15.0 & 13.1 \\
$6-1$ & 7.9 & $12-7$ & 16.8 & 15.0 \\
$5-1$ & 6.8 & $12-6$ & 18.5 & 16.8 \\
$4-1$ & 5.6 & $12-5$ & 20.1 & 18.5 \\
$3-1$ & 4.5 & $12-4$ & 21.6 & 20.1 \\
$2-1$ & 3.3 & $12-3$ & 23.0 & 21.6 \\
1 & 2.2 & $12-2$ & 24.3 & 23.0 \\
none & & $12-1$ & & 24.3 \\
\hline
\end{tabular}

* Shortest evacuation time 
Table 3. Data used for evacuation calculations of the White Flint North Building

\begin{tabular}{||lc||}
\hline \hline Item & Quantity \\
\hline Floor to Floor Height & $3.4 \mathrm{~m}(11.17 \mathrm{ft})$ \\
People per Floor & 68 \\
Width of Elevator Doors & $1.07 \mathrm{~m}(42 \mathrm{in})$ \\
Elevator Car Velocity & $2.54 \mathrm{~m} / \mathrm{s}(500 \mathrm{fpm})$ \\
Elevator Car Acceleration & $1.22\left(4 \mathrm{~m} / \mathrm{s}^{2}\right)$ \\
Number of People in a Full Elevator Car & 16 \\
Stair Riser & $0.18 \mathrm{~m}(7.0 \mathrm{in})$ \\
Stair Tread & $0.30 \mathrm{~m} \mathrm{(11.5} \mathrm{in)}$ \\
Stair Width & $1.1 \mathrm{~m} \mathrm{(44} \mathrm{in)}$ \\
Stair Door Width & $0.97 \mathrm{~m}(38 \mathrm{in})$ \\
\hline
\end{tabular}


Table 4. Evacuation times for combinations of Elevator and Stairwell Use for evacuation of the White Flint North Building

\begin{tabular}{|c|c|c|c|c|}
\hline $\begin{array}{l}\text { Floors } \\
\text { Evacuated by } \\
\text { Stairs }\end{array}$ & $\begin{array}{c}\text { Time } \\
\text { Required } \\
\text { (min) }\end{array}$ & $\begin{array}{c}\text { Floors } \\
\text { Evacuated } \\
\text { by } \\
\text { Elevator }\end{array}$ & $\begin{array}{c}\text { Time } \\
\text { Required } \\
\text { (min) }\end{array}$ & $\begin{array}{c}\text { Building } \\
\text { Evacuation } \\
\text { Time (min) } \\
\end{array}$ \\
\hline $18-2$ & 14.3 & none & & 14.3 \\
\hline $17-2$ & 13.5 & 18 & 7.1 & 13.5 \\
\hline $16-2$ & 12.8 & $18-17$ & 8.8 & 12.8 \\
\hline $15-2$ & 12.0 & $18-16$ & 10.5 & $12.0 *$ \\
\hline $14-2$ & 11.2 & $18-15$ & 12.1 & 12.1 \\
\hline $13-2$ & 10.4 & $18-14$ & 13.7 & 13.7 \\
\hline $12-2$ & 9.6 & $18-13$ & 15.2 & 15.2 \\
\hline $11-2$ & 8.8 & $18-12$ & 16.7 & 16.7 \\
\hline $10-2$ & 8.1 & $18-11$ & 18.1 & 18.1 \\
\hline $9-2$ & 7.3 & $18-10$ & 19.4 & 19.4 \\
\hline $8-2$ & 6.5 & $18-9$ & 20.8 & 20.8 \\
\hline $7-2$ & 5.7 & $18-8$ & 22.0 & 22.0 \\
\hline $6-2$ & 4.9 & $18-7$ & 23.3 & 23.3 \\
\hline $5-2$ & 4.1 & $18-6$ & 24.4 & 24.4 \\
\hline $4-2$ & 3.4 & $18-5$ & 25.5 & 25.5 \\
\hline $3-2$ & 2.6 & $18-4$ & 26.6 & 26.6 \\
\hline 2 & 1.8 & $18-3$ & 27.7 & 27.7 \\
\hline none & & $18-2$ & 28.6 & 28.6 \\
\hline
\end{tabular}

* Shortest evacuation time 
Table 5. Data used for evacuation calculations of the Seattle Building

\begin{tabular}{||lc||}
\hline Item & Quantity \\
\hline Floor to Floor Height & $3.81 \mathrm{~m}(12.5 \mathrm{ft})$ \\
People per Floor & 76 \\
Width of Elevator Doors & $1.07 \mathrm{~m}(42 \mathrm{in})$ \\
Low Rise Elevator Car Velocity & $3.05 \mathrm{~m} / \mathrm{s}(600 \mathrm{fpm})$ \\
Mid Rise Elevator Car Velocity & $5.08 \mathrm{~m} / \mathrm{s}(1000 \mathrm{fpm})$ \\
High Rise Elevator Car Velocity & $5.08 \mathrm{~m} / \mathrm{s}(1000 \mathrm{fpm})$ \\
Low Rise Elevator Car Acceleration & $1.22 \mathrm{~m} / \mathrm{s}^{2}\left(4 \mathrm{ft} / \mathrm{s}^{2}\right)$ \\
Mid Rise Elevator Car Acceleration & $1.83 \mathrm{~m} / \mathrm{s}^{2}\left(6 \mathrm{ft} / \mathrm{s}^{2}\right)$ \\
High Rise Elevator Car Acceleration & $1.83 \mathrm{~m} / \mathrm{s}^{2}\left(6 \mathrm{ft} / \mathrm{s}^{2}\right)$ \\
Number of People in a Full Elevator Car & 16 \\
Stair Riser & $0.18 \mathrm{~m}(7 \mathrm{in})$ \\
Stair Tread & $0.28 \mathrm{~m}(11 \mathrm{in})$ \\
Stair Width & $1.10 \mathrm{~m}(43.5 \mathrm{in})$ \\
Stair Door Width & $0.91 \mathrm{~m}(36 \mathrm{in})$ \\
\hline \hline
\end{tabular}


Table 6. Evacuation times for combinations of Elevator and Stairwell Use for evacuation of the Seattle Building

\begin{tabular}{||ccccc||}
\hline $\begin{array}{c}\text { Evacuees Using } \\
\begin{array}{c}\text { Elevators* } \\
(\%)\end{array}\end{array}$ & $\begin{array}{c}\text { Stairwell } \\
\text { Time } \\
(\mathrm{min})\end{array}$ & $\begin{array}{c}\text { Mid-Rise } \\
\text { Elevator } \\
\text { Time } \\
(\mathrm{min})\end{array}$ & $\begin{array}{c}\text { High-Rise } \\
\text { Elevator } \\
\text { Time } \\
(\mathrm{min})\end{array}$ & $\begin{array}{c}\text { Building } \\
\text { Evacuation } \\
\text { Time (min) }\end{array}$ \\
\hline 100 & NA & 16.5 & 16.2 & 16.5 \\
97 & 7.5 & 16.4 & 16.1 & 16.4 \\
95 & 7.8 & 16.3 & 16.0 & 16.3 \\
90 & 8.6 & 16.0 & 15.8 & 16.0 \\
85 & 9.5 & 15.9 & 15.7 & 15.9 \\
80 & 10.3 & 13.5 & 13.3 & 13.5 \\
75 & 11.1 & 13.2 & 13.0 & 13.2 \\
70 & 11.9 & 12.9 & 12.8 & 12.9 \\
\hline 65 & 12.8 & 12.8 & 12.6 & 12.8 \\
\hline 60 & 13.6 & 10.5 & 10.3 & 13.6 \\
55 & 14.4 & 10.2 & 10.0 & 14.4 \\
50 & 15.3 & 9.8 & 9.7 & 15.3 \\
45 & 16.1 & 9.7 & 9.6 & 16.1 \\
40 & 16.9 & 7.3 & 7.2 & 16.9 \\
35 & 17.8 & 7.1 & 7.0 & 17.8 \\
30 & 18.6 & 6.8 & 6.8 & 18.6 \\
25 & 19.4 & 6.5 & 6.6 & 19.4 \\
20 & 20.3 & 4.3 & 4.2 & 20.3 \\
15 & 21.1 & 4.0 & 4.0 & 21.1 \\
10 & 21.9 & 3.8 & 3.8 & 21.9 \\
5 & 22.7 & 3.5 & 3.6 & 22.7 \\
3 & 23.1 & 3.4 & 3.5 & 23.1 \\
\hline \hline
\end{tabular}

* This is the percentage of evacuees using elevators from the mid and high rise floors. For this evacuation approach, the rest of the evacuees from these floors used stairs. Floors 11 through 14 were completely evacuated by elevator. For floors 1 through $13,3 \%$ were by elevator and the rest by stairs.

** Shortest evacuation time 
Table 7. Data used for evacuation calculations of the GSA Building

\begin{tabular}{|c|c|}
\hline Item & Quantity \\
\hline Floor to Floor Height 1st Floor & $4.75 \mathrm{~m}(15.6 \mathrm{ft})$ \\
\hline Floor to Floor Height Above 1st Floor & $3.70 \mathrm{~m}(12.1 \mathrm{ft})$ \\
\hline \multicolumn{2}{|l|}{ People per Floor: } \\
\hline Floors 2 through 6 & 453 \\
\hline Floor 7 & 362 \\
\hline Width of Elevator Doors & $1.22 \mathrm{~m}(48 \mathrm{in})$ \\
\hline Elevator Car Velocity & $3.05 \mathrm{~m} / \mathrm{s}(600 \mathrm{f} / \mathrm{m})$ \\
\hline Elevator Car Acceleration & $1.22 \mathrm{~m} / \mathrm{s}^{2}\left(4 \mathrm{ft} / \mathrm{s}^{2}\right)$ \\
\hline Number of People in a Full Elevator Car & 12 \\
\hline Stair Riser & $0.10 \mathrm{~m}(12 \mathrm{in})$ \\
\hline Stair Tread & $0.06 \mathrm{~m}(7.5 \mathrm{in})$ \\
\hline Stair Width* & $1.35 \mathrm{~m}(53 \mathrm{in})$ \\
\hline Stair Door Width & $1.01 \mathrm{~m}(40 \mathrm{in})$ \\
\hline
\end{tabular}

"Except for the first floor of the three north stair which have a width of $1.52 \mathrm{~m}$ (60 in). 




Figure 1. Typical sign currently used to indicate that elevators should not to be used during fires 


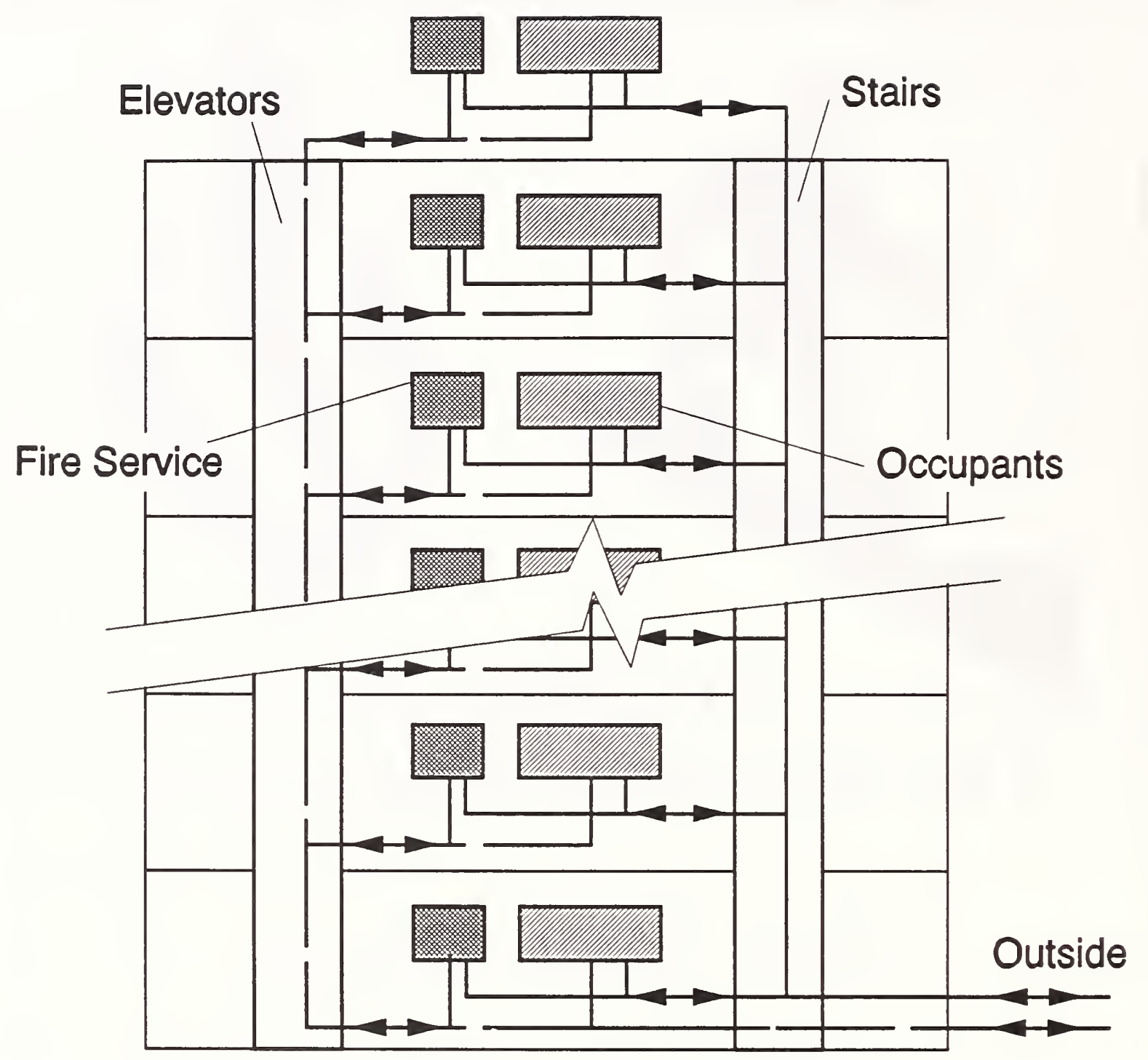

Figure 2. Diagram of physical systems and people flow for emergency use of both stairs and elevators 




Figure 3. Diagram of system interaction for emergency use of both stairs and elevators 


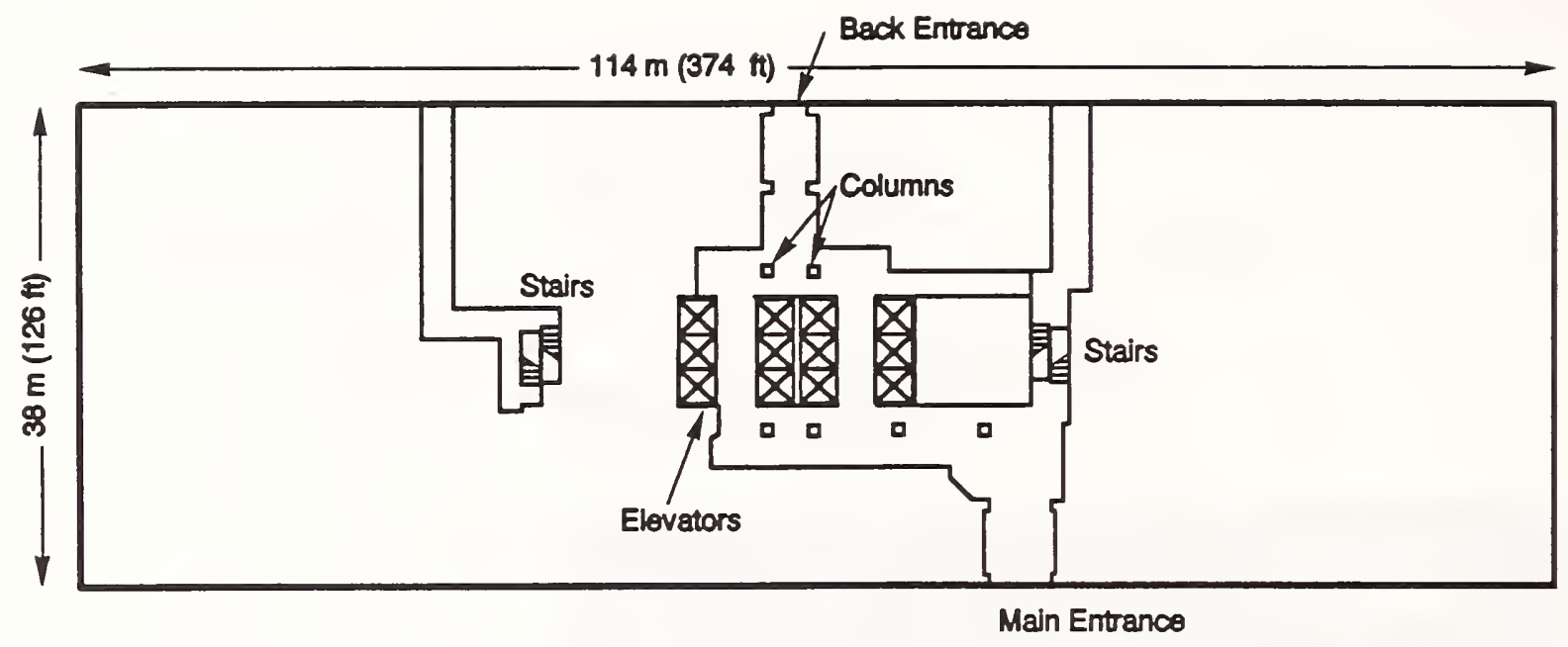

Figure 4. Ground floor plan of Hoffman Building II

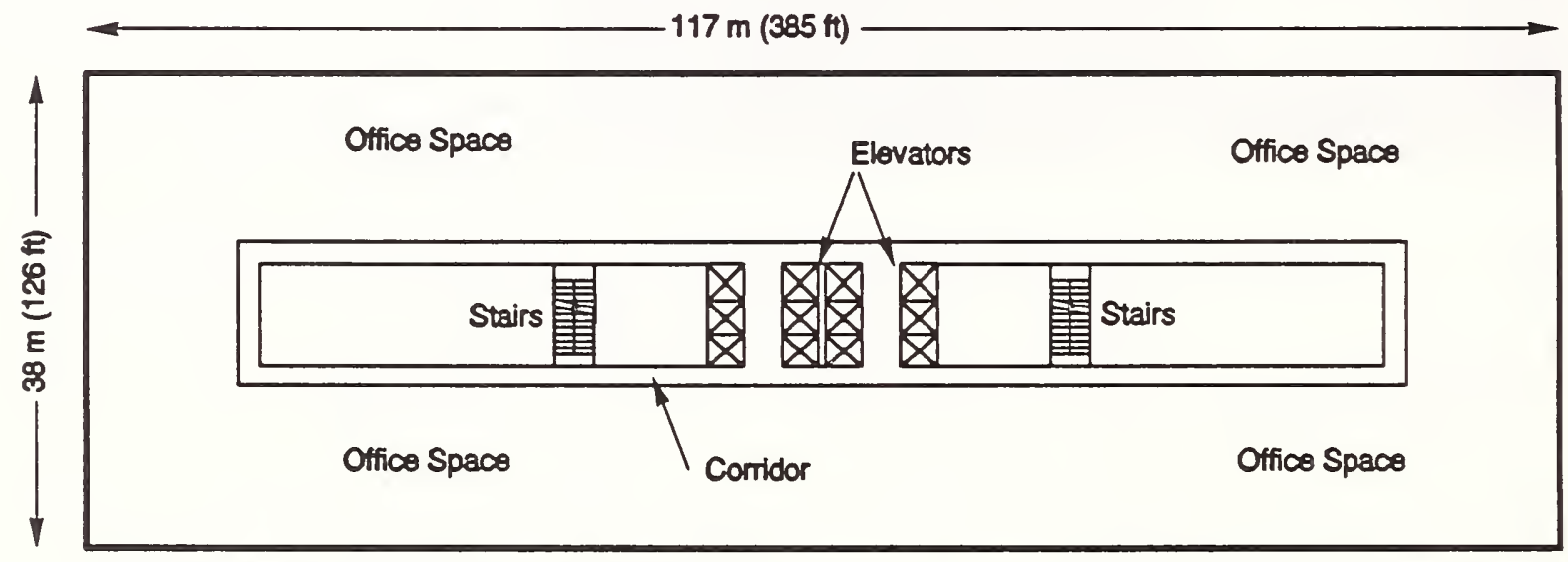

Note: Dimensions are for floors 2 through 12, and floor 1 is approximately the size of the ground floor.

Figure 5. Typical plan for floors 1 through 12 of Hoffman Building II 


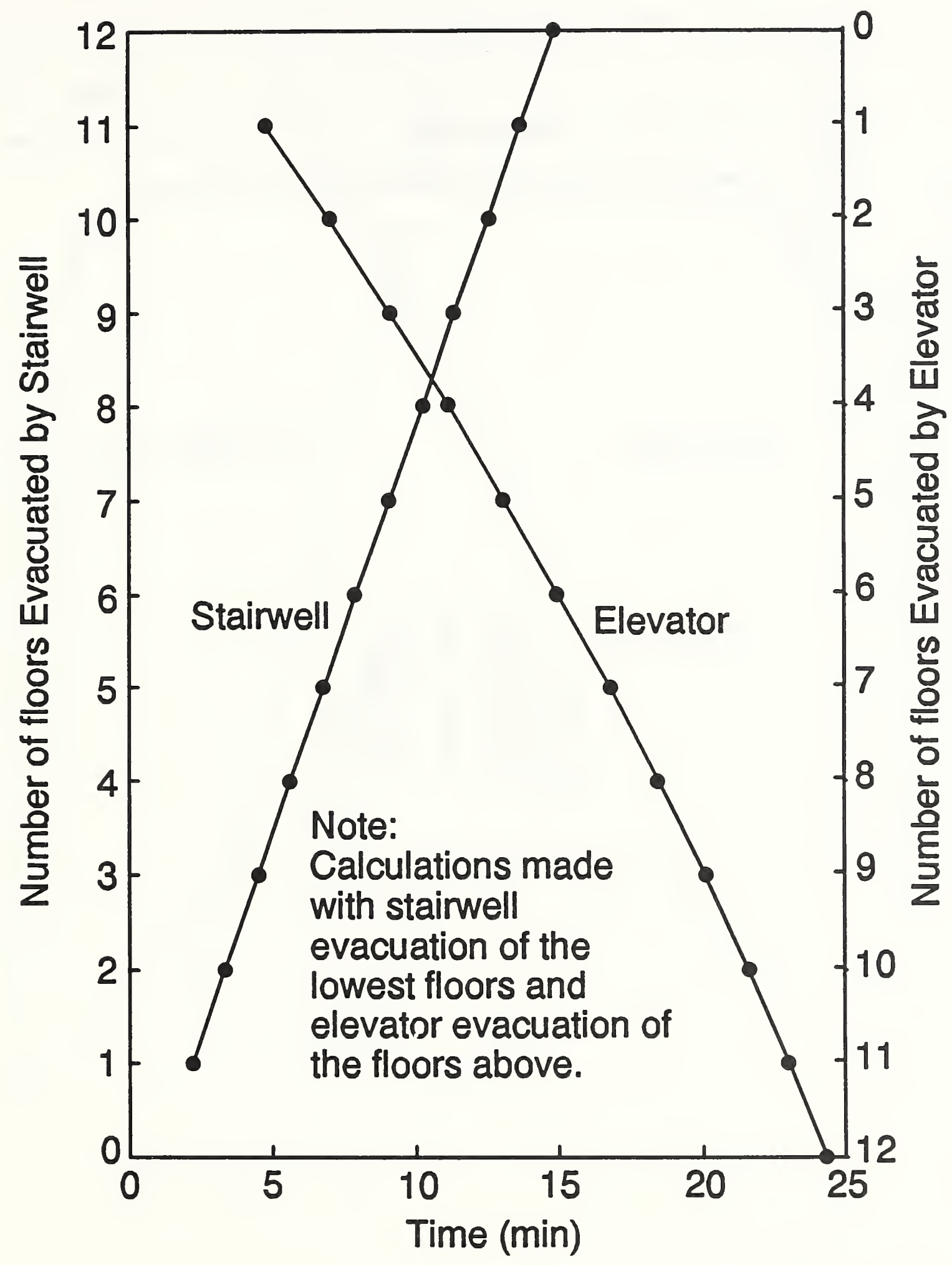

Figure 6. Time for combinations of stair and elevator evacuation for Hoffman Building II 


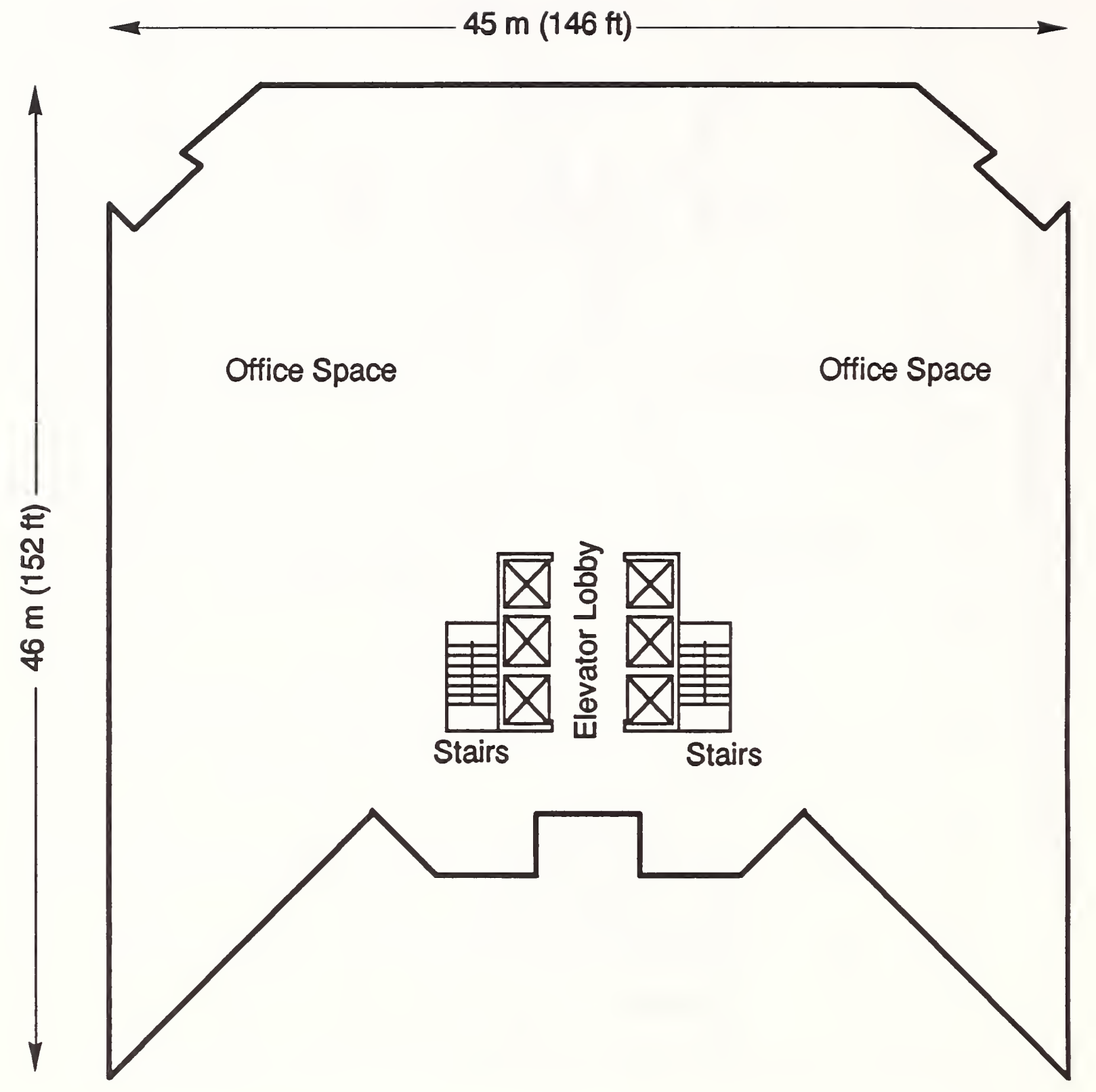

Figure 7. Typical plan of floors 2 through 16 of the White Flint North Building 


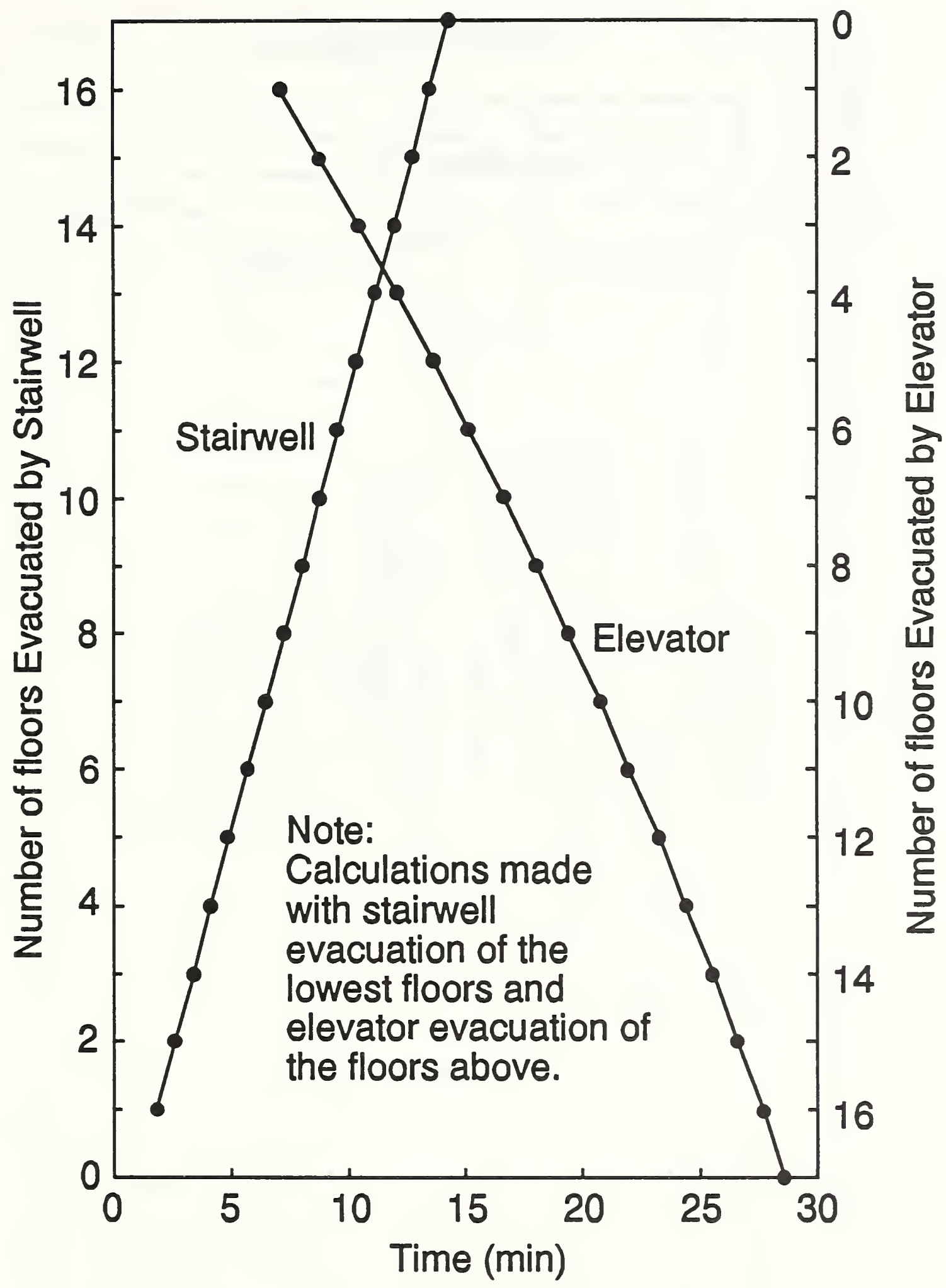

Figure 8. Time for combinations of stair and elevator evacuation for White Flint North Building 


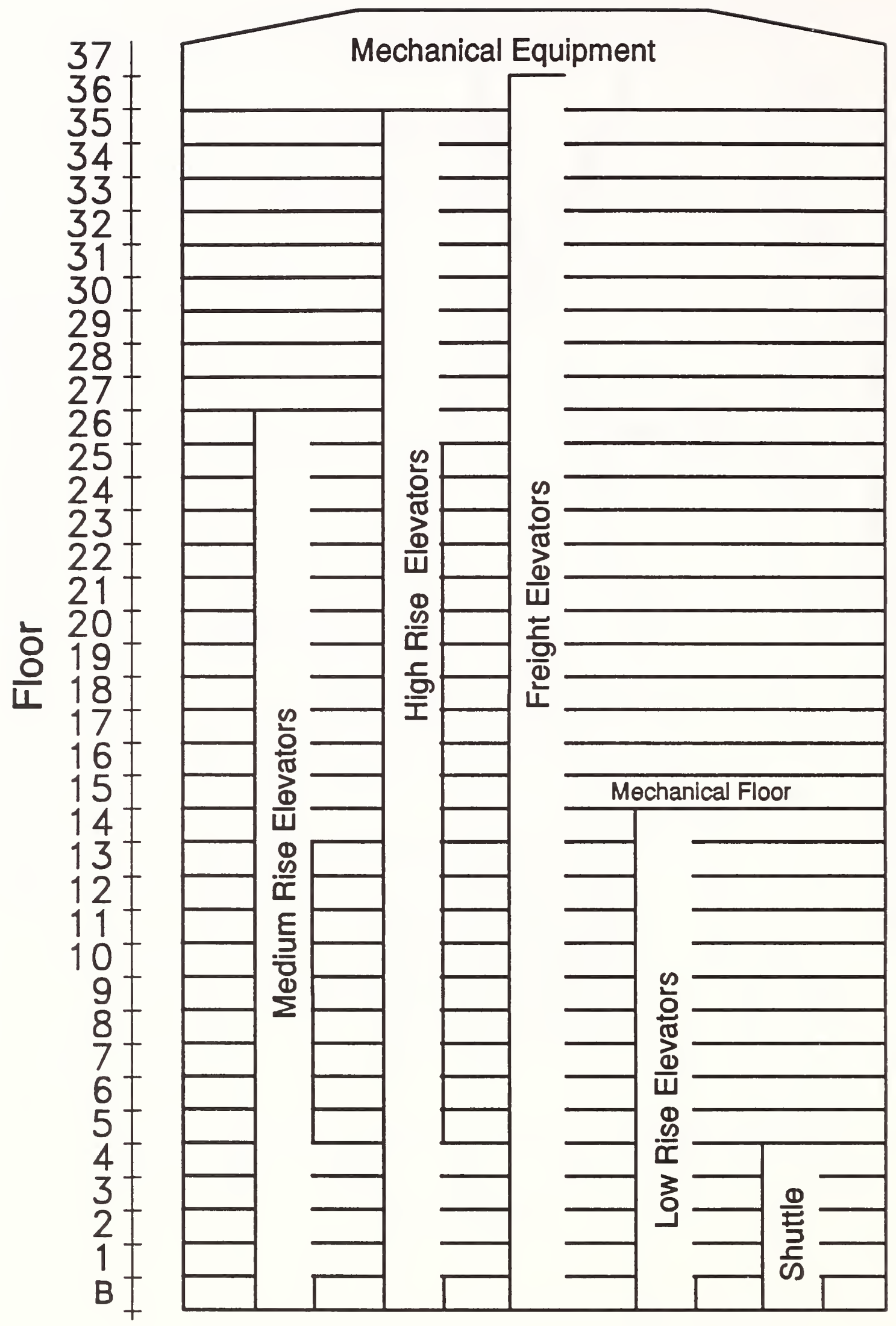

Figure 9. Diagram of the elevator rises at the Seattle Building 


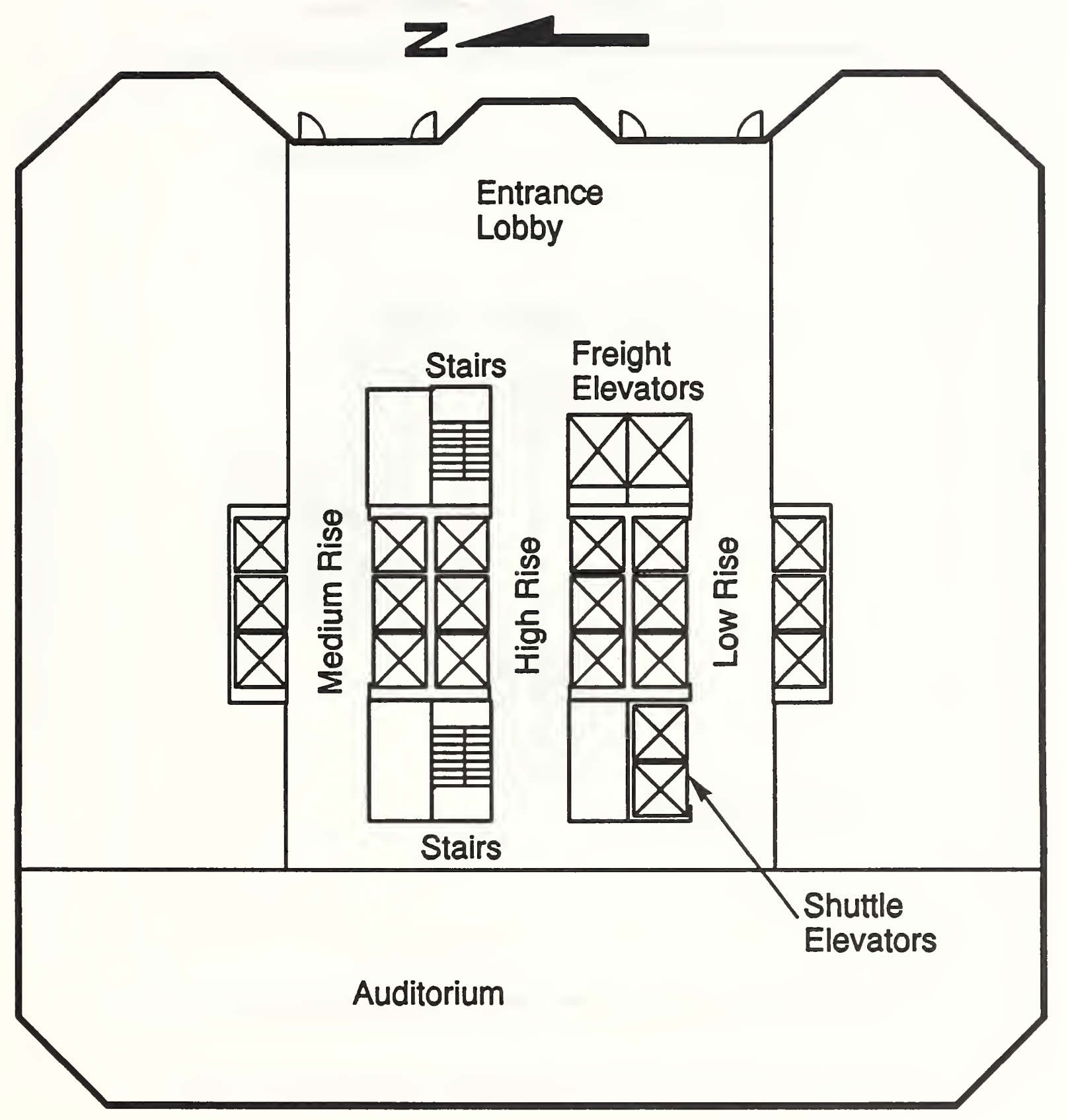

Figure 10. Fourth floor plan of the Seattle Building 


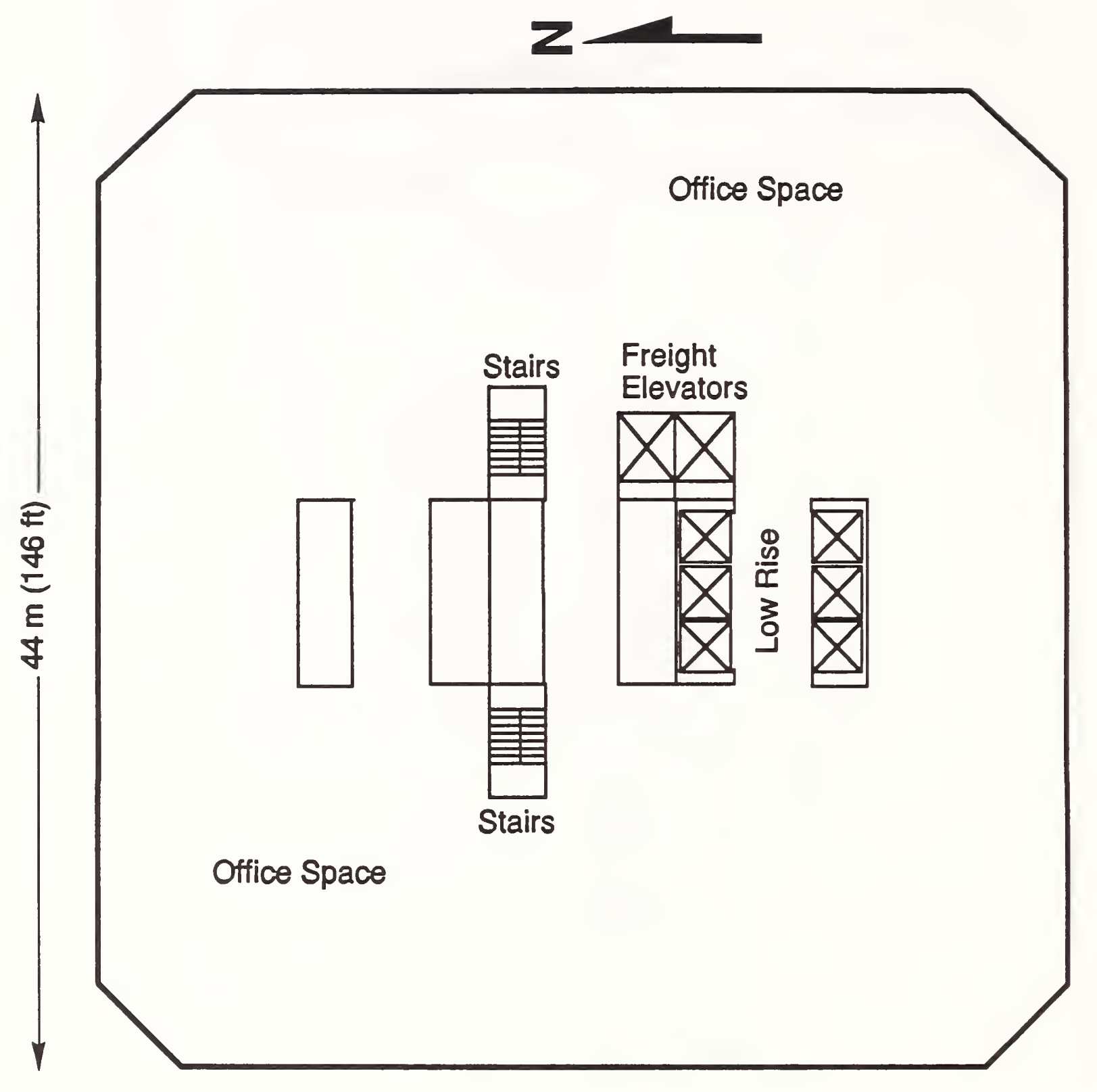

Figure 11. Typical low rise elevator plan of the Seattle Building (floors 5-13) 




Figure 12. Typical mid rise elevator plan of the Seattle Building (floors 15-25) 


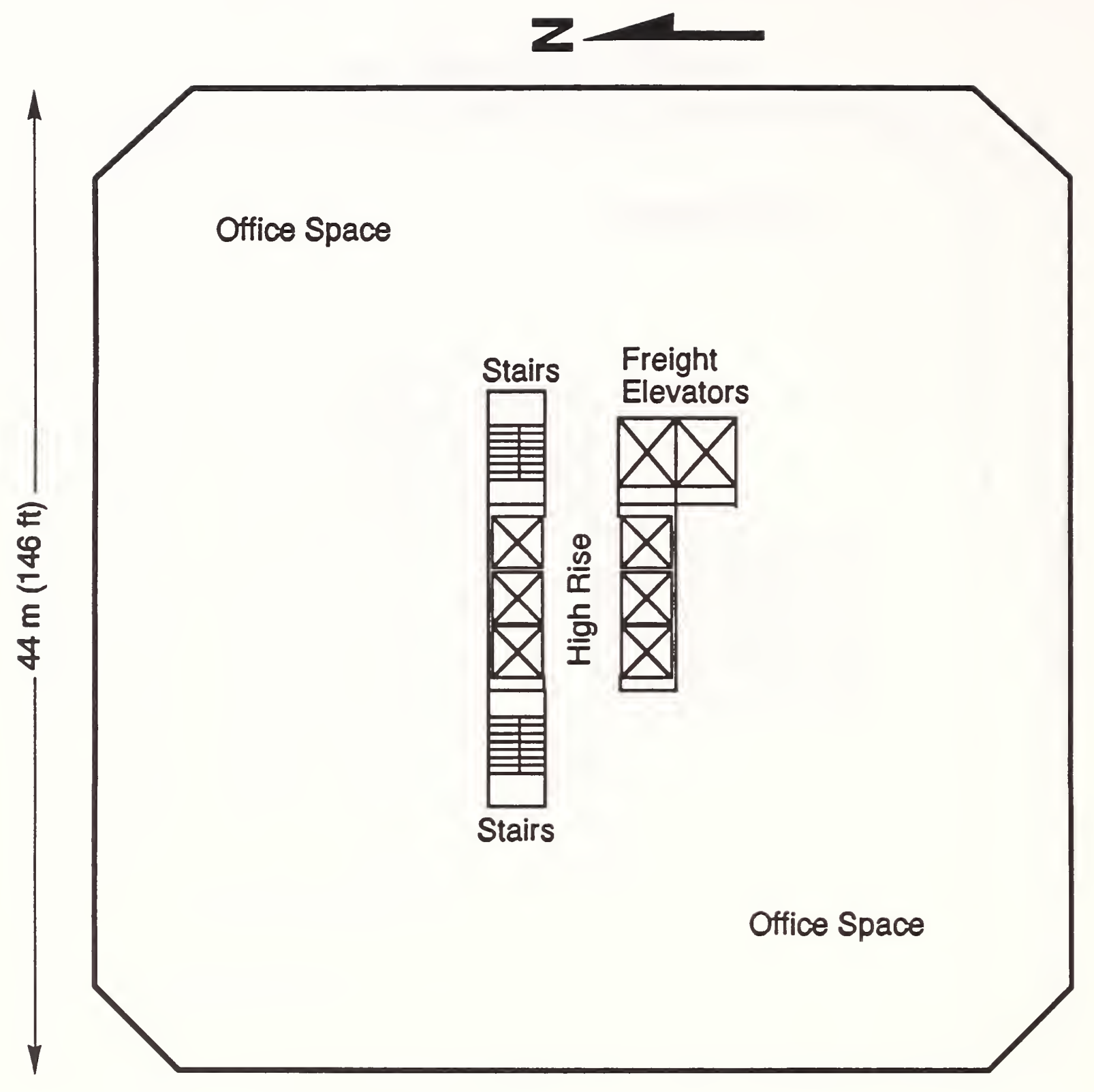

Figure 13. Typical high rise elevator plan of the Seattle Building (floors 27-35) 


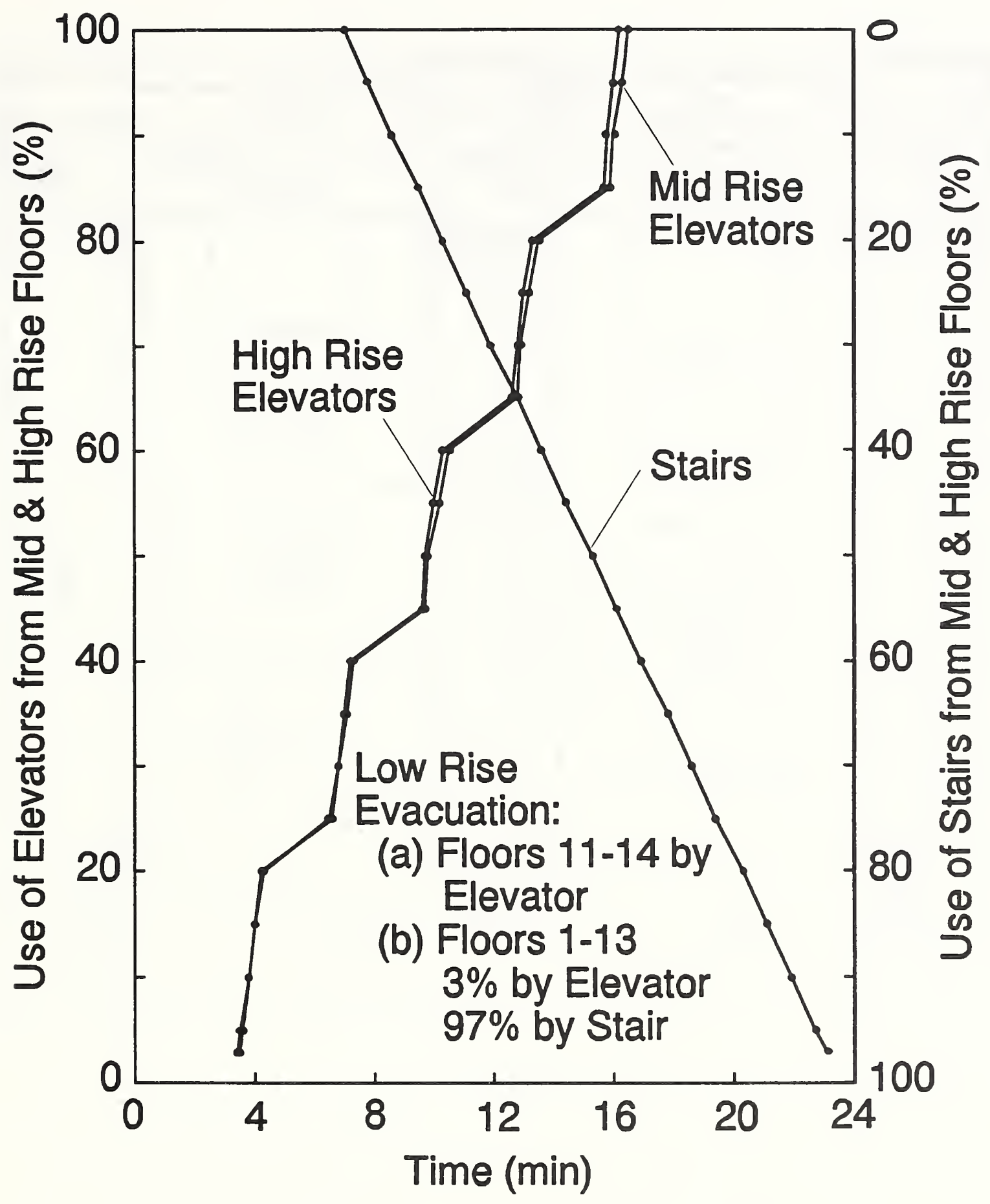

Figure 14. Time for different combinations of stair and elevator evacuation of the mid and high rise floors of the Seattle Building 


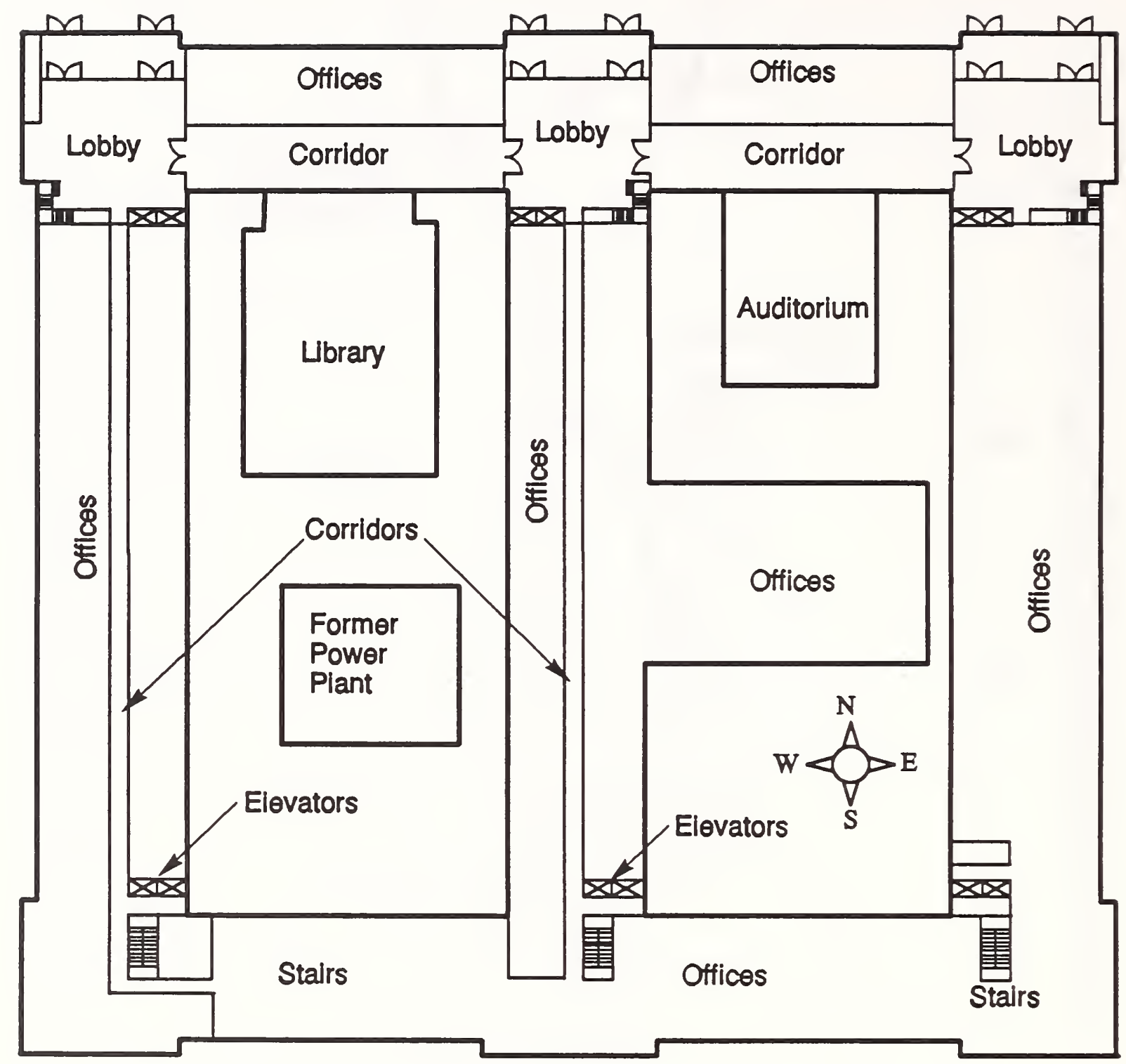

Figure 15. First floor plan of the GSA Building 


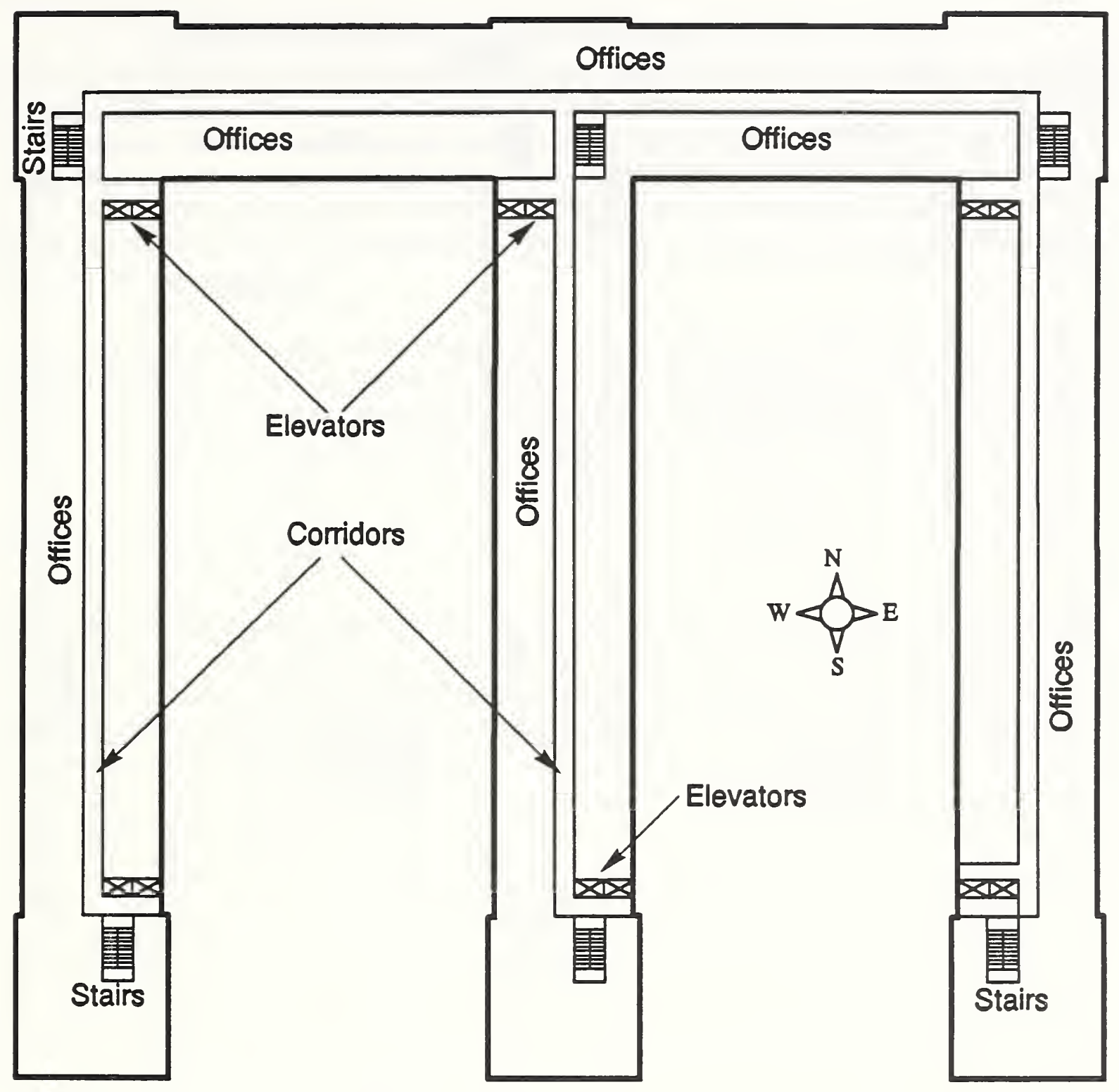

Figure 16. Typical plan of floors 2 through 6 of the GSA Building 


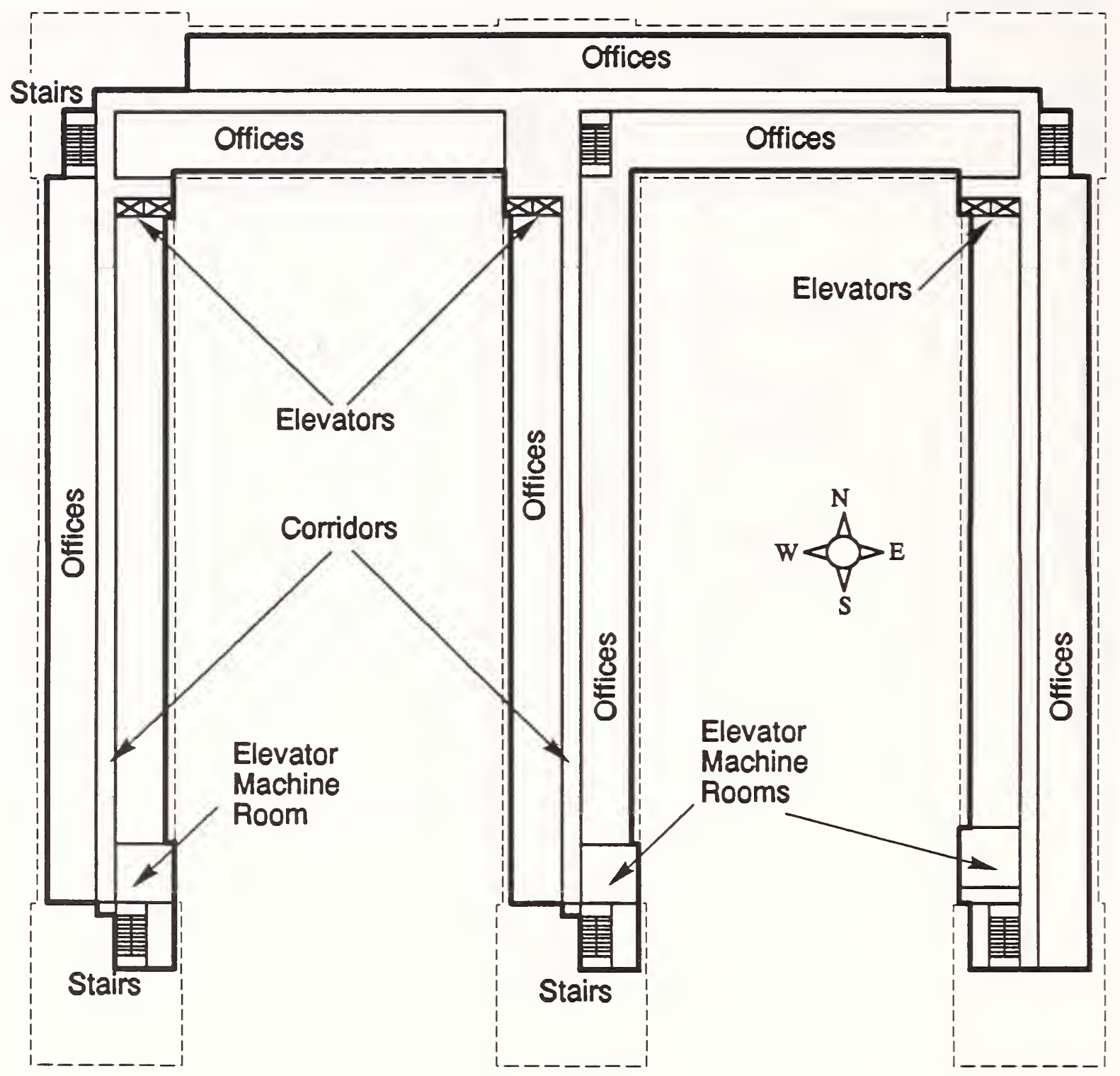

Figure 17. Seventh floor plan of the GSA Building 


\section{Appendix A Design of Elevator Smoke Control Systems ${ }^{2}$}

\section{Introduction}

Throughout most of the world, there are signs next to elevators indicating they should not be used in fire situations. These elevators are not intended as means of fire egress, and they should not be used for fire evacuation. However, some people cannot use stairwells because of physical disabilities, and for these people fire evacuation is a serious problem. The use of elevators is a potential solution to this problem. Logistics of evacuation, reliability of electric power, elevator door jamming, water damage to electric controls, and fire and smoke protection are long-standing obstacles to the use of elevators for fire evacuation.

A joint project of the National Institute of Standards and Technology (NIST) in the United States and the National Research Council of Canada (NRCC) was formed to evaluate the feasibility of using elevators for the evacuation of the handicapped during a fire. This paper summarizes the findings of the joint project that are relevant to the design of smoke control systems for elevators.

\section{Piston Effect}

Analysis of the air flows and pressures produced by elevator car motion in a pressurized hoistway (elevator shaft) was developed by Klote (1988), based on continuity equation for the contracting control volume in hoistway above an ascending car. From on this analysis, an expression was developed for the critical pressure difference from the elevator lobby to the building at which piston effect cannot overcome lobby pressurization.

$$
\Delta p_{c r i t}=\frac{\rho_{s} K_{c p}}{2}\left(\frac{A_{e} A_{s} V}{A_{r i} A_{a} C_{c}}\right)^{2}
$$

where:

$\Delta p_{\text {cris }}=$ critical pressure difference, $\mathrm{Pa}\left(\right.$ in $\left.\mathrm{H}_{2} \mathrm{O}\right)$

$\rho_{s}=$ air density in hoistway, $\mathrm{kg} / \mathrm{m}^{3}\left(\mathrm{lb} / \mathrm{ft}^{3}\right)$

$A_{s} \quad=$ cross sectional area of the hoistway, $\mathrm{m}^{2}\left(\mathrm{ft}^{2}\right)$

$A_{n} \quad=$ leakage area between the lobby and the building, $\mathrm{m}^{2}\left(\mathrm{ft}^{2}\right)$

$A_{a}=$ free area around the elevator car, $\mathrm{m}^{2}\left(\mathrm{ft}^{2}\right)$

$A_{e} \quad=$ effective area between the hoistway and the outside, $\mathrm{m}^{2}\left(\mathrm{ft}^{2}\right)$

$V=$ elevator car velocity, $\mathrm{m} / \mathrm{s}(\mathrm{ft} / \mathrm{min})$

${ }^{2}$ This appendix is abstracted from the paper Design of Elevator Smoke Control Systems for Fire Evacuation by J. H. Klote and G. T. Tamura, ASHRAE Transactions, Vol 97, Part 1, 1991. 


$$
\begin{array}{ll}
C_{c} & =\text { flow coefficient for flow around car, dimensionless } \\
K_{c p} & =\text { coefficient, } 1.00\left(1.66 \times 10^{-6}\right)
\end{array}
$$

The flow coefficient, $C_{c}$, was determined experimentally (Klote and Tamura, 1986b) at about 0.94 for a multiple car hoistway and 0.83 for a single car hoistway. An example calculation of piston effect is presented. The effective area between the hoistway and the outside is

$$
A_{e}=\left(\frac{1}{A_{s r}^{2}}+\frac{1}{A_{r i}^{2}}+\frac{1}{A_{i 0}^{2}}\right)^{-\frac{1}{2}}
$$

where:

$$
\begin{aligned}
& A_{s r} \quad=\text { leakage area between the hoistway and the lobby, } \mathrm{m}^{2}\left(\mathrm{ft}^{2}\right) \\
& A_{i o} \quad=\text { leakage area between the building and the outside, } \mathrm{m}^{2}\left(\mathrm{ft}^{2}\right)
\end{aligned}
$$

\section{System Concept}

Smoke control systems for elevator evacuation must provide smoke protection for elevator lobbies, hoistways, and machinery rooms. Protection of lobbies is essential so that people will have a safe place to wait for the elevator. Protection of the machinery room is important to prevent damage to elevator machinery. Figure 1 illustrates a system that pressurizes the hoistway directly and indirectly pressurizes the elevator lobby and the machinery room. The hoistway vent is not shown, but this topic is addressed later in this paper.

\subsection{Hoistway Pressurization and Lobby Pressurization}

Considering the leakage from the elevator lobby to the outside to be negligible, the mass flow rate from the hoistway to the elevator lobby equals the flow from the lobby to the building space

$$
m=C_{s r} K_{m} A_{s r} \sqrt{2 \rho_{s r} \Delta p_{s r}}=C_{r i} K_{m} A_{r i} \sqrt{2 \rho_{r i} \Delta p_{r i}}
$$

where:

$$
\begin{array}{ll}
m & =\text { mass flow rate, } \mathrm{kg} / \mathrm{s}(\mathrm{lb} / \mathrm{sec}) \\
C_{s r} & =\text { flow coefficient for path between hoistway and lobby, dimensionless } \\
C_{r i} & =\text { flow coefficient for path between lobby and building, dimensionless } \\
\rho_{s r} & =\text { air density in path between hoistway and lobby, } \mathrm{kg} / \mathrm{m}^{3}\left(\mathrm{lb} / \mathrm{ft}^{3}\right) \\
\rho_{r i} & =\text { air density in path between lobby and building, } \mathrm{kg} / \mathrm{m}^{3}\left(\mathrm{lb} / \mathrm{ft}^{3}\right)
\end{array}
$$




$$
\begin{array}{ll}
\Delta p_{s r} & =\text { pressure difference from hoistway to lobby, } \mathrm{Pa}\left(\text { in } \mathrm{H}_{2} \mathrm{O}\right) \\
\Delta p_{r i} & =\text { pressure difference from lobby to building, } \mathrm{Pa}\left(\text { in } \mathrm{H}_{2} \mathrm{O}\right) \\
K_{m} & =\text { coefficient, } 1.00(12.9)
\end{array}
$$

Considering $\rho_{s r}=\rho_{r i}$ and $C_{s r}=C_{r}$, equation (3) leads to

$$
\frac{\Delta p_{s r}}{\Delta p_{r t}}=\left(\frac{A_{r t}}{A_{s t}}\right)^{2}
$$

For elevator doors with wide gaps that are common in most buildings, Tamura and Shaw (1976) showed that the leakage area of the gaps is generally in the range of 0.05 to $0.07 \mathrm{~m}^{2}\left(0.5\right.$ to $\left.0.7 \mathrm{ft}^{2}\right)$. Based on general experience with building leakages (Klote and Fothergill, 1983), $A_{r} / A_{s}$ is about 0.4 for construction of average tightness and about 0.1 for tight construction. From equation (4), $\Delta p_{s r} / \Delta p_{r i}$ is therefore 0.16 and 0.01 for average and tight construction. Thus, the pressure in the elevator lobby can be expected to be close to the pressure in the hoistway, provided that the construction is not unusually leaky. Pressurization air can be supplied to the elevator lobbies (figure 2). However, from the above discussion it seems that this direct lobby pressurization does not result in any significant improvement in pressurization over supplying the air into the hoistway as illustrated in figure 1.

Direct lobby pressurization has some advantage over direct hoistway pressurization in purging small amounts of smoke from the lobby. Part of the pressurization air to an elevator smoke control system goes from the hoistway to the outside, and the rest goes from the lobby through the building to the outside. With direct lobby pressurization, both these amounts flow through the lobby. Such an increased flow rate tends to better purge any small amounts of smoke that would get into the lobby before smoke control activation or when a person is entering the lobby. The relative benefit of this improved purging compared to its cost has not been evaluated. The following discussions have been focused arbitrarily on the hoistway pressurization systems.

\subsection{Pressure Fluctuations due to Open Doors}

Elevator systems must be designed to maintain design pressure differences under the likely conditions of opened and closed doors. Klote and Tamura (1986a) showed that opening a large flow path from the pressurized spaces to the outside can result in a significant loss in pressurization. For example opening the elevator doors, elevator lobby doors, and exterior doors resulted in a pressure drop from $32 \mathrm{~Pa}\left(0.13\right.$ in $\left.\mathrm{H}_{2} \mathrm{O}\right)$ to $7 \mathrm{~Pa}\left(0.03\right.$ in $\left.\mathrm{H}_{2} \mathrm{O}\right)$ for a system without features to resist pressure fluctuation.

During a fire, it is expected that several exterior doors will be propped open, and the elevator doors will open and close as elevators are used for evacuation. Further, stairwell doors are likely to be opened and closed as people use them for evacuation. It is envisioned that lobby doors will close automatically upon smoke control system activation. However, lobby doors can be inadvertently blocked and the closing mechanism can fail. It is anticipated that occupants will close any such opened lobby doors to prevent being exposed to smoke. Doors may not be closed on floors where there is no smoke danger or there are no people waiting in the elevator lobby. The smoke control system should be designed to maintain pressurization when some elevator lobby doors are open on 
floors away from the fire. The examples presented later deal with pressure fluctuations due to doors opening and closing.

\section{Design Pressure Differences}

The maximum allowable pressure difference across the lobby doors is a value that does not result in excessive door opening forces. The force to open a door can be calculated by a hydrostatic analysis of the moments on a door including the pressure difference across the door and the force of the door closer mechanism (Klote and Fothergill, 1983). The Life Safety Code (NFPA 1991) states that the force required to open any door in a means of egress shall not exceed $133 \mathrm{~N}(30 \mathrm{lb})$. For a door closer force of $45 \mathrm{~N}$ (10 lbs) on a $0.91 \mathrm{~m}$ (36 inch) wide door, a pressure difference of $85 \mathrm{~Pa}(0.34$ in $\mathrm{H}_{2} \mathrm{O}$ ) results in a door opening force of $133 \mathrm{~N}(30 \mathrm{lb})$.

Besides the maximum value, a system should also operate above a minimum value sufficient to prevent smoke infiltration into the lobby. The design approach is for this minimum value to incorporate the fire effect of buoyancy, and account for other driving forces discussed in the analysis later. The pressure difference due to buoyancy of hot fire gases between a fire compartment and its surroundings is expressed as

$$
\Delta p=K_{s} h\left(\frac{1}{T_{0}}-\frac{1}{T_{f}}\right)
$$

where:

$$
\begin{aligned}
& \Delta p \quad=\text { pressure difference, } \mathrm{Pa}\left(\text { in } \mathrm{H}_{2} \mathrm{O}\right) \\
& h \\
& T_{o} \quad=\text { height above neutral plane, } \mathrm{m}(\mathrm{ft}) \\
& T_{f} \quad=\text { air temperature outside of fire compartment, } \mathrm{K}\left({ }^{\circ} \mathrm{R}\right) \\
& K_{s} \quad=\text { coefficient, } 3460(7.64)
\end{aligned}
$$

For a fire compartment temperature of $930^{\circ} \mathrm{C}\left(1700^{\circ} \mathrm{F}\right)$, the pressure difference $1.82 \mathrm{~m}(6.0 \mathrm{ft})$ above the neutral plane is $16 \mathrm{~Pa}\left(0.065\right.$ in $\left.\mathrm{H}_{2} \mathrm{O}\right)$. NFPA 92A (1988) suggests a minimum value of $25 \mathrm{~Pa}$ $\left(0.10\right.$ in $\left.\mathrm{H}_{2} \mathrm{O}\right)$ for an unsprinklered building with a ceiling height of $2.74 \mathrm{~m}(9 \mathrm{ft})$. This considers the neutral plane at $1.82 \mathrm{~m}(6 \mathrm{ft})$ below the ceiling, and allows a safety factor of $9 \mathrm{~Pa}\left(0.035\right.$ in $\left.\mathrm{H}_{2} \mathrm{O}\right)$. NFPA 92A also suggests a minimum value of $12 \mathrm{~Pa}\left(0.05\right.$ in $\left.\mathrm{H}_{2} \mathrm{O}\right)$ for sprinklered buildings.

The minimum pressure difference discussed above applies to the fire floor, because this is where the fire puts its major stress on the smoke control system. Smoke control systems, that require no information about the location of the fire floor, must maintain at least the minimum pressure difference across the lobby doors on all floors.

The above discussion of minimum pressure differences does not apply to variable-supply air systems that maintain a set pressure difference across the lobby doors on the fire floor. This set pressure difference is discussed later. The set pressure should be high enough so that the system is not 
adversely effected by transient pressures when the system is adjusting to the opening or closing of doors.

\section{Smoke Control Systems}

Elevator smoke control systems can incorporate features to deal with pressure fluctuations due to opening and closing doors. These features include pressure relief vents, vents with barometric dampers, variable-supply air fans, fire floor venting, and fire floor exhaust.

\subsection{Pressure Relief Vent System}

This system has a "constant-supply" air rate fan and a pressure relief vent to the outside as illustrated in figure 3. The area of this vent is fixed, and sized for operation in the smoke control system. The vent can be fitted with automatic dampers, if it is desired for it to be normally closed. The supply rate varies to some extent with the pressure across the fan, but the term "constant-supply" is used to differentiate this fan from one that has a "variable-supply" rate. The vent must be large enough that the maximum allowable pressure difference is not exceeded when all doors are closed. When paths to the outside are opened, air flows through them and the hoistway pressure drops. This system must maintain at least the minimum allowable pressure difference when some design combination of paths is open.

\subsection{Barometric Damper System}

This system is similar to the one above, except that the vent has a barometric damper which closes when the pressure drops below a specified value. The use of these dampers minimizes air losses when paths from the elevator shaft are opened, and the pressurization fan can be sized smaller than for the above system. A normally closed automatic damper in parallel with the barometric damper can prevent damper chatter caused by the wind.

\subsection{Variable-Supply Air System}

Variable-supply air can be achieved by using one of many fans commercially available for variable flow rate. Alternatively, a fan bypass arrangement of ducts and dampers can be used to vary the flow rate of supply air to the hoistway. The variable flow fans are controlled by one or more static pressure sensors that sense the pressure difference between the lobby and the building. There are two approaches for use of the sensors. The air flow rate can be controlled by the average of all signals from the sensors or it can be controlled by the signal from the fire floor.

Using the average of all the signals has the advantage that no information is required about where the fire is located. Using the fire floor sensor signal requires information about the fire location. This information can come from smoke detectors, heat detectors, or sprinkler water flow indicators. Using the fire floor signal has the advantage that the system maintains a set pressure difference at this most critical location. 


\subsection{System with Fire Floor Venting or Exhaust}

Smoke venting and smoke exhaust of the fire floor can improve system performance. The venting or exhaust increases the pressure difference from the lobby to the fire floor. The vents can be exterior wall vents or non-powered smoke shafts. Figure 4 shows a fan-duct system intended to exhaust the fire floor. Upon detection of fire or smoke, the damper opens on the fire floor and the exhaust fan is activated. The detection system must be configured to identify the fire floor.

\section{Analysis of Smoke Control Systems}

The design of an elevator smoke control system includes selection of a system for dealing with pressure fluctuations, determining appropriate values for leakage areas and other parameters, as well as calculating the performance of the smoke control system. The following section discusses a computer program that can be used for analysis of these systems. This program evaluates the effects of outside temperature, forced ventilation, and the wind.

Neither of the example analyses that are provided addresses the effects of wind. A wind of $22 \mathrm{~m} / \mathrm{s}$ ( 50 $\mathrm{mph})$ result in a velocity pressure on the order of $250 \mathrm{~Pa}\left(1 \mathrm{in}_{2} \mathrm{O}\right)$. Occurrence of such high velocity wind is infrequent. However, such high velocities should not pose a problem, provided that windows do not break. The likelihood of the fire resulting in broken windows is considered to be much lower for a sprinklered building than an unsprinklered one. Further, local obstructions like surrounding buildings can significantly reduce wind pressures on building surfaces. The variablesupply air system analyzed below has the advantage that it will work to maintain its set pressure difference even under conditions of broken windows with wind effects.

\subsection{Network Computer Program}

Elevator smoke control systems can be analyzed by the computer program for analysis of smoke control systems (ASCOS) presented by Klote and Fothergill (1983). In this program, a building is represented by a network of spaces or nodes, each at a specific pressure and temperature. Shafts such as hoistways and stairwells are modeled by a series of vertical spaces, one for each floor. Air flows through openings from regions of high pressure to regions of low pressure.

In this model, air from the outside can be introduced by a pressurization system into any level of a shaft or even into other building spaces. This allows simulation of elevator smoke control systems. The flows and leakage paths are considered to be the mid-height of each level. The net air supplied by the HVAC system or by the pressurization system is considered constant and independent of pressure. The outside air temperature is considered constant. The program calculates the steady flows and pressures throughout the network, including the driving forces of wind, pressurization system, and inside-to-outside temperature difference.

\subsection{Example Analysis of Pressure Relief Vent System}

An eleven-story building with a typical floor plan shown in figure 5 was selected arbitrarily for this example. Because the building is symmetric, only half of each floor was analyzed. The minimum and maximum allowable pressure differences from the lobby to the building are 12 and $85 \mathrm{~Pa}(0.05$ and 
0.34 in $\left.\mathrm{H}_{2} \mathrm{O}\right)$. The other design parameters are listed in table 1. An value of $2.23 \mathrm{~m}^{2}\left(24 \mathrm{ft}^{2}\right)$ for the relief vent area is selected arbitrarily.

Pressurization air is supplied to the hoistway at the second floor. The objective of the design analysis is to determine a flow rate of pressurization air that will result in acceptable pressurization with a minimum and a maximum design number of large open paths from the hoistway to the outside. One approach to the analysis for the pressure relief vent system is:

1 Calculate the flow rate of pressurization air that results in the minimum allowable pressure difference when the maximum design number of large paths are open from the hoistway to the outside. This flow rate is for either summer or winter design conditions, whichever flow rate is largest.

2 Calculate the pressure differences resulting from the flow rate of step 1 when the minimum design number of large paths are open.

3 If the pressure differences from step 2 are less than or equal to the maximum allowable pressure difference, the system can maintain acceptable pressurization. If not, another system or another variation of this system should be considered.

4 Apply a safety factor to the flow rate calculated above.

The maximum design number of large paths should consist of one on the first floor plus some others on upper floors. The first floor path consists of open elevator doors, elevator lobby doors and exterior doors. The paths on the other floors consist of an open elevator lobby door and an open stairwell door. This results in large paths to the outside, because the exterior stairwell door is open. For this analysis the design numbers of large open paths have been selected arbitrarily as:

Minimum Number of Large

Paths Open:

Zero - All doors are closed.

Maximum Number of

First floor path plus paths on the top two floors.

Large Paths Open:

Table 2 lists the arrangement of doors for the computer analysis. Runs 1 and 2 are the maximum number of paths open (step 1), and runs 3 and 4 are the minimum paths open (step 2). The pressure differences for these runs are listed in tables 3 and 4. For winter conditions, the ASCOS program was executed a few times to determine that $15,800 \mathrm{~L} / \mathrm{s}(33,400 \mathrm{cfm})$ of pressurization air is needed to maintain at least the minimum allowable pressure difference when the maximum design number of large paths are open (run 1). At this flow rate with the maximum design number of large paths open in summer (run 2), the pressure differences are all greater than the minimum allowable pressure difference. At this same rate of pressurization, the pressure differences with the minimum paths open (runs 3 and 4) are all below the maximum allowable pressure difference.

For the design analysis, $15,800 \mathrm{~L} / \mathrm{s}(33,400 \mathrm{cfm})$ of pressurization air is sufficient to maintain acceptable pressurization under design conditions of large open paths from the hoistway to the outside. A safety factor is suggested to account for differences between the estimated leakage areas of this analysis and those of the actual building. If a safety factor of $25 \%$ were used, the supply fan 
would be sized far about $19,800 \mathrm{~L} / \mathrm{s}(42,000 \mathrm{cfm})$. The system should be designed so that the flow rate can be adjusted in the field as appropriate.

\subsection{Example Analysis of Variable-Supply Air System}

The same building is used as in the above example. The flow rate of the variable-supply air fan is controlled by a sensor on the fire floor to maintain a set point of $12 \mathrm{~Pa}\left(0.05\right.$ in $\left.\mathrm{H}_{2} \mathrm{O}\right)$. The system maintains the set point when the elevator lobby door is closed on the fire floor. However, when the elevator lobby door is open on the fire floor, the flow rate of pressurization air increases in an attempt to maintain the set point, and high pressure differences can result across elevator lobby doors on other floors. These high pressures should not exceed the maximum allowable pressure difference. As with the previous example, the maximum allowable pressure difference is $85 \mathrm{~Pa}\left(0.34\right.$ in $\left.\mathrm{H}_{2} \mathrm{O}\right)$. Again, pressurization air is supplied to the hoistway at the second floor.

As with preceding example, the objective of the design analysis is to determine a flow rate of pressurization air that will result in acceptable pressurization with a minimum and a maximum design number of large open paths from the hoistway to the outside. One approach to the analysis for the pressure relief vent system is:

1 Calculate the flow rate of pressurization air that results in the maximum allowable pressure difference across any closed elevator lobby door when the lobby door is open on the fire floor. This calculation should be made for summer and winter design conditions with the fire floor being on the top or second floor. The smallest of these flow rates is the value that should not be exceeded.

2 Calculate the flow rate of pressurization air that results in the minimum allowable pressure difference when the maximum design number of large paths are open from the hoistway to the outside. This flow rate is for either summer or winter design conditions, whichever flow rate is largest.

3 If the flow rate from step 1 is greater than that from step 2, the system can maintain acceptable pressurization. If not, another system or another variation of this system should be considered.

Apply a safety factor to the flow rate calculated above.

The maximum design number of large paths open is the same as the first example. Initially the minimum number of large paths open was also zero. However, step 3 of the analysis indicated that this system would not maintain acceptable pressurization. The system was modified such that the minimum number of large paths open is the one on the first floor. This means that the elevator lobby doors and the exterior doors must be opened automatically or remain opened upon system activation. The data presented in the rest of this analysis is for this second system with these doors opened on activation.

The conditions of open and closed doors are listed in table 5 for six computer runs, and the resulting pressurization flows and pressure differences are listed in tables 6 and 7. For each run, the ASCOS program was executed a few times to find the flow rate of pressurization air that produced the desired pressure difference. Computer runs 1, 2, 3, and 4 were made for step 1. From these runs, the pressurization flow rate should not exceed $9300 \mathrm{~L} / \mathrm{s}(19,800 \mathrm{cfm})$. Runs 5 and 6 are for step 2, and they indicate that the flow rate must be at least $4000 \mathrm{~L} / \mathrm{s}(8,500 \mathrm{cfm})$. Thus, the system can maintain acceptable pressurization (step 3). Using the same safety factor as the first example, the fan should be 
sized to deliver $8,200 \mathrm{~L} / \mathrm{s}(11,000 \mathrm{cfm})$. The system should be designed so that the flow rate can be adjusted in the field as appropriate.

\subsection{Example Piston Effect Analysis}

For the smoke control systems of the above examples, the parameters for analysis of piston effect are listed in table 8 for two cars in a hoistway. The elevator flow coefficient, $C_{c}$, was evaluated experimentally (Klote and Tamura, 1986b). From equation (2), the effective area, $A_{e}$, is $0.0302 \mathrm{~m}^{2}$ $\left(0.325 \mathrm{ft}^{2}\right)$. From equation (1), the critical pressure difference from the elevator lobby to the building is $6.0 \mathrm{~Pa}\left(0.024\right.$ in $\left.\mathrm{H}_{2} \mathrm{O}\right)$. For these example smoke control systems, the lowest pressure difference across this same path is $12 \mathrm{~Pa}\left(0.05\right.$ in $\left.\mathrm{H}_{2} \mathrm{O}\right)$ in the winter. Thus piston effect would not be a problem for these systems.

All other things being equal, the critical pressure difference from the lobby to the building is higher for a single car hoistway than for a multiple car one. For a single car hoistway with $A_{s}$ of $5.61 \mathrm{~m}^{2}$ $\left(60.4 \mathrm{ft}^{2}\right), A_{a}$ of $1.80 \mathrm{~m}^{2}\left(19.4 \mathrm{ft}^{2}\right), C_{c}$ of 0.83 and the other parameters listed in table 8 , equation (1) gives a critical pressure difference of $33 \mathrm{~Pa}\left(0.13\right.$ in $\left.\mathrm{H}_{2} \mathrm{O}\right)$. This pressure would be a concern for the smoke control systems of the above examples. Possible solutions include a slower car speed, use of another elevator with multiple cars in the hoistway, and a higher level of hoistway pressurization.

\section{Conclusions}

1. Elevator smoke control systems can be designed to provide acceptable levels of pressurization under severe conditions of doors opening and closing.

2. While the example analyses were for a pressure relief vent system and a variablesupply air system, other systems can be used to deal with the pressure fluctuations caused by doors opening and closing.

3. Transient pressures produced by the motion of a car in a hoistway are of concern, because of the potential to pull smoke into an elevator lobby. All other things being equal, this elevator piston effect is considerably greater for single car hoistways than for multiple car hoistways. Equation (1) can be used to design systems so that piston effect is not a problem.

\section{References}

Klote, J.H. 1988. An Analysis of the Influence of Piston Effect on Elevator Smoke Control, Nat. Bur. Stand. (U. S.), NBSIR 88-3751.

Klote, J.H. and Fothergill, J.W. 1983. Design of Smoke Control Systems for Buildings, American Society of Heating, Refrigerating and Air-conditioning Engineers, Atlanta, GA.

Klote, J.H. and Tamura, G.T. 1986a. Smoke Control and Fire Evacuation by Elevators, ASHRAE Transactions, Vol 92, Part 1A, pp 231-245. 
Klote, J.H. and Tamura, G.T., 1986b. Elevator Piston Effect and the Smoke Problem, Fire Safety Journal, Vol 11, No 3, May, pp 227-233.

NFPA 1991. Code for Safety to Life from Fire in Buildings and Structures, NFPA 101-1988, National Fire Protection Association, Inc., Quincy, MA, National Fire Protection Assn.

NFPA 1988. Recommended Practice for Smoke Control Systems, NFPA 92A, Quincy, MA, National Fire Protection Assn.

Tamura, G.T. and Shaw, C.Y. 1976. "Air Leakage Data for the Design of Elevator and Stair Shaft Pressurization Systems", ASHRAE Trans., Vol. 83 Part 2, pp. 179-190. 
Table 1. Parameters of example smoke control systems

Flow Areas:

$\mathrm{m}^{2}$

$\mathrm{ft}^{2}$

First floor exterior wall (exterior doors closed)

$0.0873 \quad 0.940$

First floor exterior wall (exterior doors opened)

Exterior walls (except on 1st floor)

Stairwell to building (stair door closed)

$0.0502 \quad 0.540$

$0.0251 \quad 0.270$

Stairwell to building (stair door opened)

Building floor

0.975

10.5

Building to elevator lobby (lobby doors closed)

$0.0251 \quad 0.270$

$0.0390 \quad 0.42$

Building to elevator lobby (lobby doors opened)
2.04
22.0

Elevator lobby to hoistway (elevator door closed)

$0.149 \quad 1.60$

Elevator lobby to hoistway (elevator door opened)
0.743
8.00

Pressure relief vent from hoistway to outside at 8 th floor

Other Parameters:

Height between building floors

$0.929 \mathrm{~m} \quad 10.0 \mathrm{ft}$

Number of floors

11

11

Building air temperature

$12^{\circ} \mathrm{C} \quad 70^{\circ} \mathrm{F}$

Winter outside temperature

$-15^{\circ} \mathrm{C}$

$5^{\circ} \mathrm{F}$

Summer outside temperature

$32^{\circ} \mathrm{C}$

$90^{\circ} \mathrm{F}$ 
Table 2. Arrangement of doors for computer analysis of example smoke control system with a pressure relief vent

\begin{tabular}{|c|c|c|c|c|c|}
\hline Run & Season & $\begin{array}{l}\text { 1st Floor } \\
\text { Exterior } \\
\text { Door } \\
\text { Open }\end{array}$ & $\begin{array}{l}\text { Elevator } \\
\text { Doors } \\
\text { Open on } \\
\text { Floors: }\end{array}$ & $\begin{array}{l}\text { Elevator } \\
\text { Lobby } \\
\text { Doors } \\
\text { Open on } \\
\text { Floors: }\end{array}$ & $\begin{array}{l}\text { Stairwell } \\
\text { Doors } \\
\text { Open on } \\
\text { Floors }\end{array}$ \\
\hline 1 & Winter & Yes & 1 & $1,10,11$ & 10,11 \\
\hline 2 & Summer & Yes & 1 & $1,10,11$ & 10,11 \\
\hline 3 & Winter & No & None & None & None \\
\hline 4 & Summer & No & None & None & None \\
\hline
\end{tabular}

${ }^{1}$ Exterior stairwell door on the ground floor is closed when no other stair doors are opened, and it is open when any other stair door is opened.

Table 3. Computer calculated pressure differences for example smoke control system with a pressure relief vent in English Units

\begin{tabular}{|c|c|c|c|c|c|c|c|c|c|c|c|}
\hline \multirow{2}{*}{$\begin{array}{l}\text { R } \\
\mathbf{u} \\
\mathbf{n}\end{array}$} & \multicolumn{11}{|c|}{ Pressure Difference in inches $\mathrm{H}_{2} \mathrm{O}$ from Elevator Lobby to Building on Floors: } \\
\hline & 1 & 2 & 3 & 4 & 5 & 6 & 7 & 8 & 9 & 10 & 11 \\
\hline 1 & Open & 0.08 & 0.07 & 0.07 & 0.06 & 0.06 & 0.06 & 0.05 & 0.05 & Open & Open \\
\hline 2 & Open & 0.15 & 0.13 & 0.12 & 0.11 & 0.10 & 0.09 & 0.08 & 0.08 & Open & Open \\
\hline 3 & 0.16 & 0.16 & 0.15 & 0.14 & 0.13 & 0.12 & 0.11 & 0.11 & 0.11 & 0.12 & 0.12 \\
\hline 4 & 0.24 & 0.22 & 0.20 & 0.19 & 0.17 & 0.15 & 0.14 & 0.12 & 0.12 & 0.12 & 0.12 \\
\hline
\end{tabular}

Table 4. Computer calculated pressure differences for example smoke control system with a pressure relief vent in SI Units

\begin{tabular}{|c|c|c|c|c|c|c|c|c|c|c|c|}
\hline \multirow{2}{*}{$\begin{array}{l}\mathbf{R} \\
\mathbf{u} \\
\mathbf{n}\end{array}$} & \multicolumn{11}{|c|}{ Pressure Difference in pascals from Elevator Lobby to Building on Floors: } \\
\hline & 1 & 2 & 3 & 4 & 5 & 6 & 7 & 8 & 9 & 10 & 11 \\
\hline 1 & Open & 20 & 17 & 17 & 15 & 15 & 15 & 12 & 12 & Open & Open \\
\hline 2 & Open & 37 & 32 & 30 & 27 & 25 & 22 & 20 & 20 & Open & Open \\
\hline 3 & 40 & 40 & 37 & 35 & 32 & 30 & 27 & 27 & 27 & 30 & 30 \\
\hline 4 & 60 & 55 & 50 & 47 & 42 & 37 & 35 & 30 & 30 & 30 & 30 \\
\hline
\end{tabular}


Table 5. Arrangement of doors for computer analysis of example smoke control system with variable-supply fan

\begin{tabular}{cccccc}
\hline & & $\begin{array}{c}\text { Elevator } \\
\text { Lxt Floor } \\
\text { Exterior } \\
\text { Door } \\
\text { Open }\end{array}$ & $\begin{array}{c}\text { Elevator } \\
\text { Doors } \\
\text { Open on } \\
\text { Floors: }\end{array}$ & $\begin{array}{c}\text { Doors } \\
\text { Open on } \\
\text { Floors: }\end{array}$ & $\begin{array}{c}\text { Stairwell Doors } \\
\text { Open on } \\
\text { Floors: }\end{array}$ \\
\hline 1 & Weason & Yes & 1 & 1,2 & None \\
2 & Winter & Yes & 1 & 1,11 & None \\
3 & Summer & Yes & 1 & 1,2 & None \\
4 & Summer & Yes & 1 & 1,11 & None \\
5 & Winter & Yes & 1 & $1,10,11$ & 10,11 \\
6 & Summer & Yes & 1 & $1,10,11$ & 10,11 \\
\hline
\end{tabular}

Table 6. Computer calculated pressure differences for example smoke control system with variable-supply fan in English Units

\begin{tabular}{cccccccccccccc}
\hline & $\begin{array}{c}\text { Flow } \\
\text { Rate }\end{array}$ & \multicolumn{7}{c}{ Pressure Difference in inches $\mathrm{H}_{2} \mathrm{O}$ from Elevator Lobby to Building on Floors: } \\
Run & (cfm) & 1 & 2 & 3 & 4 & 5 & 6 & 7 & 8 & 9 & 10 & 11 \\
\hline 1 & 19,800 & Open & Open & 0.29 & 0.32 & 0.32 & 0.33 & 0.33 & 0.34 & 0.34 & 0.34 & 0.34 \\
2 & 20,200 & Open & 0.34 & 0.34 & 0.34 & 0.34 & 0.34 & 0.34 & 0.34 & 0.34 & 0.33 & Open \\
3 & 22,000 & Open & Open & 0.32 & 0.34 & 0.34 & 0.34 & 0.34 & 0.34 & 0.34 & 0.34 & 0.34 \\
4 & 20,200 & Open & 0.34 & 0.32 & 0.32 & 0.31 & 0.31 & 0.31 & 0.31 & 0.30 & 0.28 & Open \\
5 & 8,500 & Open & 0.05 & 0.05 & 0.06 & 0.06 & 0.07 & 0.08 & 0.08 & 0.08 & Open & Open \\
6 & 8.500 & Open & 0.05 & 0.05 & 0.04 & 0.04 & 0.04 & 0.03 & 0.03 & 0.03 & Open & Open \\
\hline
\end{tabular}

'Flow rate of pressurization air into the hoistway at the second floor 
Table 7. Computer calculated pressure differeaces for example smoke control system with variable-supply fan in SI Units

\begin{tabular}{|c|c|c|c|c|c|c|c|c|c|c|c|c|}
\hline \multirow[b]{2}{*}{ Run } & \multirow{2}{*}{$\begin{array}{l}\text { Flow } \\
\text { Rate' } \\
\text { (Ls) }\end{array}$} & \multicolumn{11}{|c|}{ Pressure Difference in pascals from Elevator Lobby to Building on Floors: } \\
\hline & & 1 & 2 & 3 & 4 & 5 & 6 & 7 & 8 & 9 & 10 & 11 \\
\hline 1 & 9300 & Open & Open & 72 & 80 & 80 & 82 & 82 & 85 & 85 & 85 & 85 \\
\hline 2 & 9500 & Open & 85 & 85 & 85 & 85 & 85 & 85 & 85 & 85 & 82 & Open \\
\hline 3 & 10400 & Open & Open & 80 & 85 & 85 & 85 & 85 & 85 & 85 & 85 & 85 \\
\hline 4 & 9500 & Open & 85 & 80 & 80 & 77 & 77 & 77 & 77 & 75 & 70 & Open \\
\hline 5 & 4000 & Open & 12 & 12 & 15 & 15 & 17 & 20 & 20 & 20 & Open & Open \\
\hline 6 & 4000 & Open & 12 & 12 & 10 & 10 & 10 & 7 & 7 & 7 & Open & Open \\
\hline
\end{tabular}

${ }^{1}$ Flow rate of pressurization air into the hoistway at the second floor

Table 8. Parameters for piston effect example

\begin{tabular}{lcc}
\hline$A_{s}$ & $121 \mathrm{ft}^{2}$ & $11.2 \mathrm{~m}^{2}$ \\
$A_{r i}$ & $0.420 \mathrm{ft}^{2}$ & $0.0390 \mathrm{~m}^{2}$ \\
$A_{a}$ & $79.8 \mathrm{ft}^{2}$ & $7.41 \mathrm{~m}^{2}$ \\
$A_{s r}$ & $1.60 \mathrm{ft}^{2}$ & $0.149 \mathrm{~m}^{2}$ \\
$A_{i o}$ & $0.54 \mathrm{ft}^{2}$ & $0.0502 \mathrm{~m}^{2}$ \\
$\rho_{s}$ & $0.075 \mathrm{lb} / \mathrm{ft}^{3}$ & $1.20 \mathrm{~kg} / \mathrm{m}^{3}$ \\
$V$ & $500 \mathrm{ft} / \mathrm{min}$ & $2.54 \mathrm{~m} / \mathrm{s}$ \\
$C_{c}$ & 0.94 & 0.94 \\
\hline
\end{tabular}




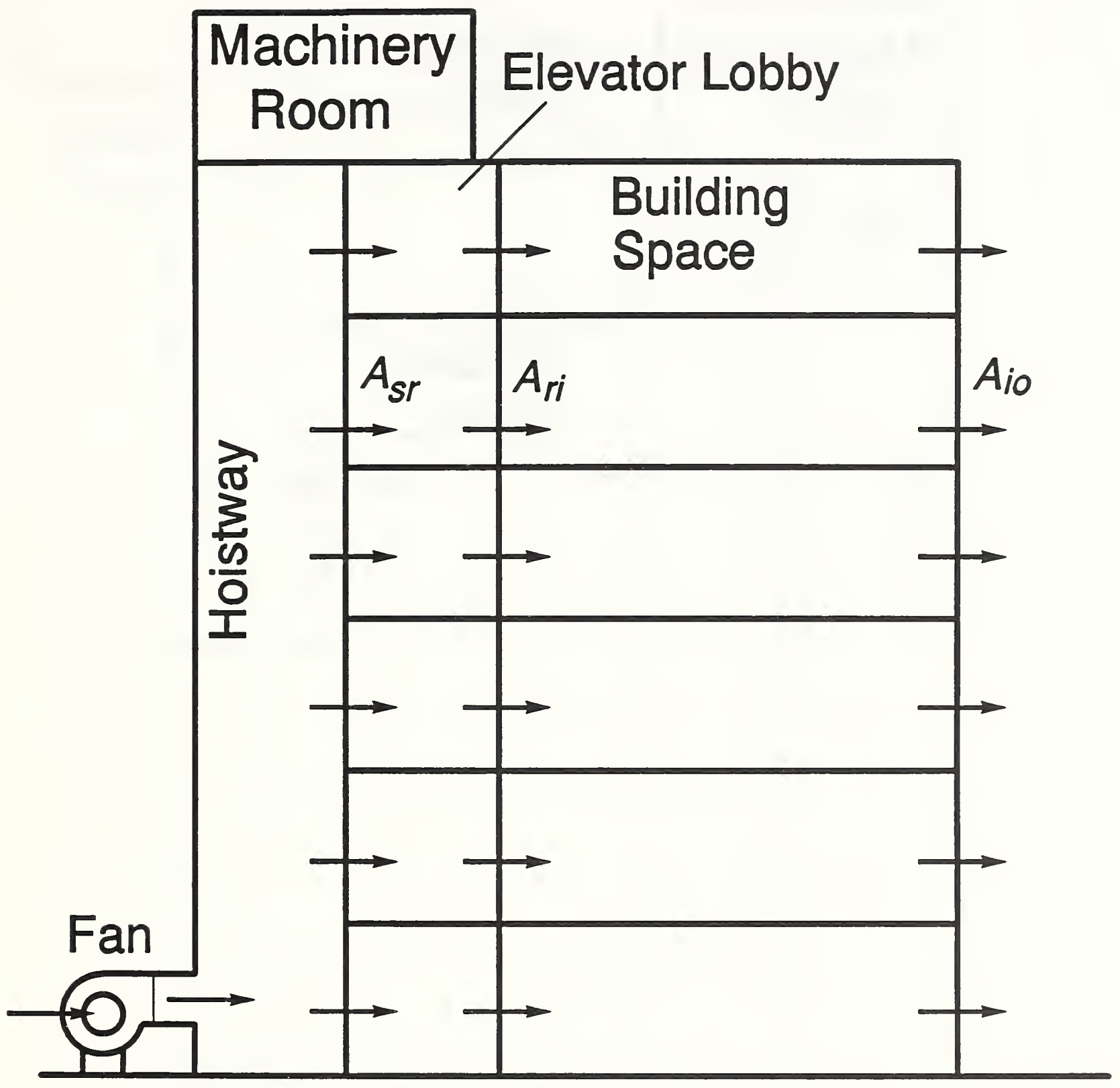

Figure 1. Elevator smoke control by shaft pressurization 


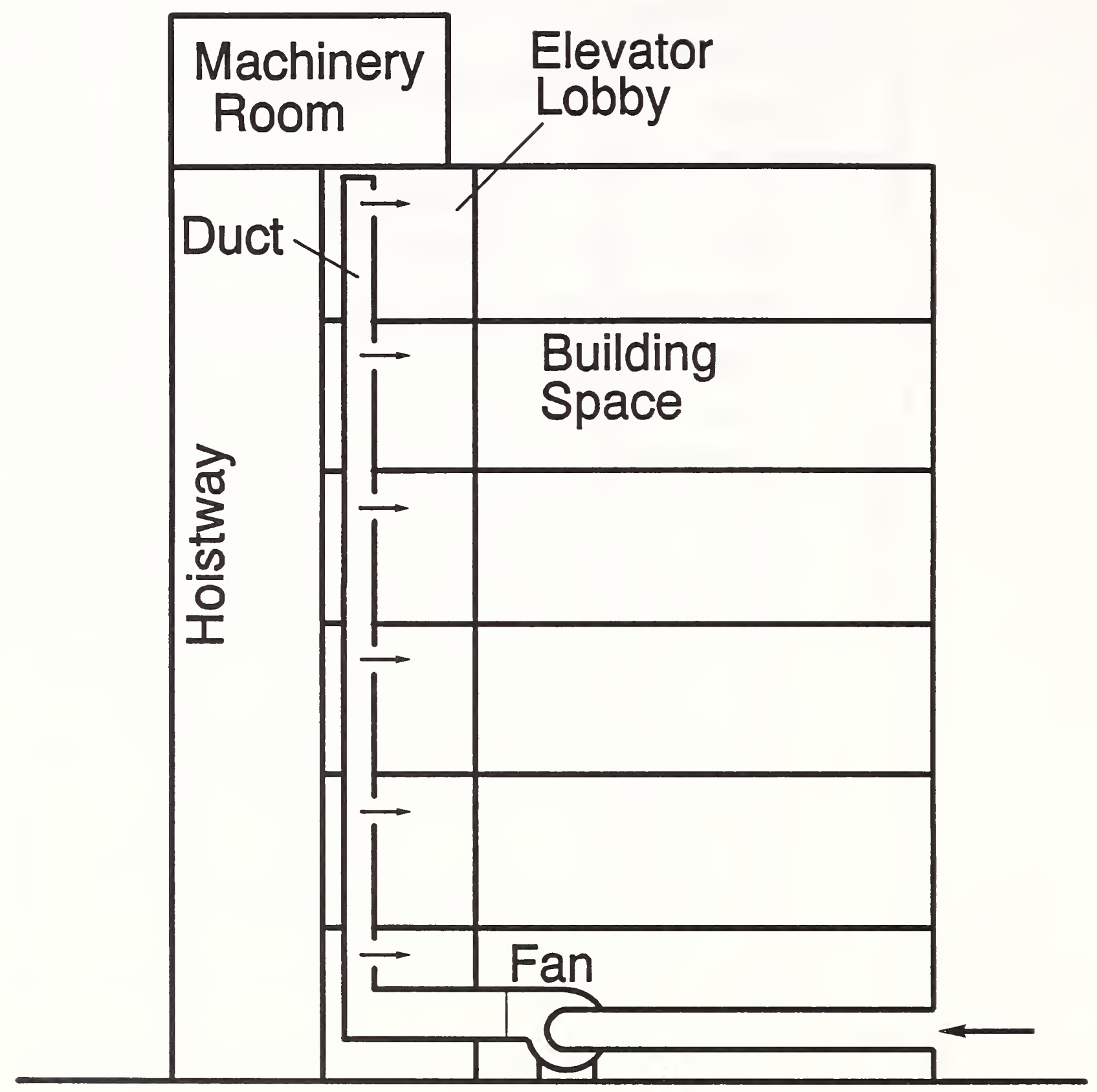

Figure 2. Elevator smoke control by lobby pressurization 


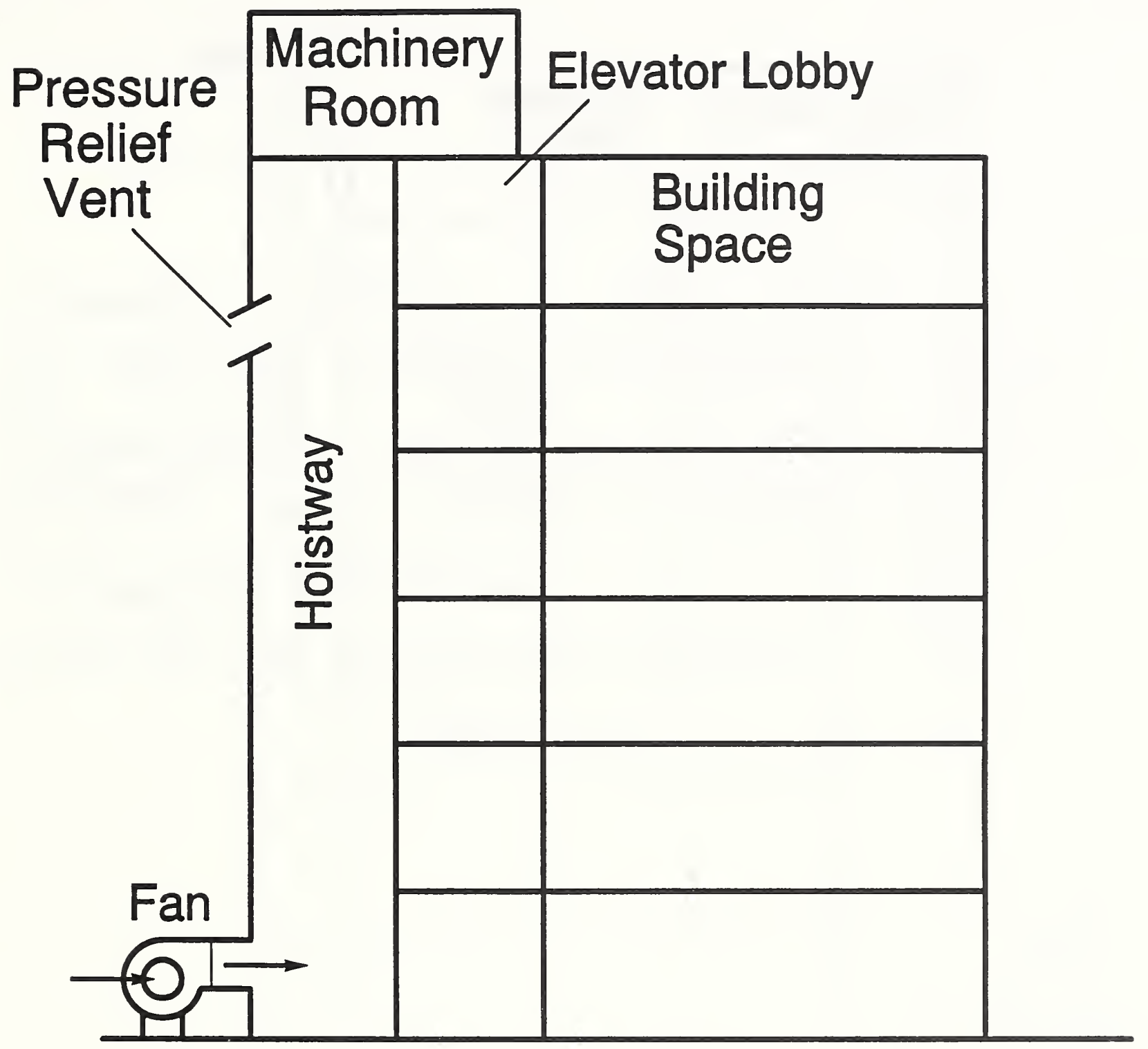

Figure 3. Elevator smoke control with a pressure relief vent 


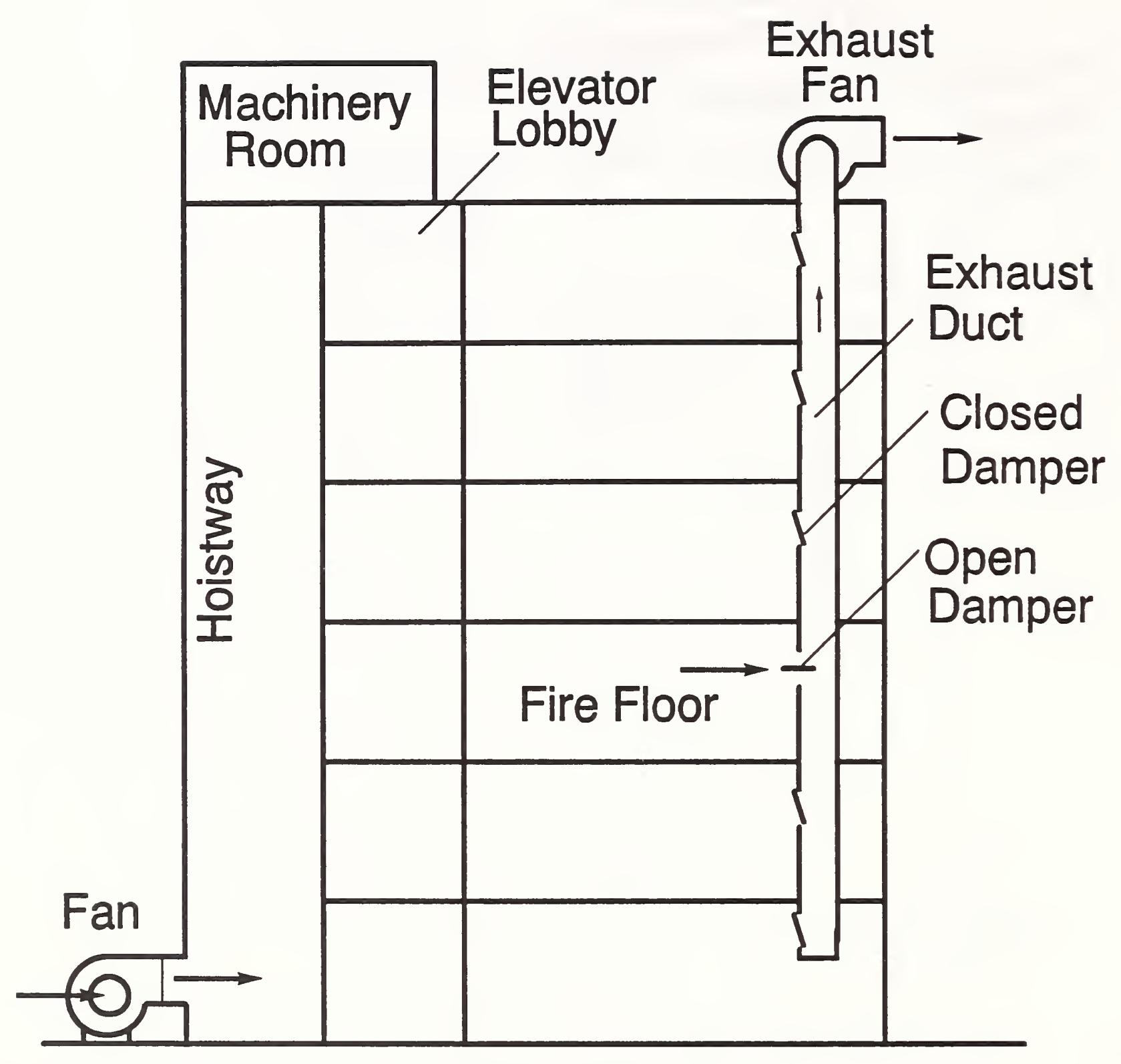

Figure 4. Elevator smoke control with fire floor exhaust 


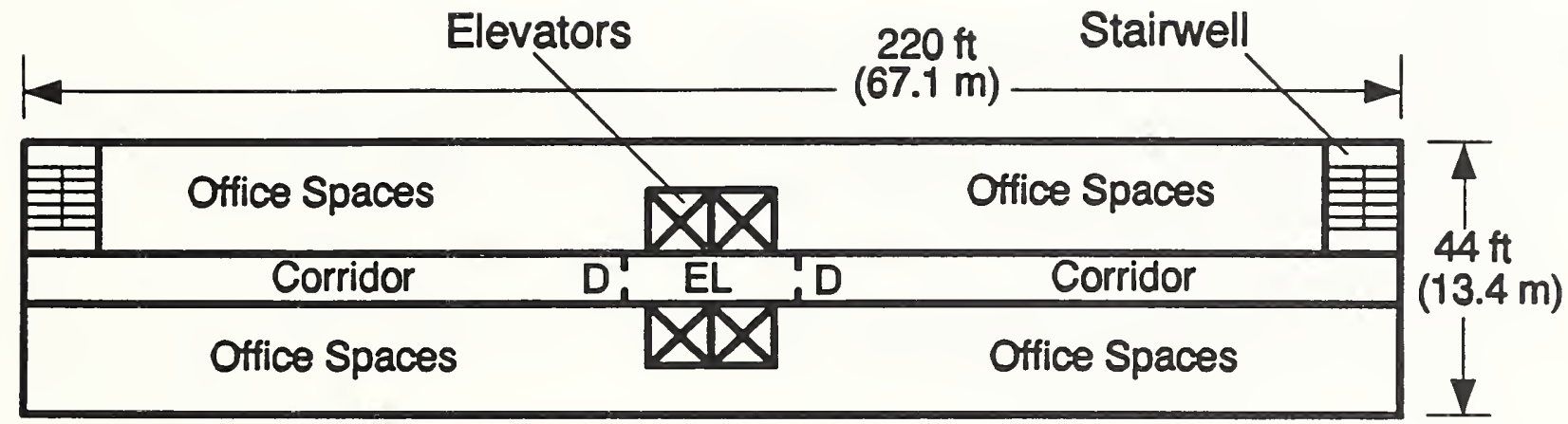

Symbols: D Door, EL Elevator Lobby

Figure 5. Typical floor plan (above first floor) of example building 


\section{Appendix B Calculation of the People Movement Time for Elevator Evacuation $^{3}$}

\section{Nomenclature}

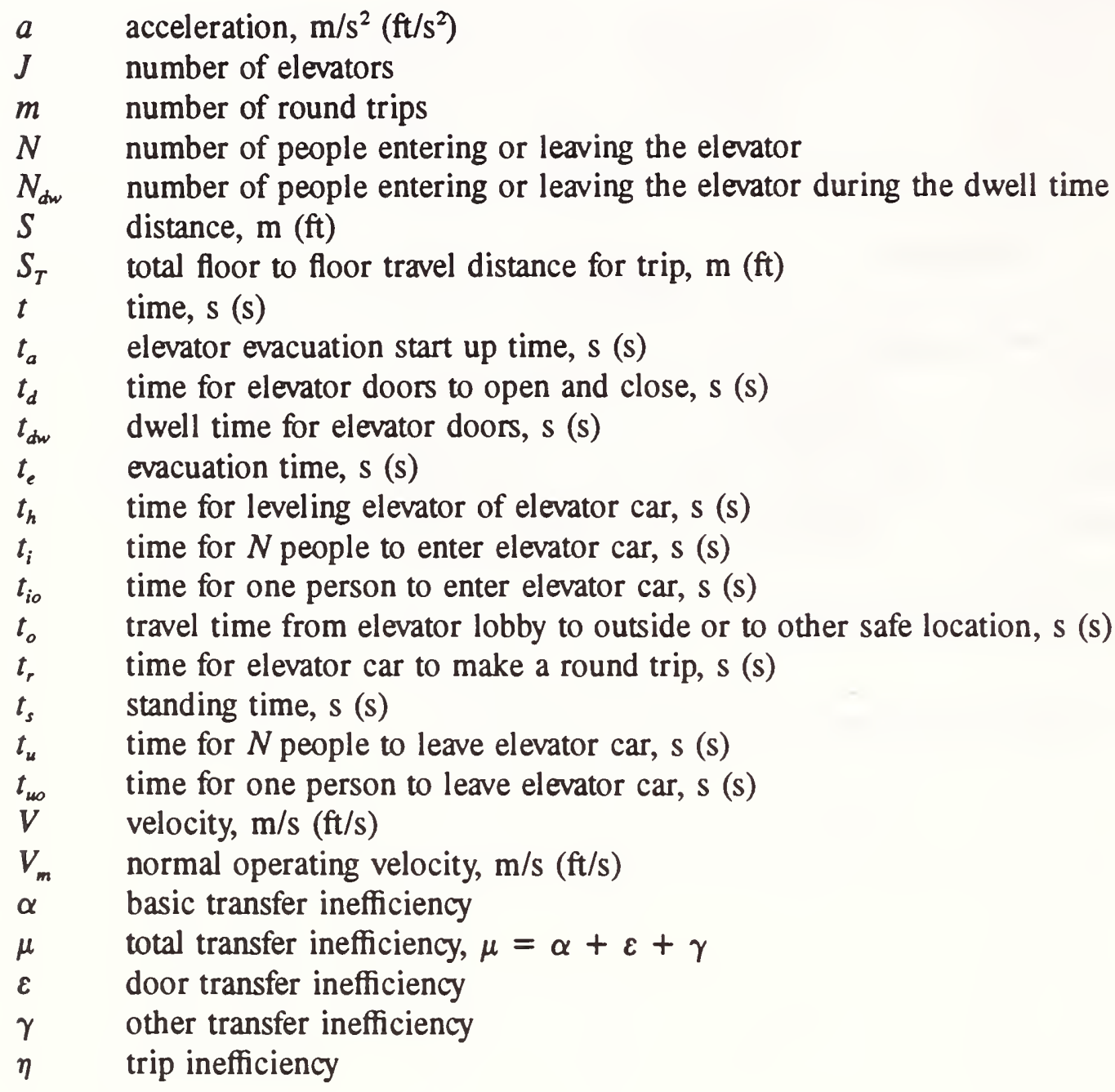

\section{Subscripts}

$\mathrm{T} \quad$ end of leveling car motion (also end of travel)

1 end of constant acceleration motion

2 end of transitional acceleration motion

3 end of constant velocity motion

4 end of transitional deceleration motion

5 end of constant deceleration motion

${ }^{3}$ This appendix and appendices C, D, E and F are abstracted from the paper Routine for Analysis of the People Movement Time for Elevator Evacuation by J. H. Klote and D. M. Alvord, National Institute of Standards and Technology, NISTIR 4730, 1992. 


\section{Introduction}

This paper presents a detailed method of analysis of people movement by elevators during emergency building evacuation, based on principles of elevator engineering (Strakosch 1983). Bazjanac (1977) and Pauls (1977) have developed methods of calculation of evacuation time by elevator, but the method presented here incorporates more detail about elevator motion and elevator loading and unloading. Also a computer program, ELVAC, for people movement during elevator evacuation is described and example calculations are presented. Appendix C is a listing of the ELVAC program, and appendices D, E, and $\mathrm{F}$ are example applications of the program. The method and computer routine presented in this paper are intended to be used in a later part of the GSA elevator project to help study the feasibility of elevator fire evacuation. Other people wanting to evaluate the extent to which elevators can speed up evacuation may also want to use the methods presented in this paper.

The sequence of elevator operation for emergency evacuation is complicated and has many possible variations. The following general sequence is presented to provide a framework for the method of analysis presented in this paper. Upon activation of emergency evacuation, elevators in normal service will go to a discharge floor where any passengers on the elevators will exit. This discharge floor may either lead to the outside or lead to an area of relative safety where people may stay during the fire. The elevators will make a number of round trips to transfer occupants from other floors to the discharge floor. During evacuation, the elevators may be under a special emergency evacuation mode of automatic control or under manual control.

The evacuation time addressed in this paper is an idealized time for people movement which does not account for the complex human behavior that often occurs during emergencies. It is believed that the analysis of this paper is about as accurate as that for evacuation by stairs ${ }^{4}$. There is little guidance available regarding the extent to which actual evacuation time is greater than the idealized times for stairs or elevators, but Nelson and MacLennan (1988) indicate that actual evacuation time can be two or even three times as long. The approximate nature of such calculations should be taken into account in any applications of the methods presented in this paper.

\section{Evacuation Time}

Analysis of people movement during elevator evacuation must take into account the number and arrangement of elevators in a building. Generally elevators are located in groups of up to eight elevators. Elevators in a group are located near each other and are controlled together to efficiently move people. Arrangements of elevator groups are discussed later. The method of analysis and the computer program of this paper are for the calculation of the evacuation time for one group of elevators. For buildings with multiple groups of elevators, the approach presented in this paper can be applied separately to each group of elevators.

Ideally the time to evacuate a number of people using one group of elevators consists of the sum of all the round trip times divided by the number of elevators plus the time needed to start up the elevator evacuation and the travel time from the elevator lobby to the outside (or to another safe location). Accounting for inefficiencies of elevator operation, this evacuation time can be expressed as

${ }^{4}$ For a discussion of times for people movement during emergency evacuation on stairs, readers are referred to Nelson and MacLennan (1988) and Pauls (1988). 


$$
t_{e}=t_{a}+t_{0}+\frac{(1+\eta)}{J} \sum_{j=1}^{m} t_{r, j}
$$

where $t_{r, j}$ is the time for round trip $j, m$ is the number of round trips, $J$ is the number of elevators, $\eta$ is the trip inefficiency, $t_{a}$ is elevator evacuation start up time, and $t_{o}$ is the travel time from the elevator lobby to the outside or to another safe location. The round trip time depends on the travel time of the elevator and on the number of people carried by the elevator as discussed later. The travel time from the elevator lobby to a safe location can be evaluated by conventional methods of people movement [i.e. Nelson and MacLennan (1988) or Pauls (1988)]. The trip inefficiency accounts for trips to empty floors and trips to pick only a few stragglers. The elevator evacuation start up time is discussed in the next section.

The number of elevators, $J$, used in equation (1) may be less than the number of elevators in the group to account for out-of-service elevators. The probability of elevators being out-of-service depends on a number of factors including the age of the elevators and the quality of maintenance. Because the out-ofservice condition can significantly increase elevator evacuation time, any analysis of elevator evacuation should take this condition into account.

\section{Start Up Time}

The elevator evacuation start up time is the time from activation to the start of the round trips that evacuate people. For automatic elevator operation during evacuation, a simple approach is to start elevator evacuation after all of the elevators have been moved to the discharge floor. For this approach, the start up time, $t_{a}$, consists of the time for elevators to go to the discharge floor plus the time for the passengers to leave the elevators. This can be expressed as

$$
t_{a}=t_{T}+\left(t_{\mu}+t_{d}\right)(1+\mu)
$$

where $t_{T}$ is the travel time for the elevator car to go from the farthest floor to the discharge floor, $t_{u}$ is the time for passengers to leave the elevator, $t_{d}$ is the time for the doors to open and close once, and $\mu$ is the total transfer inefficiency. These terms are discussed in detail later.

An alternative to the simple approach discussed above consists of starting the evacuation operation individually for each elevator when it reaches the discharge floor. This alternative could result in slightly reduced evacuation time. However, this alternative is not discussed further here, because of its limited benefit and added complexity.

For manual elevator operation, the time for elevator operators to be alerted and then get to the elevators must be included in the estimate of start up time. This additional time may be considerably greater than that calculated from equation (2). 


\section{Elevator Round Trip Time}

The round trip starts at the discharge floor and consists of the following sequence: elevator doors close, car travels to another floor, elevator doors open, passengers enter the car, doors close, car travels to discharge floor, doors open, and passengers leave the car. The round trip time, $t_{r}$, is can be written as

$$
t_{r}=2 t_{T}+t_{s}
$$

where $t_{s}$ is the standing time and $t_{T}$ is the travel time for one way of the round trip. This equation is based on the elevator only stopping at one floor to pick up passengers. It is expected that most elevators will fill up on one floor and proceed to the discharge floor. What constitutes a full elevator is discussed later. If an elevator stops to pick up passengers at more than one floor during a round trip, equation (3) can be modified accordingly. However, the trip inefficiency accounts for such multiple stops.

\subsection{Standing Time}

The standing time is the sum of the time to open and close the elevator doors twice, the time for people to enter the elevator, and the time for people to leave the elevator. Considering transfer inefficiencies, the standing time for a round trip can be expressed as

$$
t_{s}=\left(t_{i}+t_{u}+2 t_{d}\right)(1+\mu)
$$

where

$\mu=\alpha+\varepsilon+\gamma$

The basic transfer inefficiency, $\alpha$, allows for rounding off of probable stops, door operating time, door starting and stopping time, and the unpredictability of people. Typically a value of 0.10 is used for the basic transfer inefficiency for commonly accepted arrangements of elevator groups as illustrated in figure 1. For each of these arrangements, the configuration of the elevator lobby is such that passengers can recognize which elevator has arrived and get on the elevator without excessive delay. Further, these lobbies have sufficient space so that people exiting one elevator will have a minimal impact on the flow of people leaving another elevator.

Arrangements of elevator groups other than those commonly accepted can be less efficient and require an increased value of the basic transfer inefficiency. These unusual arrangements include cars separated [fig 2(a)], too many cars in a line [fig 2(b)], angular arrangement [fig 2(c)], and cornered arrangement [fig 2(d)]. Separation of elevators results in increased boarding time for passengers waiting by one elevator to walk to another when it arrives. If the separation is too large, some passengers choose to let elevators go by without boarding. Use of too many elevators in a line has similar inefficiencies. With the angular arrangement [fig 2(c)], cars at the narrow end tend to be to close together while cars at the wide end tend to be too far apart. In the cornered arrangement [fig 2(d)], passengers entering or leaving corner cars tend to interfere with each other. 
The door inefficiency, $\varepsilon$, is used to adjust for any increase in transfer time over that of a $1200 \mathrm{~mm}$ (48 in) wide center opening door. Values of $\varepsilon$ are listed in table 1. The inefficiency, $\gamma$, is used to account for any other inefficiencies in people transfer into or out of elevators, such as increased movement times within an elevator car due to an unusual elevator car shape or limited physical capability of passengers. For example, $\gamma$ often is chosen to be 0.05 for hospital elevators. Generally for office buildings, $\gamma$ is taken as zero.

The time, $t_{d}$, for the doors to open and close depends on the width and type of the doors as listed in table 1. The kinetic energy of closing doors is limited by elevator safety codes and is usually not more than $0.29 \mathrm{~J}\left(7 \mathrm{ft}\right.$ poundal $\left.{ }^{5}\right)$. This is why doors from different manufacturers take about the same time to open and close. Types of elevator doors are shown in figure 3. Door operating time is important because of the many times that doors open and close during an evacuation. Further, an elevator can not leave a floor before the doors are closed and locked, and passengers can not leave an elevator until the doors are fully opened or nearly fully opened. Generally elevator doors do not open until the car has stopped and is level with the floor. However, some center opening doors start opening while the car is leveling, and the times listed in table 1 should be reduced by one second for these preopening doors.

The time, $t_{i}$, for people to enter an elevator depends on the number, $N$, of people entering and on the door operation. As previously stated, it is expected that most elevators will fill up on one floor and proceed to the discharge floor. However, elevators will be less than full when there are not enough people waiting in the lobby to fill an elevator or elevators. Thus the analysis must include partially filled elevators. Strakosch (1983) has observed elevator loadings for which passengers will not board an elevator and choose to wait for the next one. These observed values are based on $0.22 \mathrm{~m}^{2}\left(2.3 \mathrm{ft}^{2}\right)$ of floor space in the elevator car per person. It should be noted that the ASME A17.1 (1987) elevator standard allows a maximum loading at $0.14 \mathrm{~m}^{2}\left(1.5 \mathrm{ft}^{2}\right)$ per person, but this high density is not achieved in normal practice. For this study, the observed values of Strakosch are used as the number of persons in a full elevator car, and these loadings are listed in tables 3 and 4.

When elevator doors open, the doors remain open for a least fixed time referred to as the dwell-time, $t_{d w}$. The time that the door is open can be extended beyond the dwell-time by blocking of the light beam across the door opening or by pushing the door safety edge. The time, $t_{i}$, for $N$ people to enter an elevator car can be expressed as

$$
t_{i}= \begin{cases}t_{d w} & \text { for } N \leq 2 \\ t_{d w}+t_{i 0}\left(N-N_{d w}\right) & \text { for } N>2\end{cases}
$$

where the $N_{d w}$ is the number of people entering the elevator during the dwell time, and $t_{i o}$ is the average time for one person to enter the elevator. The number of people entering the elevator during the dwell time is the term $\left(t_{d w} / t_{i o}\right)$ rounded down to the nearest integer. The time for $N$ people to leave an elevator can be expressed in a similar manner.

${ }^{5}$ The poundal is the unit of force in the pound mass-poundal system of units, and one poundal equals 0.0311 pounds force. 


$$
t_{u}= \begin{cases}t_{d w} & \text { for } N \leq 2 \\ t_{d w}+t_{u o}\left(N-N_{d w}\right) & \text { for } N>2\end{cases}
$$

For the computer program of this paper, the dwell-time is taken to be 4 seconds, the average time for one passenger to enter an elevator is taken to be 1 second, and the average time for one passenger to leave an elevator is taken to be 0.6 seconds.

\subsection{Travel Time}

Elevator motion is depicted in figure 4 for most trips. Motion starts with constant acceleration, followed by transitional acceleration, and constant velocity motion. Constant acceleration ends when the elevator reaches a predetermined velocity which is typically about $60 \%$ of the normal operating velocity $\left(V_{1}=\right.$ $\left.0.6 V_{m}\right)$. For office buildings, the normal operating velocity is generally from 1 to $9 \mathrm{~m} / \mathrm{s}$ (200 to 1800 $\mathrm{fpm}$ ), and acceleration is from 0.6 to $2.4 \mathrm{~m} / \mathrm{s}^{2}\left(2\right.$ to $\left.8 \mathrm{ft} / \mathrm{s}^{2}\right)$. Deceleration has the same magnitude as the acceleration, and the total acceleration time equals the total deceleration time $\left(t_{2}=t_{5}-t_{3}\right)$. The method of analysis that follows takes advantage of this symmetry.

Analysis of elevator motion that reaches the normal operating velocity is presented next. For short trips elevators do not always reach the normal operating velocity, and methods of analysis for these short trips are presented later.

\section{Motion Reaching Normal Operating Velocity}

The time to complete constant acceleration motion (going to point 1 on figure 4 ) is

$$
t_{1}=\frac{V_{1}}{a}
$$

The distance traveled during constant acceleration is

$$
S_{1}=\frac{V_{1}^{2}}{2 a}
$$

Transitional acceleration is approximated by considering the product of velocity and acceleration to be a constant. The time to reach the end of transitional acceleration (point 2 of figure 4 ) is

$$
t_{2}=\frac{V_{m}^{2}-V_{1}^{2}}{2 V_{1} a}+t_{1}
$$


The distance traveled by the end of transitional acceleration is

$$
S_{2}=\frac{1}{3 a}\left(\frac{V_{m}^{3}}{V_{1}}-V_{1}^{2}\right)+S_{1}
$$

The one way travel time is

$$
t_{5}=2 t_{2}+\frac{S_{T}-2 S_{2}}{V_{m}}
$$

The leveling time must be added to the above time to get the total travel time for a one way trip.

$$
t_{T}=t_{s}+t_{h}
$$

Usually elevators do not stop exactly at the desired floor at the end deceleration, so the elevator must be moved slowly up or down to get it nearly level with the floor. For calculations in this paper, leveling time, $t_{h}$, is taken to be 0.5 seconds.

\section{Motion Reaching Transitional Acceleration}

If the trip is too short for the elevator to reach the normal operating velocity, but it reaches transitional acceleration, the velocity is represented by either figure 5(a). The time, $t_{1}$, and distance, $S_{1}$, traveled during constant acceleration are given by equations (7) and (8). The velocity at the end of transitional acceleration is

$$
V_{2}=\left[V_{1}^{3}+3 a V_{1}\left(\frac{S_{T}}{2}-S_{1}\right)\right]^{1 / 3}
$$

The time at the end of transitional acceleration is

$$
t_{2}=\frac{V_{2}^{2}-V_{1}^{2}}{2 a V_{1}}+t_{1}
$$

The one way travel time is 


$$
t_{T}=2 t_{2}+t_{h}
$$

\section{Motion Not Reaching Transitional Acceleration}

When the trip does not go beyond constant acceleration, the motion is illustrated in figure 5(b). The one way travel time is

$$
t_{T}=2 \sqrt{\frac{S_{T}}{a}}+t_{h}
$$

\section{Example 1. Round Trip Time in SI Units}

A $1600 \mathrm{~kg}$ elevator in an office building makes a round trip from the ground floor to pick up a full load of passengers from the $21 \mathrm{st}$ floor and return them to the ground floor. The operating velocity is $3 \mathrm{~m} / \mathrm{s}$ with an acceleration of $1.2 \mathrm{~m} / \mathrm{s}^{2}$, and the elevator door is $1200 \mathrm{~mm}$ wide centeropening. The distance between floors is $3.2 \mathrm{~m}$, and the total travel distance, $S_{T}$, is $64 \mathrm{~m}$.

From table 2, the number of people in the full elevator is approximated at 16 . From table $1, t_{d}$ is $5.3 \mathrm{~s}$, and $\varepsilon$ is 0 . The elevator shape is not unusual and the passenger capability is normal, so $\gamma$ is 0 . The total transfer inefficiency is

$$
\mu=\alpha+\varepsilon+\gamma=0.10+0+0=0.10
$$

From equation (5), the time for 16 people to enter the elevator is

$$
t_{i}=N=16 \mathrm{~s}
$$

From equation (6), the time for 16 people to leave the elevator is

$$
t_{u}=4+0.6(N-0)=4+0.6(16-0)=10 \mathrm{~s}
$$

From equation (4), the standing time is

$$
t_{s}=\left(t_{i}+t_{u}+2 t_{d}\right)(1+\mu)=(16+10+2(5.3))(1+0.1)=40.26 \mathrm{~s}
$$


Consider $V_{1}$ is $60 \%$ of $V_{m}$, then

$$
V_{1}=0.6 V_{m}=0.6(3)=1.8 \mathrm{~m} / \mathrm{s}
$$

From equation (7), the time at the end of constant acceleration is

$$
t_{1}=\frac{V_{1}}{a}=\frac{1.8}{1.2}=1.5 \mathrm{~s}
$$

From equation (8), the distance traveled during constant acceleration is

$$
S_{1}=\frac{V_{1}^{2}}{2 a}=\frac{(1.8)^{2}}{2(1.2)}=1.35 \mathrm{~m}
$$

From equation (9), the time at the end of transitional acceleration is

$$
t_{2}=\frac{V_{m}^{2}-V_{1}^{2}}{2 V_{1} a}+t_{1}=\frac{(3)^{2}-(1.8)^{2}}{2(1.8)(1.2)}+1.5=2.83 \mathrm{~s}
$$

From equation (10), the distance traveled by the end of transitional acceleration is

$$
S_{2}=\frac{1}{3 a}\left(\frac{V_{m}^{3}}{V_{1}}-V_{1}^{2}\right)+s_{1}=\frac{1}{3(1.2)}\left(\frac{3^{3}}{1.8}-1.8^{2}\right)+1.35=4.62 \mathrm{~m}
$$

The one way travel time is calculated from equation (11).

$$
t_{5}=2 t_{2}+\frac{S_{T}-2 S_{2}}{V_{m}}=2(2.83)+\frac{64-2(4.62)}{3}=23.9 \mathrm{~s}
$$

The total travel time is calculated from equation (12).

$$
t_{T}=t_{5}+t_{h}=23.9+0.5=24.4 \mathrm{~s}
$$

The round trip time is calculated from equation (3).

$$
t_{r}=2 t_{T}+t_{s}=2(24.4)+40.3=89.1 \mathrm{~s}
$$


Example 2. Round Trip Time in English Units

A $3500 \mathrm{lb}$ elevator in an office building makes a round trip from the ground floor to pick up a full load of passengers from the 21 st floor and return them to the ground floor. The operating velocity is $600 \mathrm{fpm}$ with an acceleration of $4 \mathrm{ft} / \mathrm{s}^{2}$, and the elevator door is 48 in wide centeropening. The distance between floors is $10.5 \mathrm{ft}$, and the total travel distance, $S_{r}$, is $210 \mathrm{ft}$.

From table 3, the number of people in the full elevator is approximated at 16 . From table $1, t_{d}$ is $5.3 \mathrm{~s}$, and $\varepsilon$ is 0 . The elevator shape is not unusual and the passenger capability is normal, so $\gamma$ is 0 . The total transfer inefficiency is

$$
\mu=\alpha+\varepsilon+\gamma=0.10+0+0=0.10
$$

From equation (5), the time for 16 people to enter the elevator is

$$
t_{i}=N=16 \mathrm{~s}
$$

From equation (6), the time for 16 people to leave the elevator is

$$
t_{u}=4+0.6(N-6)=4+0.6(16-6)=10 \mathrm{~s}
$$

From equation (4), the standing time is

$$
t_{s}=\left(t_{i}+t_{u}+2 t_{d}\right)(1+\mu)=(16+10+2(5.3))(1+0.1)=40.26 s
$$

Consider $V_{1}$ is $60 \%$ of $V_{m}$, then

$$
V_{1}=0.6 V_{m}=0.6(3)=1.8 \mathrm{~m} / \mathrm{s}
$$

The normal operating velocity is

$$
V_{m}=600 \frac{\mathrm{ft}}{\min } \frac{1 \mathrm{~min}}{60 \mathrm{~s}}=10 \mathrm{ft} / \mathrm{s}
$$

From equation (7), the time at the end of constant acceleration is

$$
t_{1}=\frac{V_{1}}{a}=\frac{6}{4}=1.5 \mathrm{~s}
$$

From equation (8), the distance traveled during constant acceleration is 


$$
S_{1}=\frac{V_{1}^{2}}{2 a}=\frac{()^{2}}{2(4)}=4.5 \mathrm{ft}
$$

From equation (9), the time at the end of transitional acceleration is

$$
t_{2}=\frac{V_{m}^{2}-V_{1}^{2}}{2 V_{1} a}+t_{1}=\frac{(10)^{2}-(0)^{2}}{2(6)(4)}+1.5=2.83 \mathrm{~s}
$$

From equation (10), the distance traveled by the end of transitional acceleration is

$$
S_{2}=\frac{1}{3 a}\left(\frac{V_{m}^{3}}{V_{1}}-V_{1}^{2}\right)+S_{1}=\frac{1}{3(4)}\left(\frac{10^{3}}{6}-6^{2}\right)+4.5=15.4 \mathrm{ft}
$$

The one way travel time is calculated from equation (11).

$$
t_{5}=2 t_{2}+\frac{S_{T}-2 S_{2}}{V_{m}}=2(2.83)+\frac{210-2(15.4)}{10}=23.6 \mathrm{~s}
$$

The total travel time is calculated from equation (12).

$$
t_{T}=t_{5}+t_{h}=23.6+0.5=24.1 \mathrm{~s}
$$

The round trip time is calculated from equation (3).

$$
t_{r}=2 t_{T}+t_{s}=2(24.1)+40.3=88.5 \mathrm{~s}
$$

\section{Computer Elevator Evacuation Analysis}

A computer program (ELVAC), written in Quick BASIC, for analysis of elevator evacuation is listed in appendix C. This program calculates evacuation time for one group of elevators. For buildings with multiple groups of elevators, the program can be used a number of times to calculate the evacuation time for each group.

Example 3. Elevator evacuation time

Estimate the time needed for elevator evacuation of all the people from the upper 11 floors of a 21 story building to the outside of the building. Additionally, $3 \%$ of the people on the other floors are included in the elevator evacuation. The rest of the people on the lower floors will use the stairs. Each floor is occupied by 90 people. A group of six $1600 \mathrm{~kg}(3500 \mathrm{lb})$ elevators are used for the evacuation, and the elevator doors are $1200 \mathrm{~mm}$ (48 in) wide, center opening. One 
of the six cars is considered out-of-service, thus only five of the cars are used in the analysis. Other parameters of this example are listed in table 4.

Table 5 lists trip times and the evacuation time calculated by ELVAC. The evacuation time using five elevators is calculated at $1258 \mathrm{~s}$ or about 21 minutes.

Discussion of table 5 provides insight into the computer program. The round trip time for floor 21 is 89.1 $s$ (the same as calculated in example 1). In order to move 90 people from floor 21 , the elevator trips are considered to consist of five trips with a full car (16 people) plus one trip of a partially filled (10 people) car. The time for the partially filled round trip is $78.6 \mathrm{~s}$ (not shown in table 5). Thus the total trip time to move 90 people from floor 21 is $5(89.1)+78.6=524.1 \mathrm{~s}$. This time is listed under the heading "Time per Floor" for floor 21 in the table.

On floor 10 of this example $3 \%$ of 90 people are evacuated, this is rounded up to three people. Because this is done by one trip, the round trip time of $45.8 \mathrm{~s}$ listed in table 5 is for moving 3 people rather than the full car load of 16. The total round trip time of $5395.6 \mathrm{~s}$ is sum of all the round trips to move people from all the floors. The evacuation time of $1258.3 \mathrm{~s}$ using 5 elevators was calculated from equation (1).

\section{Summary}

A detailed method of analysis of people movement by elevators during emergency building evacuation is presented. This method is for one group of elevators. For buildings with multiple groups of elevators, the approach presented in this paper can be applied separately to each group. The time to evacuate a number of people using one group of elevators includes the sum of all the round trip times divided by the number of elevators plus the times needed to start up the elevator evacuation and to travel from the elevator lobby to the outside or to another safe location. A trip inefficiency is used to account for trips to empty floors and trips to pick up a few stragglers.

The round trip starts at the discharge floor and consists of the following sequence: elevator doors close, car travels to another floor, elevator doors open, passengers enter the car, doors close, car travels to discharge floor, doors open, and passengers leave the car. The round trip time is the sum of the standing time plus twice the one way travel time. The standing time is the sum of the time to open and close the elevator doors twice, the time for people to enter the elevator, and the time for people to leave the elevator. Elevator travel time is described by equations of motion under conditions of constant acceleration, constant velocity, and transitional acceleration between the first two. The computer program ELVAC can be used to calculate people movement during elevator evacuations. 


\section{References}

ASME 1987. American Standard Safety Code for Elevators, Escalators, Dumbwaiters and Moving Walks, A17.1, American Society of Mechanical Engineers, New York.

Bazjanac, V. 1977. Simulation of Elevator Performance in High-Rise Buildings Under Conditions of Emergency, Human Response to Tall Buildings, Ed by D.J. Conway. Dowden, Hutchinson \& Ross, Stroudsburg, PA, pp 316-328.

Nelson, H.E. and MacLennan, H.A. 1988. Emergency Movement, SFPE Handbook of Fire Protection Engineering, Society of Fire Protection Engineers, Boston, MA.

Pauls, J. 1977. Management and Movement of Building Occupants in Emergencies, DBR Paper No. 788, National Research Council, Ottawa, Canada.

Pauls, J. 1988. People Movement, SFPE Handbook of Fire Protection Engineering, Society of Fire Protection Engineers, Boston, MA.

Strakosch, G.R. 1983. "Vertical Transportation: Elevators and Escalators", 2nd Edition, Wiley \& Sons, New York, NY. 
Table 1. Door Operating Time and Transfer Inefficiency

\begin{tabular}{llcc}
\hline \hline & $\begin{array}{c}\text { Width } \\
\text { mm (in) }\end{array}$ & $\begin{array}{c}\text { Time } \\
\text { and Close } \\
t_{d}(\mathrm{~s})\end{array}$ & $\begin{array}{c}\text { Door Transfer } \\
\text { Inefficiency }\end{array}$ \\
\hline \hline Soor Type & $900(36)$ & 6.6 & 0.10 \\
Two-Speed & $900(36)$ & 5.9 & 0.10 \\
Center-Opening & $900(36)$ & 4.1 & 0.08 \\
\hline Single-Slide & $1100(42)$ & 7.0 & 0.07 \\
Two-Speed & $1100(42)$ & 6.6 & 0.07 \\
Center-Opening & $1100(42)$ & 4.6 & 0.05 \\
\hline Two-Speed & $1200(48)$ & 7.7 & 0.02 \\
Center-Opening & & 5.3 & 0 \\
\hline Two-Speed & $1200(48)$ & 8.8 & 0.02 \\
Center-Opening & $1400(54)$ & 6.0 & 0 \\
\hline Two-Speed & $1400(54)$ & 9.9 & 0.02 \\
Center-Opening & $1600(60)$ & 6.5 & 0 \\
Two-Speed, Center- & $1600(60)$ & 6.0 & 0 \\
Opening & $1600(60)$ & & \\
\hline \hline
\end{tabular}

${ }^{1}$ Time to open and close doors includes 0.5 second for car to start.

${ }^{2}$ When preopening can be used, the time to open and close these doors can be reduced by 1 second. 
Table 2. Car size and observed loading in SI Units

\begin{tabular}{|c|c|c|c|c|}
\hline \multicolumn{4}{|c|}{ Car Inside (mm) } & \multirow{2}{*}{$\begin{array}{l}\text { Observed } \\
\text { Loading }^{1} \\
\text { (people) }\end{array}$} \\
\hline $\mathrm{kg}(\mathrm{lb})$ & Wide & Deep & Area $\left(\mathrm{m}^{2}\right)$ & \\
\hline $1200(2640)$ & 2100 & 1300 & 2.73 & 10 \\
\hline $1400(3080)$ & 2100 & 1450 & 3.05 & 12 \\
\hline $1600(3520)$ & 2100 & 1650 & 3.47 & 16 \\
\hline 1600 (alt.) & 2350 & 1450 & 3.41 & 16 \\
\hline $1800(3960)$ & 2100 & 1800 & 3.78 & 18 \\
\hline 1800 (alt.) & 2350 & 1650 & 3.88 & 18 \\
\hline $2000(4400)$ & 2350 & 1800 & 4.23 & 20 \\
\hline $2250(4950)$ & 2350 & 1950 & 4.58 & 22 \\
\hline $2700(5940)$ & 2350 & 2150 & 5.05 & 25 \\
\hline
\end{tabular}

${ }^{1}$ See footnote on table 3.

Table 3. Car size and observed loading in English Units

\begin{tabular}{|c|c|c|c|c|}
\hline \multirow{2}{*}{$\begin{array}{l}\text { Capacity } \\
\text { (lb) }\end{array}$} & \multicolumn{2}{|c|}{ Car Inside (in) } & \multirow[b]{2}{*}{ Area $\left(\mathrm{ft}^{2}\right)$} & \multirow{2}{*}{$\begin{array}{l}\text { Observed } \\
\text { Loading } \\
\text { (people) } \\
\end{array}$} \\
\hline & Wide & Deep & & \\
\hline 2000 & 68 & 51 & 24.1 & 8 \\
\hline 2500 & 82 & 51 & 29.0 & 10 \\
\hline 3000 & 82 & 57 & 32.5 & 12 \\
\hline 3500 & 82 & 66 & 37.6 & 16 \\
\hline 3500 (alt.) & 92 & 57 & 36.4 & 16 \\
\hline 4000 & 82 & 73 & 41.6 & 19 \\
\hline 4000 (alt.) & 92 & 66 & 42.2 & 19 \\
\hline 4500 & 92 & 72 & 46.0 & 21 \\
\hline 5000 & 92 & 77 & 49.2 & 23 \\
\hline 6000 & 92 & 90 & 57.5 & 27 \\
\hline
\end{tabular}

${ }^{1}$ This loading is given by Strakosch (1983) as that for which passengers will not board an elevator and choose to wait for the next one. 
Table 4. Parameters for Example 3

\begin{tabular}{lc}
\hline \hline Number of Stories & 21 \\
Number of Elevator Cars & 5 \\
Number of People Per Floor & 90 \\
Percent of People Evacuating by Elevators From Floors 2 to 10 & 3 \\
Percent of People Evacuating by Elevators From Floors 11 to 21 & 100 \\
Height Between Floors & $3.2 \mathrm{~m}(10.5 \mathrm{ft})$ \\
Operating Velocity of Elevator Car, $V_{m}$ & $3.0 \mathrm{~m} / \mathrm{s}(590 \mathrm{fpm})$ \\
Car Acceleration, $a$ & $1.20 \mathrm{~m} / \mathrm{s}^{2}\left(3.94 \mathrm{ft} / \mathrm{s}^{2}\right)$ \\
Other Transfer Inefficiency, $\gamma$ & 0 \\
Trip Inefficiency, $\eta$ & 0.10 \\
Car Full Load & $16 \mathrm{people}$ \\
\hline \hline
\end{tabular}


Table 5. Elevator trip and evacuation time calculated by ELVAC computer program

\begin{tabular}{|c|c|c|c|c|c|c|c|c|}
\hline \multirow[b]{2}{*}{ Floor } & \multicolumn{2}{|c|}{ Elevation } & \multirow{2}{*}{$\begin{array}{c}\text { One Way } \\
\text { Trip } \\
\text { Time (s) }\end{array}$} & \multirow{2}{*}{$\begin{array}{l}\text { Round } \\
\text { Trip } \\
\text { Time (s) }\end{array}$} & \multirow{2}{*}{$\begin{array}{l}\text { People } \\
\text { on Floor }\end{array}$} & \multirow{2}{*}{$\begin{array}{c}\text { Percent } \\
\text { Elevator } \\
\text { Evacuation }\end{array}$} & \multirow{2}{*}{$\begin{array}{c}\text { Number } \\
\text { of } \\
\text { Round } \\
\text { Trips } \\
\end{array}$} & \multirow{2}{*}{$\begin{array}{l}\text { Time per } \\
\text { Floor }(\mathrm{s})\end{array}$} \\
\hline & (m) & (ft) & & & & & & \\
\hline 21 & 64.0 & 210.0 & 24.4 & 89.1 & 90 & 100 & 6 & 524.1 \\
\hline 20 & 60.8 & 199.5 & 23.4 & 87.0 & 90 & 100 & 6 & 511.3 \\
\hline 19 & 57.6 & 189.0 & 22.3 & 84.8 & 90 & 100 & 6 & 498.5 \\
\hline 18 & 54.4 & 178.5 & 21.2 & 82.7 & 90 & 100 & 6 & 485.7 \\
\hline 17 & 51.2 & 168.0 & 20.2 & 80.6 & 90 & 100 & 6 & 472.9 \\
\hline 16 & 48.0 & 157.5 & 19.1 & 78.4 & 90 & 100 & 6 & 460.1 \\
\hline 15 & 44.8 & 147.0 & 10.2 & 76.3 & 90 & 100 & 6 & 447.3 \\
\hline 14 & 41.6 & 136.5 & 17.0 & 74.2 & 90 & 100 & 6 & 434.5 \\
\hline 13 & 38.4 & 126.0 & 15.9 & 72.0 & 90 & 100 & 6 & 421.7 \\
\hline 12 & 35.2 & 115.5 & 14.2 & 69.9 & 90 & 100 & 6 & 408.9 \\
\hline 11 & 32.0 & 105.0 & 13.8 & 67.8 & 90 & 100 & 6 & 396.1 \\
\hline 10 & 28.8 & 94.5 & 12.7 & 45.8 & 90 & 3 & 1 & 45.8 \\
\hline 9 & 25.6 & 84.0 & 11.6 & 43.7 & 90 & 3 & 1 & 43.7 \\
\hline 8 & 22.4 & 73.5 & 10.6 & 41.6 & 90 & 3 & 1 & 41.6 \\
\hline 7 & 19.2 & 63.0 & 9.5 & 39.4 & 90 & 3 & 1 & 39.4 \\
\hline 6 & 16.0 & 52.5 & 8.4 & 37.3 & 90 & 3 & 1 & 37.3 \\
\hline 5 & 12.8 & 42.0 & 7.4 & 35.2 & 90 & 3 & 1 & 35.2 \\
\hline 4 & 9.6 & 31.5 & 6.3 & 33.0 & 90 & 3 & 1 & 33.0 \\
\hline 3 & 6.4 & 21.0 & 5.2 & 30.8 & 90 & 3 & 1 & 30.8 \\
\hline 2 & 3.2 & 10.5 & 3.8 & 28.0 & 90 & 3 & 1 & 28.0 \\
\hline \multirow[t]{5}{*}{1} & 0.0 & 0.0 & & & & & & \\
\hline & \multicolumn{7}{|c|}{ Total round trip time $=$} & 5395.6 \\
\hline & \multicolumn{7}{|c|}{ Start up time $=$} & 41.3 \\
\hline & \multicolumn{7}{|c|}{ Time to get outside after leaving the elevator $=$} & 30.0 \\
\hline & \multicolumn{7}{|c|}{ Evacuation time using 5 elevators $=$} & 1258.3 \\
\hline
\end{tabular}




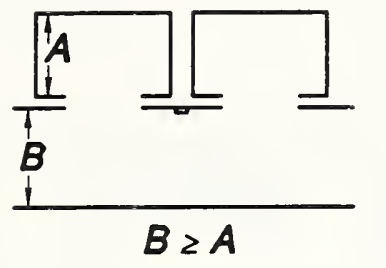

(a) Two Car Group

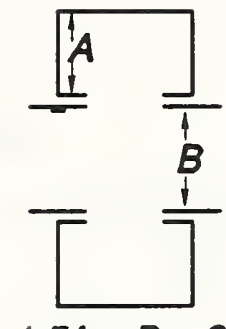

$1.5 A \leq B \leq 2 A$

(b) Two Car Group



(c) Three Car Group

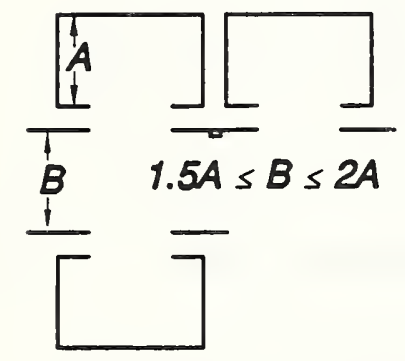

(d) Three Car Group

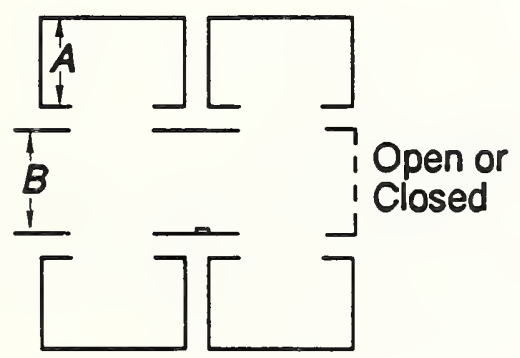

$1.5 A \leq B \leq 2 A$

(f) Four Car Group

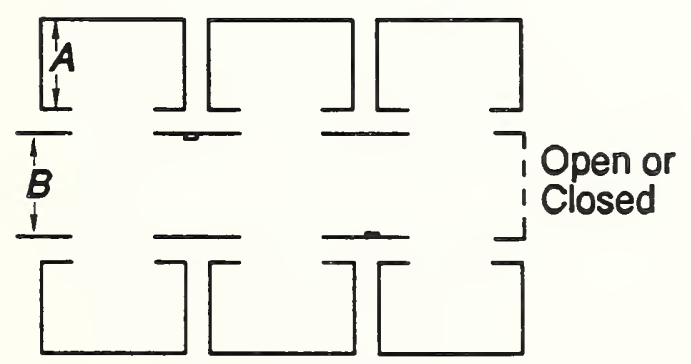

$1.75 A \leq B \leq 2 A$

(h) Six Car Group

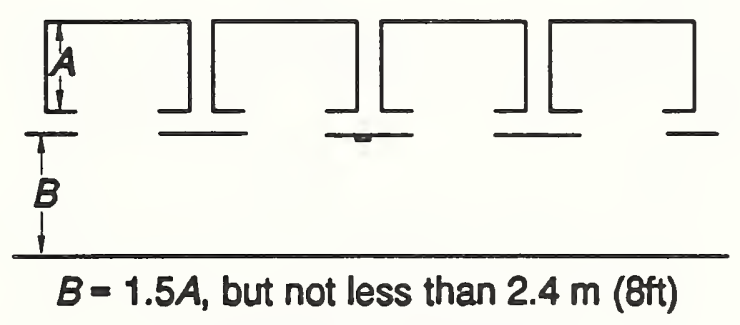

(e) Four Car Group

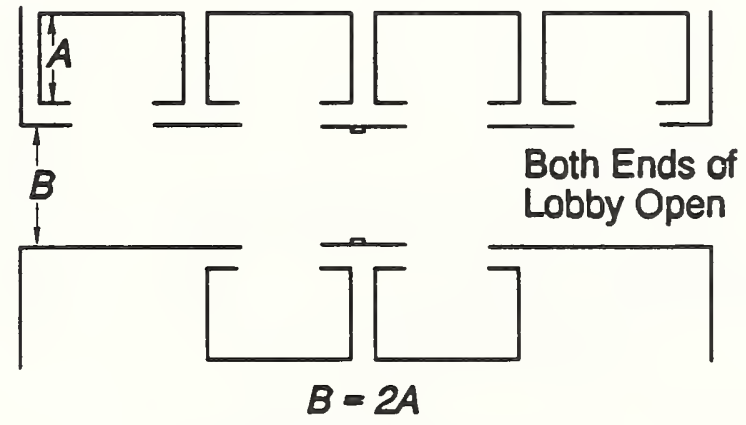

(g) Six Car Group

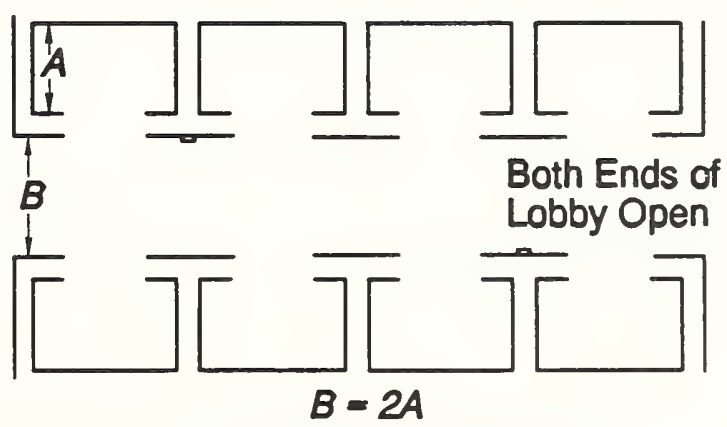

(i) Eight Car Group

Figure 1. Commonly accepted elevator arrangements 


$$
\underline{\square} \text { Corridor }[\square
$$

(a) Cars Separated

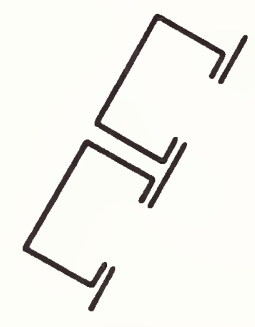

(c) Angular Arrangement $\underline{\square}[\square] \square[\square]$

(b) Too Many Cars in a Line

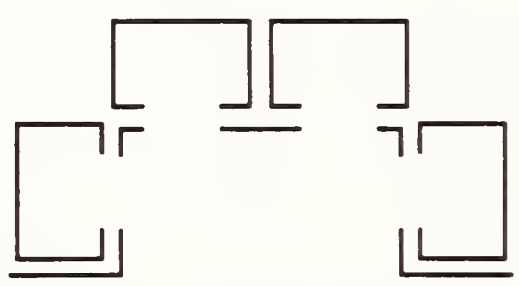

(d) Cornered Arrangement

Figure 2. Unusual elevator arrangements resulting in inefficient people movement

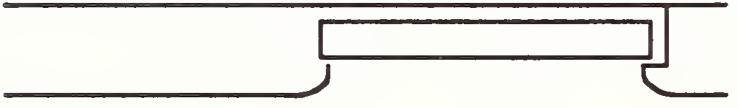

(a) Single-Sliding Door

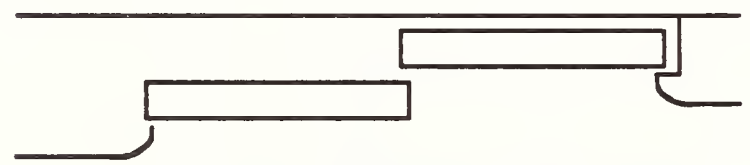

(b) Two-Speed Sliding Doors

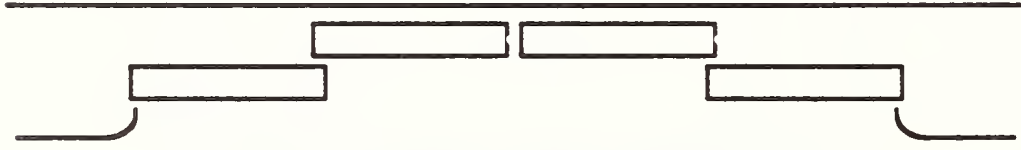

(c) Two-Speed, Center-Opening Doors

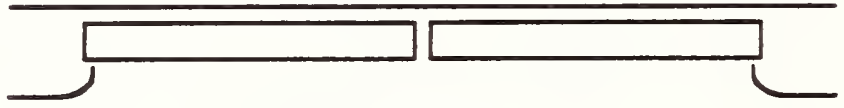

(d) Center Opening Doors

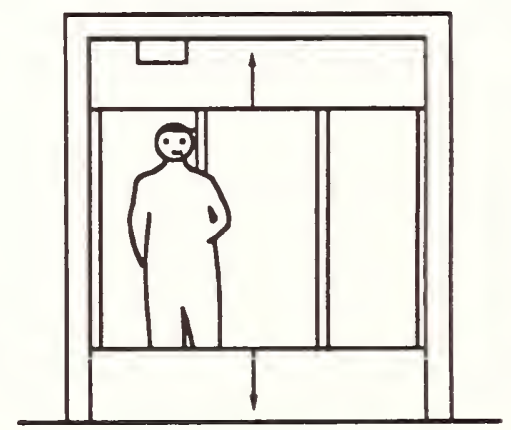

(e) Vertical Biparting Doors

Figure 3. Types of elevator doors 


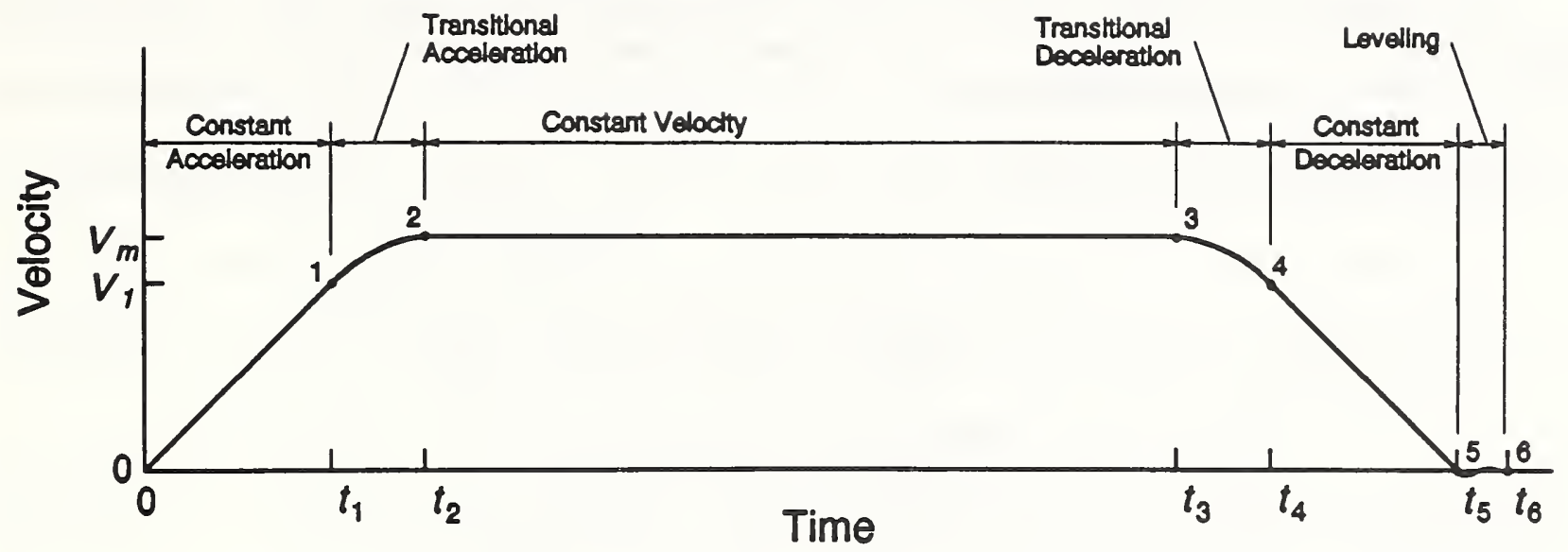

Figure 4. Velocity of elevator reaching normal operating velocity, $\mathrm{V}_{\mathrm{m}}$

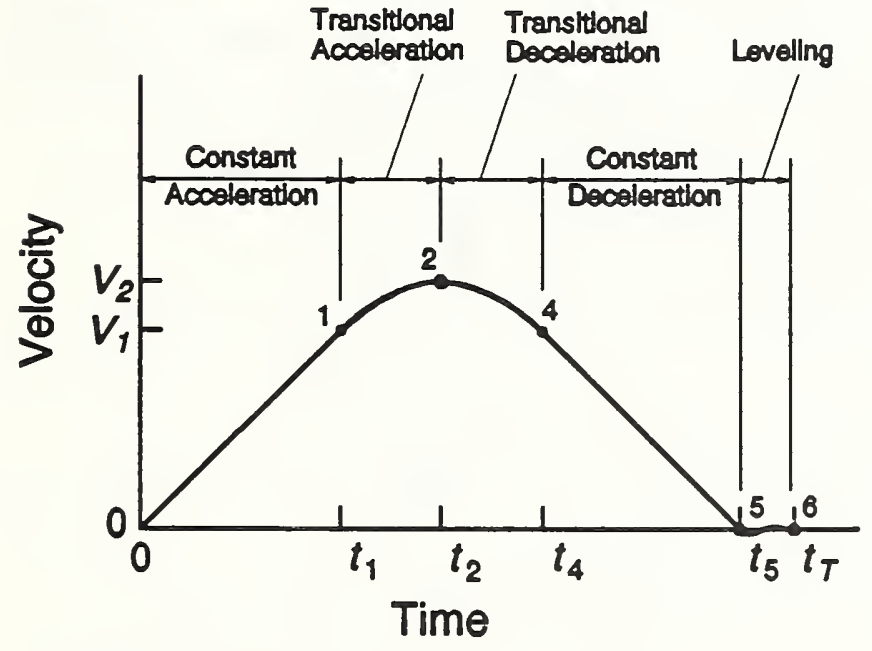

(a) Car Reaching Transitional Acceleration

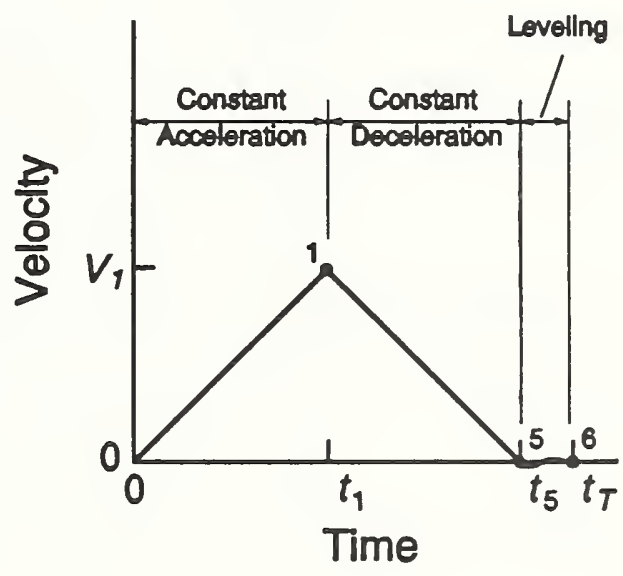

(b) Car Not Reaching Transitional Acceleration

Figure 5. Velocity of elevators not reaching normal operating velocity 


\section{Appendix C Listing of ELVAC Computer Program}

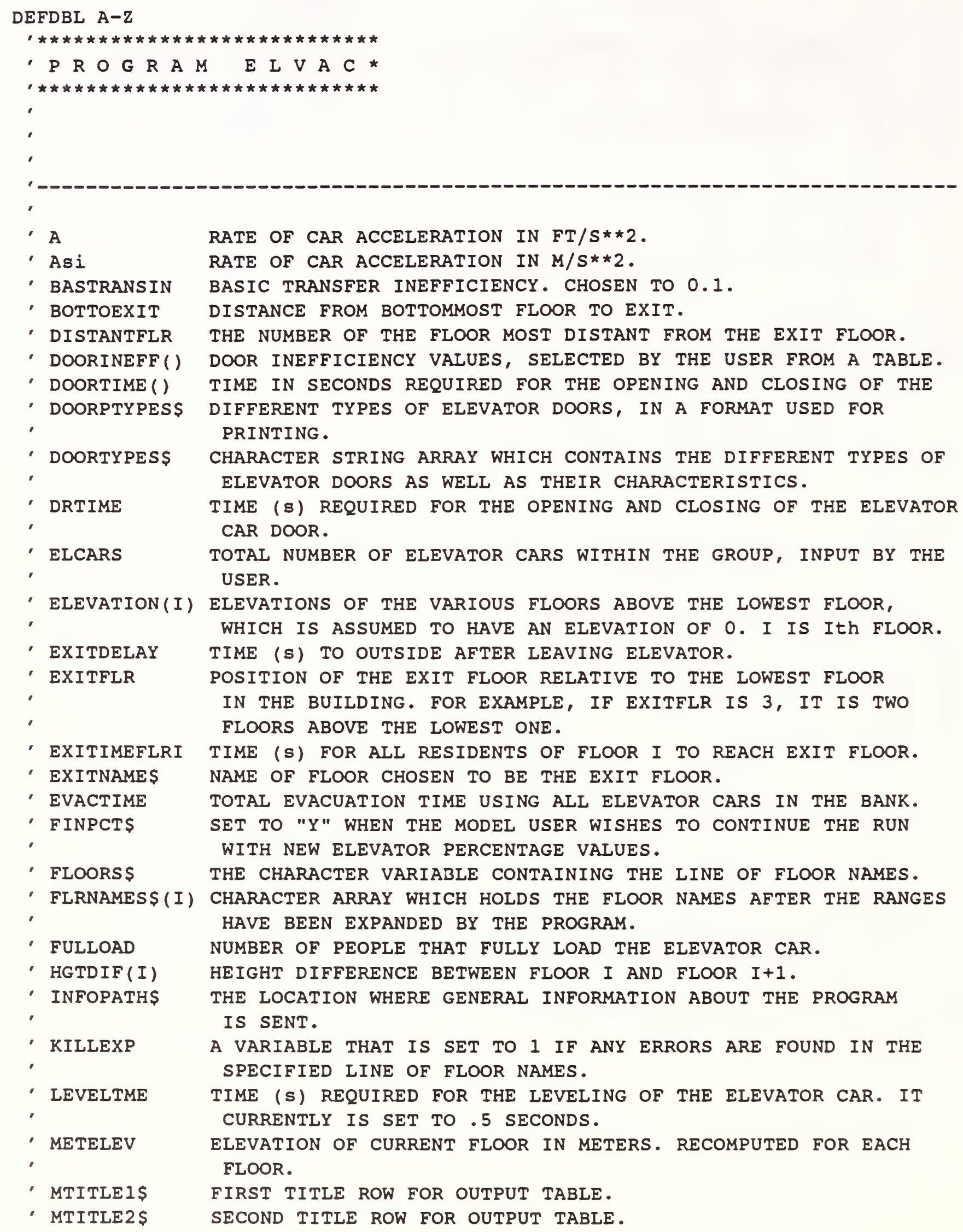


MTITLE3\$ THIRD TITLE ROW FOR OUTPUT TABLE.

NPPLELAST THIS IS THE NUMBER OF PEOPLE IN THE ELEVATOR CAR DURING THE LAST TRIP, AND IS RECOMPUTED FOR EACH FLOOR.

NTRIPSFULL THE NUMBER OF ROUND TRIPS WITH A FULLY LOADED ELEVATOR CAR, RECOMPUTED FOR EACH FLOOR.

OPTIONERRORS A FLAG THAT IS SET TO "YES" IF THE OUTPUTOPTION IS NOT 1 OR 2 .

OTHERTRANSIN OTHER TRANSFER INEFFICIENCY VALUE, DUE TO ELEVATOR CAR SHAPE AND OCCUPANT USE.

OUTPUTOPTION AN INTEGER BETWEEN 1 AND 2 WHICH IS CHOSEN BY THE USER TO DETERMINE WHERE STORED OUTPUT IS SENT.

PATHSELS

"N" IF ONLY SCREEN OUTPUT IS DESIRED, "PRN" IF THE FINAL OUTPUT RESULTS ARE TO BE PRINTED, OR A DOS FILENAME IF THE FINAL OUTPUT RESULTS ARE TO BE SENT TO A FILE.

PEOPLE(I) NUMBER OF PEOPLE ON THE Ith FLOOR.

PERCNT(I) PERCENT OF PEOPLE ON Ith FLOOR WHO USE ELEVATOR CARS TO LEAVE THE BUILDING.

PPLEFLR

PPLEI

TYPICAL NUMBER OF PEOPLE ON A FLOOR, GIVEN BY THE USER.

$$
\text { , }
$$

PRINTINFOS

RERUNPERCNT

ACTUAL NUMBER OF PEOPLE ON ITh FLOOR WHO USE THE ELEVATOR CAR. IT IS THE PRODUCT OF PEOPLE(I) AND PERCNT(I).

A FLAG SET TO Y IF THE USER WISHES TO READ ABOUT THE MODEL.

, FLAG SET EQUAL TO O WHEN THE USER WISHES TO LEAVE THE MAIN DO LOOP, OR 1 WHEN HE WISHES TO RERUN IT WITH NEW ELEVATOR USAGE PERCENTAGE VALUES.

RERUNOUTPUT\$ SET EQUAL TO Y WHEN THE USER DESIRES TO SEND THE OUTPUT RESULTS TO THE PRINTER OR A FILE.

RERUNPROG\$

RNDTIMES (I)

STARTUPTIME

SET EQUAL TO "Y" WHEN THE USER WISHES TO RERUN THE PROGRAM. TOTAL TIME (s) FOR THE TRIPS REQUIRED TO EVACUATE FLOOR I. TIME SPENT BEFORE THE ACTUAL EVACUATION BY ELEVATOR CARS BEGINS. IT IS COMPUTED FIRST TO BE THE TIME REQUIRED TO BRING A FULLY LOADED ELEVATOR CAR FROM THE MOST DISTANT FLOOR TO THE EXIT FLOOR. IF THIS IS NOT SATISFACTORY, THE USER INPUTS A LARGER VALUE.

STNDTMEFULL STANDING TIME CALCULATED FOR A FULLY LOADED ELEVATOR.

TIMEFULL SUM OF THE TIMES OF FULLY LOADED ROUND TRIPS. RECOMPUTED FOR EACH FLOOR.

TIMELAST

TIMES (I)

TITLE\$

TOKENS $\$(I)$

TOPTOEXIT

TOTFLRS

TOTINEFF

TOTTIME

TRANS

TRIPINEFF

-

TRIPS

TYPDIF

TYPDIFSI

TYPPERCNT

UNITS

VMAX

TIME REQUIRED FOR THE LAST ROUND TRIP FROM A FLOOR.

TIME FOR A ONE WAY TRIP TO FLOOR I.

TITLE OF THE CURRENT RUN.

NON-BLANK SUBSTRINGS CONTAINED WITHIN EACH PARSED LINE (SEE PARSING ROUTINE).

DISTANCE FROM TOP FLOOR TO EXIT FLOOR.

TOTAL NUMBER OF FLOORS IN THE BUILDING.

BASIC TRANSFER INEFFICIENCY + DOOR INEFFICIENCY + OTHER TRANSFER INEFFICIENCY.

TOTAL TIME TO EVACUATE BUILDING BY ELEVATOR.

TRANSITIONAL COEFFICIENT. V1 = TRANS*VMAX.

TRIP INEFFICIENCY DUE TO GATHERING STRAGGLERS, TRAVEL TO

EMPTY FLOORS, FLOW RESTRICTIONS, ETC.

NUMBER OF ROUND TRIPS NEEDED TO EVACUATE A FLOOR.

TYPICAL FLOOR TO FLOOR HEIGHT IN FEET.

TYPICAL FLOOR TO FLOOR HEIGHT IN METERS.

TYPICAL PERCENT OF ELEVATOR USAGE.

1 IF SI UNITS ARE DESIRED, 2 IF ENGLISH UNITS ARE REQUESTED. MAXIMUM ELEVATOR CAR VELOCITY IN ft./second. 
FIRST, DECLARE THE FIVE SUBROUTINES AND THE FUNCTION CALLED BY THE MAIN PROGRAM. THESE SIX SUBPROGRAMS AND THEIR ARGUMENTS WILL BE DESCRIBED BY COMMENT STATEMENTS APPEARING LATER.

DECLARE SUB CHECK (NUMTOK\#, LLIMIT\#, UPLIMIT\#, ARRPTR\#)

DECLARE SUB PARSE (STORE\$, NUMTOKS\#)

DECLARE SUB HEIGHTS ()

DECLARE SUB RANGEEXP (FLRSTR\$, FLRSUB1, FLRSUB2, FLR1\$, FLR2\$, EXPEXCP) DECLARE SUB TRIPTIME ()

DECLARE FUNCTION CALCSTAND* (PEOP*)

THESE ARE THE VARIABLES SHARED WITH OTHER ROUTINES.

DIM SHARED TOKENS\$(200), FLOORS\$, UNITS

DIM SHARED FLRNAMES\$(200), HGTDIF(200), ELEVATION(200)

DIM SHARED TIMES(200), people(200), PERCNT(200)

DIM SHARED KILLEXP, TOTFLRS, EXITFLR

DIM SHARED TYPDIF, TYPDIFSI, VMAX, TRANS, A, LEVELTME, FULLOAD

DIM SHARED DRTIME, TOTINEFF

DIMENSION THE ARRAYS WHICH ARE NOT SHARED.

DIM DOORTYPES\$(15), DOortime(14), DOORINEFF(14), RNDTIMES(200)

DIM DOORPTYPES\$(13)

DATA STATEMENTS INITIALIZING THE DOORTIME AND DOOR TRANFER INEFFICIENCY ARRAY NOW APPEAR.

DATA $6.6,5.9,4.1,7.0,6.6,4.6,7.7,5.3,8.8,6.0,9.9,6.5,6.0$

DATA $.10, .10, .08, .07, .07, .05, .02,0, .02,0, .02,0,0$

FOR I $=1$ TO 13: READ Doortime(I): NEXT I

FOR I $=1$ TO 13: READ DOORINEFF(I): NEXT I

DATA STATEMENTS USED IN INITIALIZING THE DOOR TYPE ARRAY

ARE NOW GIVEN. THE ARRAY IS THEN INITIALIZED.

\begin{tabular}{|c|c|c|c|c|c|}
\hline DATA" & A Single-slide & $900 \mathrm{~mm}$ & (36in) & 6.6 & $0.10^{\circ}$ \\
\hline DATA" & B Two-Speed & $900 \mathrm{~mm}$ & (36in) & 5.9 & $0.10^{\prime}$ \\
\hline DATA" & C Center-Opening & $900 \mathrm{~mm}$ & (36in) & 4.1 & $0.08^{\prime}$ \\
\hline DATA" & D Single-slide & $1100 \mathrm{~mm}$ & (42in) & 7.0 & $0.07^{\prime}$ \\
\hline DATA" & E Two-Speed & $1100 \mathrm{~mm}$ & (42 in) & 6.6 & $0.07^{\prime \prime}$ \\
\hline DATA" & F Center-Opening & $1100 \mathrm{~mm}$ & (42 in) & 4.6 & $0.05^{\prime}$ \\
\hline DATA" & G Two-Speed & $1200 \mathrm{~mm}$ & (48in) & 7.7 & $0.02^{\prime}$ \\
\hline DATA" & H Center-Opening & $1200 \mathrm{~mm}$ & (48in) & 5.3 & 0 \\
\hline DATA" & I Two-Speed & $1400 \mathrm{~mm}$ & (54in) & 8.8 & $0.02^{\prime}$ \\
\hline DATA" & $\mathrm{J}$ Center-opening & $1400 \mathrm{~mm}$ & (54in) & 6.0 & 0 \\
\hline DATA" & K Two-Speed & $1600 \mathrm{~mm}$ & (60in) & 9.9 & $0.02^{\prime}$ \\
\hline DATA" & I Center-opening & $1600 \mathrm{~mm}$ & (60in) & 6.5 & 0 \\
\hline DATA" & M Two-Speed, & $1600 \mathrm{~mm}$ & (60in) & 6.0 & 0 \\
\hline DATA" & Center-Opening & & & & \\
\hline DATA" & THFR & & & & \\
\hline
\end{tabular}

FOR I $=1$ TO 15: READ DOORTYPES\$(I): NEXT I 
APPEAR. INITIALIZATION OF THE ARRAY IS PERFORMED.

DATA" A single-slide

DATA" B Two-speed

DATA" C Center-Opening

$900 \mathrm{~mm}$ (36in) wide"

$900 \mathrm{~mm}$ (36in) wide"

$900 \mathrm{~mm}$ (36in) wide"

DATA" D Single-slide

$1100 \mathrm{~mm}$ ( $42 \mathrm{in}$ ) wide"

DATA" E Two-speed

DATA" F Center-opening

$1100 \mathrm{~mm}$ (42 in) wide"

$1100 \mathrm{~mm}$ (42in) wide"

DATA" G Two-speed

$1200 \mathrm{~mm}$ (48in) wide"

DATA" H Center-Opening

$1200 \mathrm{~mm}$ (48in) wide"

DATA" I Two-speed

$1400 \mathrm{~mm}$ ( $54 \mathrm{in}$ ) wide"

DATA" J Center-Opening

$1400 \mathrm{~mm}$ (54in) wide"

DATA" K Two-speed

$1600 \mathrm{~mm}$ (60in) wide"

DATA" I Center-Opening

$1600 \mathrm{~mm}$ (60in) wide"

DATA" M Two-speed, Center-opening 1600mm (60in) wide"

FOR $I=1$ TO 13: READ DOORPTYPESS(I): NEXT I

SET THE DEFAULT VALUES OF SOME OF THE VARIABLES.

BASTRANSIN $=.1$ \#

TRANS $=.6 \#$

LEVELTME $=.5$ \#

RERUNOUTPUTS $=" \mathrm{~N} "$

PATHSELS = "SCRN:"

THE MAIN TITLES FOR THE OUTPUT TABLE ARE NOW CREATED.

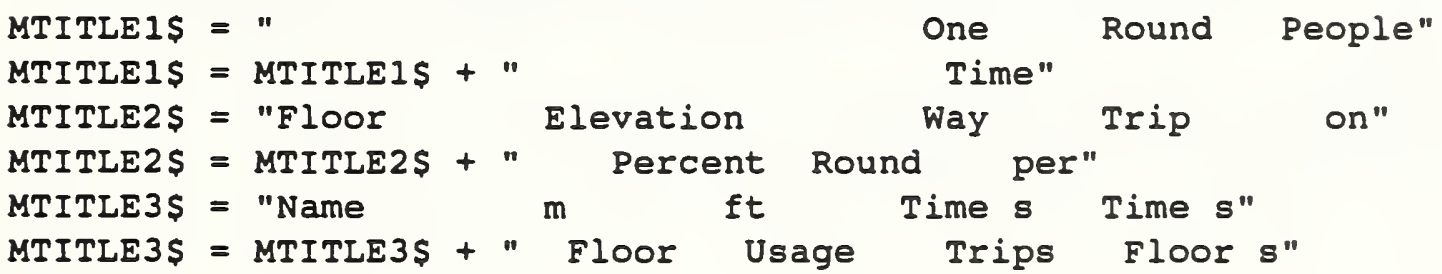

MTITLE3\$ = MTITLE3\$ + " Floor Usage Trips Floor $\mathbf{s} "$

MAIN PROGRAM EXECUTION DO LOOP.

THIS LOOP RUNS THE ENTIRE PROGRAM. AT THE END, THE USER IS ASKED IF HE WISHES TO RERUN IT. IF SO, THE PROGRAM IS RERUN. OTHERWISE, THE LOOP IS EXITED AND THE PROGRAM STOPS.

Do

INITIALLY SEND COMPUTED OUTPUT TO THE SCREEN.

CLS

OPEN "SCRN:" FOR OUTPUT AS \#I

PRINT " "

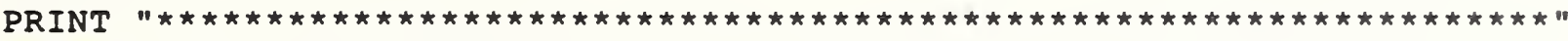

PRINT " ELVAC VERSION 1.00

PRINT " WRITTEN BY DANIEL M. ALVORD AND

PRINT " JOHN H. KLOTE 


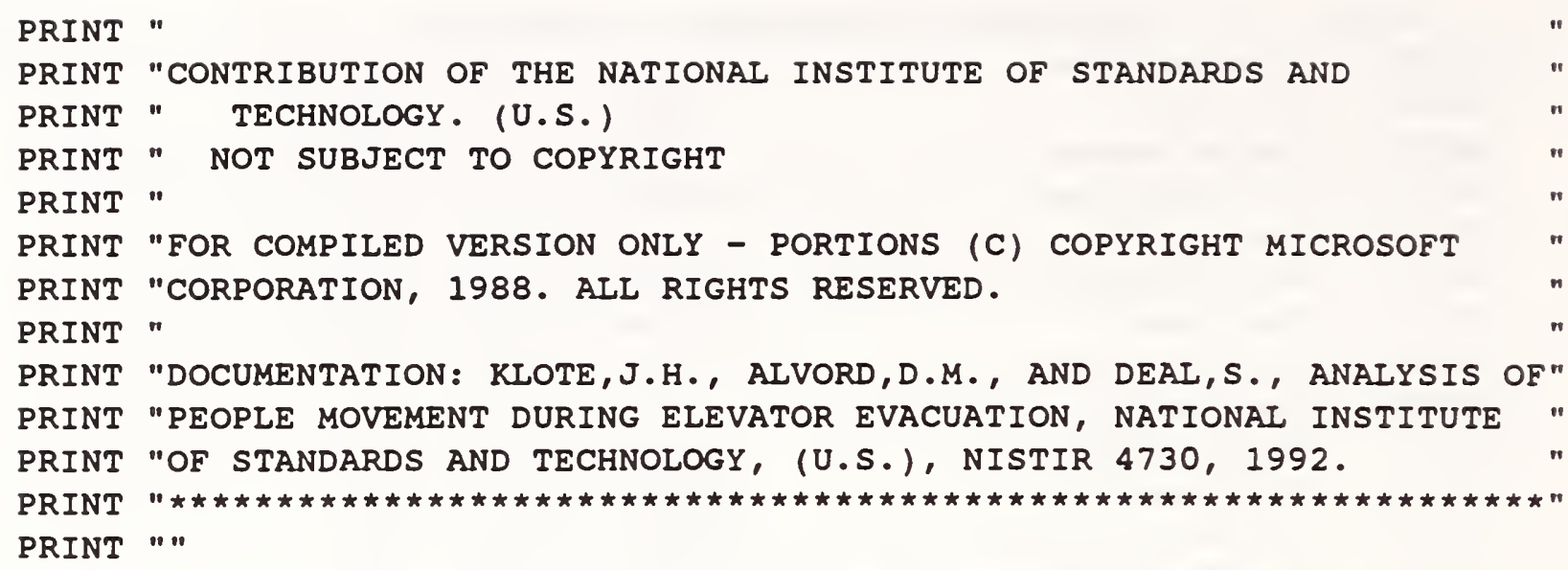

THE USER NOW INDICATES IF HE WISHES TO READ GENERAL INFORMATION ABOUT PARTICULAR CONCEPTS OF THE ELEVATOR MODEL.

INPUT "DO You want to read about the model ( $Y$ or $N$ )? ", PRINTINFOS PRINTINFO = UCASE\$(PRINTINFO\$)

THE USER NOW SPECIFIES WHERE THE GENERAL INFORMATION SHOULD BE PLACED.

PRINT " "

IF PRINTINFOS = "Y" THEN

PRINT "Where do you wish the general information to appear?"

PRINT " (a filename, PRN for printer, or ENTER for output"

INPUT " to the screen.) ", INFOPATHS

INFOPATH $\$$ UCASE\$ (INFOPATH\$)

IF INFOPATHS = " "THEN INFOPATHS = "SCRN:"

OPEN INFOPATHS FOR OUTPUT AS \#2

END IF

GENERAL INFORMATION ABOUT THE MODEL AND ITS COMPUTER IMPLEMENTATION IS NOW GIVEN, IF THE USER SO SPECIFIES.

IF PRINTINFOS = "Y" THEN

CLS

PRINT " "

PRINT \#2, " -------------Basic concepts of the model-----------------"

PRINT \#2," Basic transfer inefficiency- a factor that allows for "

PRINT \#2, " rounding off of probable stops, door operating time, door"

PRINT \#2," starting and stopping time, and the unpredictability of "

PRINT \#2," people. A value of 0.10 is used for commonly accepted "

PRINT \#2," arrangements of elevator groups. "

PRINT \#2," Discharge floor- When emergency evacuation starts, "

PRINT 2, " elevators will take people to a discharge floor where "

PRINT \#2," passengers on the elevators will exit. This floor may "

PRINT \#2," lead to the outside or to an area of relative safety. "

PRINT \#2, " Door inefficiency- Adjusts for any increase in transfer "

PRINT \#2," time over that of a $1200 \mathrm{~mm}$ (48 in) wide center opening "

PRINT \#2," door.

IF INFOPATHS = "SCRN:" THEN

PRINT " "

INPUT "Press ENTER to continue......", junk\$

CLS 


\section{END IF}

PRINT \#2, " Dwell time- The minimum time an elevator car door remains

PRINT \#2," open. The time used in this program is 4 seconds. "

PRINT \#2, "Groups- Elevators are located in groups of up to eight "

PRINT \#2," elevators. The elevators in a group are located near each"

PRINT \#2," other and are controlled together to move people "

PRINT *2," efficiently. "

PRINT \#2, "Elevator evacuation start up time- The time from activation"

PRINT \#2," of the alarms(for example) to the start of the round trips"

PRINT *2," that evacuate people. If the elevators are operated "

PRINT *2," automatically during evacuation, one starts the elevator "

PRINT \#2," evacuation after all of the elevators have been moved "

PRINT \#2," to the discharge floor and the people in them have left."

PRINT \#2," In the case of manual elevator operation, the time for "

PRINT \#2," elevators operators to reach the cars must be included. "

PRINT \#2, "Motion- Elevator motion starts with constant acceleration,"

PRINT \#2," followed by transitional acceleration until constant "

PRINT \#2," velocity motion at the normal operating velocity of the "

PRINT \#2," car is attained.

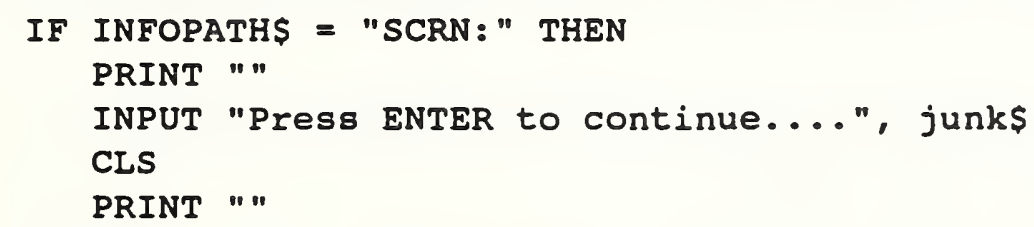

END IF

PRINT \#2, "Other transfer inefficiency- accounts for inefficiencies " PRINT \#2," due to unusual elevator car shape or limited physical " PRINT \#2," capability of passengers. In office buildings, a value of" PRINT \#2," 0 is used.

PRINT \#2," Round trip- a round trip starts at the discharge floor and " PRINT \#2," consists of the sequence: elevator doors close, car " PRINT \#2," travels to another floor, doors open, passengers enter " PRINT \#2," the car, doors close, car travels to discharge floor, " PRINT \#2," doors open, and passengers leave the car. Alternatively," PRINT \#2," it may be defined as two one way trips and a standing " PRINT \#2," period. " PRINT \#2," Standing time- Twice the time required to open and close " PRINT \#2," the elevator doors, plus the time for people to enter the" PRINT \#2," elevator, plus the time for people to leave the elevator." PRINT \#2, "Trip inefficiency- a multiplicative factor that accounts " PRINT \#2," for trips to empty floors and for trips to pick up only a" PRINT \#2," few stragglers.

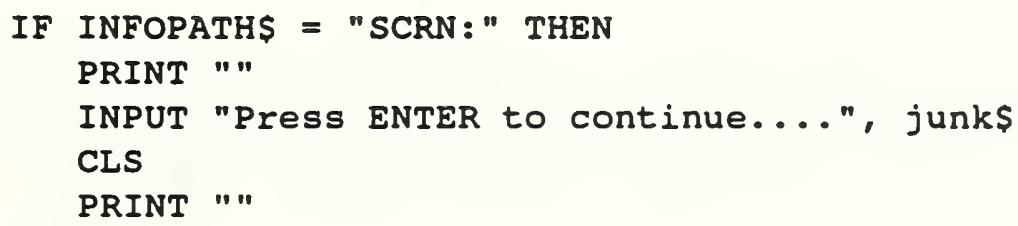

END IF

PRINT \#2," --.---Concepts inherent to the computer program---.---.-" PRINT \#2, " Range- A range is a set of floor names that is expanded by " PRINT \#2," the program into a set of contiguous floor numbers. For " PRINT \#2," example, the range $2-10$ is expanded into $2,3,4,5,6, \ldots$, " 


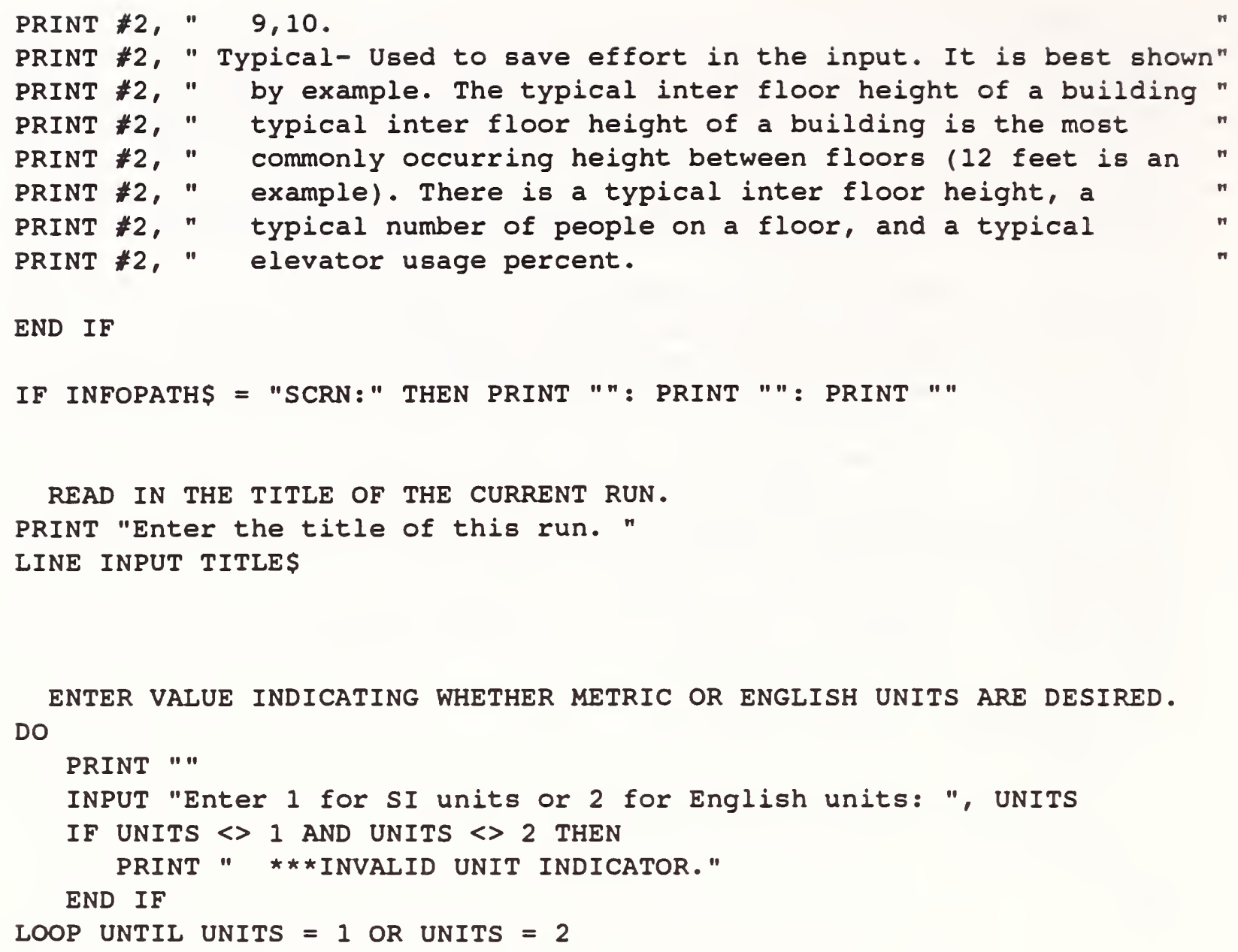

ENTER VALUE INDICATING WHETHER METRIC OR ENGLISH UNITS ARE DESIRED. DO

READ IN THE LINE OF FLOOR NAMES. THE LINE IS EXAMINED BY THE PROGRAM AND, IF ANY ERRORS ARE DISCOVERED, THE USER MUST REENTER THE LINE. IF NO ERRORS ARE FOUND, THE PROGRAM WILL USE THE FLOOR NAME IINE TO CREATE THE INDIVIDUAL FLOOR NAMES. THE HEIGHTS SUBROUTINE IS THEN CALLED TO READ IN THE TYPICAL FLOOR HEIGHT, ANY HEIGHT EXCEPTIONS, AND THEN TO COMPUTE THE ELEVATIONS OF EACH FLOOR.

DO

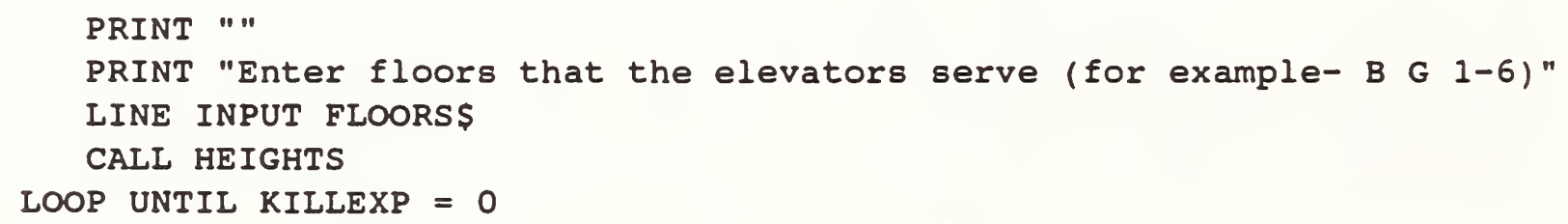

THE USER IS NOW PROMPTED BY THE PROGRAM TO KEY IN THE EXIT (DISCHARGE) FLOOR NAME. IF THE NAME IS NOT FOUND IN THE LIST OF FLOOR NAMES, AN ERROR MESSAGE APPEARS AND THE USER MUST RETYPE THE EXIT FLOOR NAME. DO

PRINT " "

INPUT "Discharge floor"; EXITNAME\$

EXITFLR $=0$

FOR I $=1$ TO TOTFLRS

IF EXITNAME $\$=$ FLRNAMES $\$(I)$ THEN 


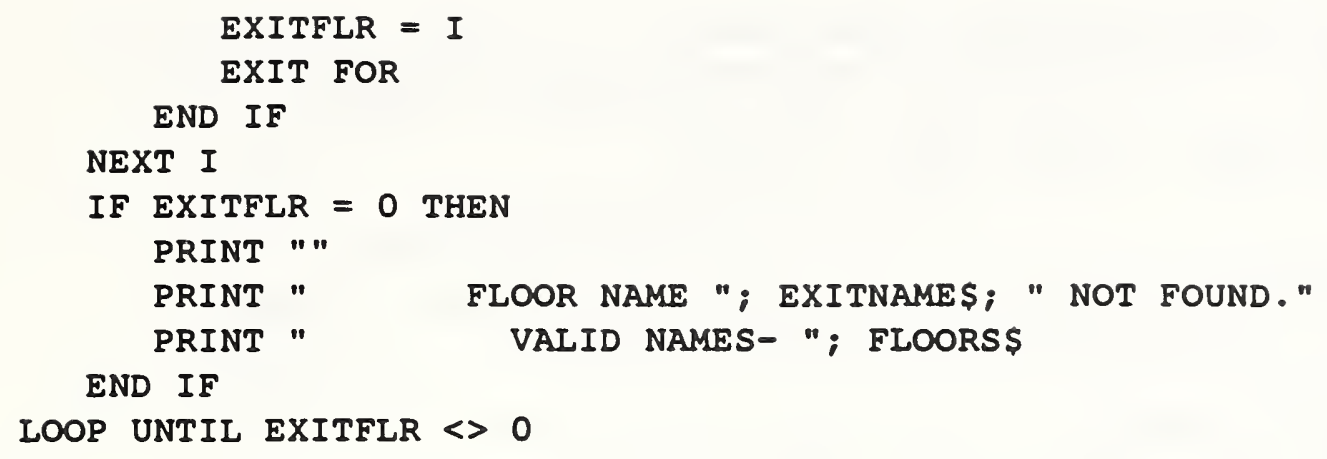

THE EXIT DELAY TIME MUST NOW BE INPUT. IF IT IS NOT WITHIN A CERTAIN RANGE, THE PROGRAM PROMPTS THE USER TO RETYPE IT. DO

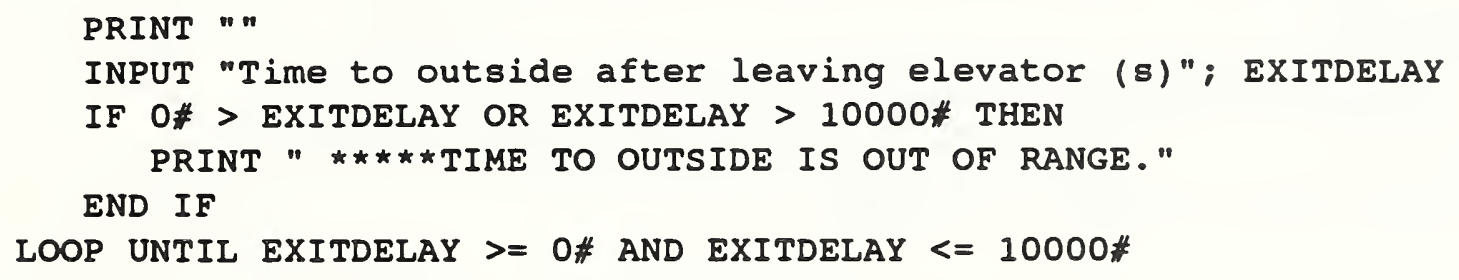

THE USER NOW ENTERS THE NORMAL OPERATING VELOCITY OF THE ELEVATOR CAR.

DO

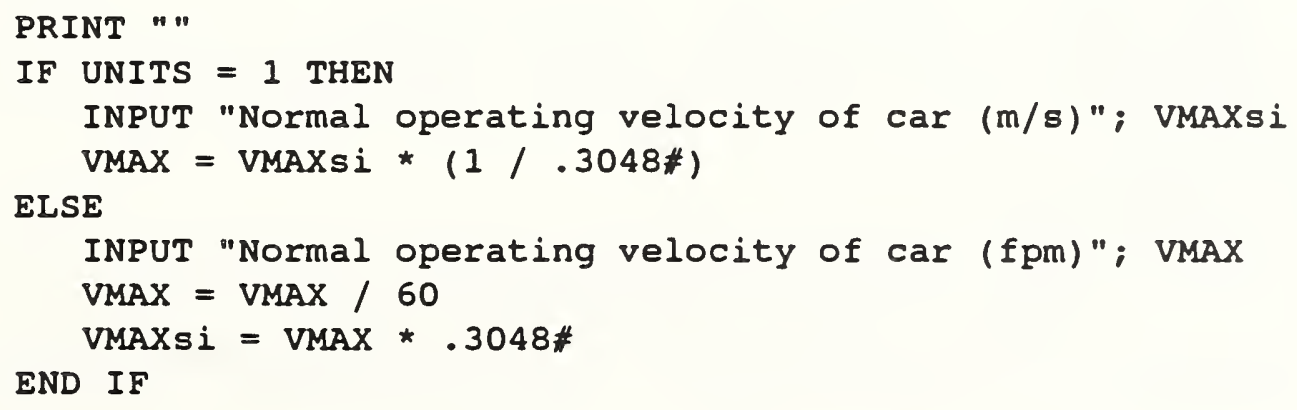




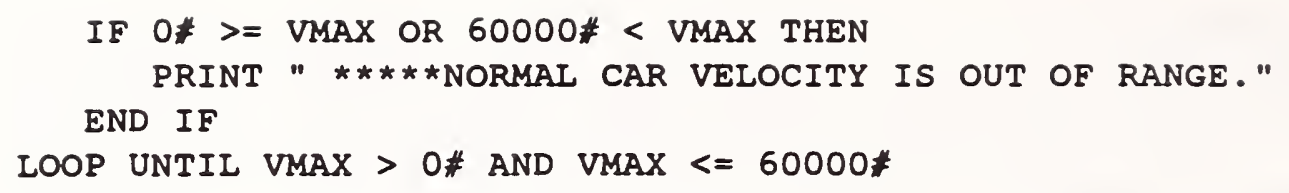

THE TIME REQUIRED TO OPEN AND CLOSE THE ELEVATOR CAR DOORS IS NOW ENTERED. DO

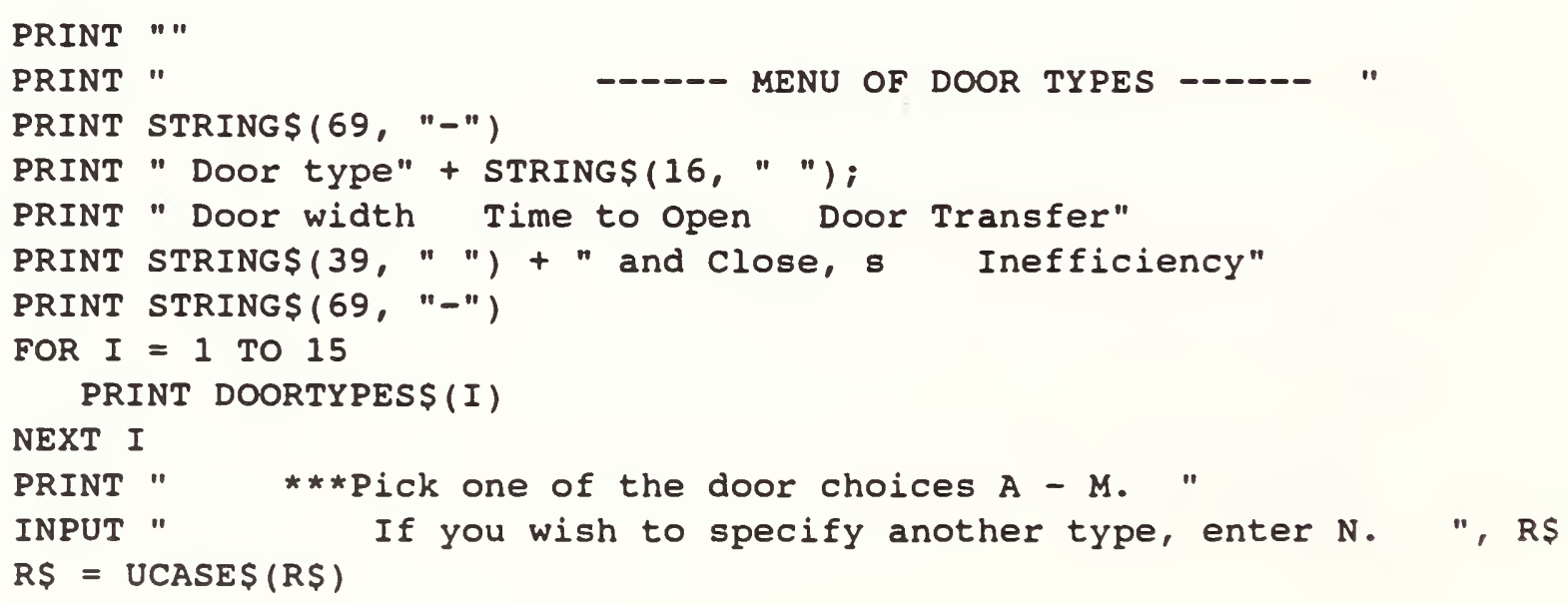


IF LEN $(R \$)=1$ THEN

DOORCHOICE = ASC (RS) -64

IF DOORCHOICE < 1 OR DOORCHOICE > 14 THEN

PRINT "

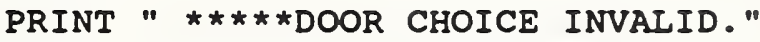

ELSEIF DOORCHOICE $=14 \mathrm{THEN}$

PRINT " "

PRINT " $* \star *$ ANOTHER DOOR TYPE SPECIFIED****

PRINT " "

INPUT " New doortime value (s)? ", Doortime(14)

DO

PRINT " " New door inefficiency value? ", DOORINEFF(14)

$M M=$ DOORINEFF $(14)$

IF $M M<0 *$ OR MM > 1* THEN

PRINT $n$

PRINT " $\quad$ **Door inefficiency value is out of range."

END IF

LOOP UNTIL MM $>=0 \#$ AND $M M<=1 \#$

ELSE

END IF

PRINT " "

PRINT " $\star * \star * \star D O O R$ CHOICE CONTAINS MORE THAN ONE CHARACTER."

END IF

LOOP UNTIL LEN(R\$) $=1$ AND DOORCHOICE $>=1$ AND DOORCHOICE $<=14$

THE OTHER TRANSFER INEFFICIENCY FACTOR IS NOW INPUT.

DO

PRINT " "

INPUT "Other transfer inefficiency? ", OTHERTRANSIN

IF OTHERTRANSIN < O\# OR OTHERTRANSIN > 1\# THEN

PRINT " $* \star * \star *$ OTHER TRANSFER INEFFICIENCY IS OUT OF RANGE." END IF

LOOP UNTIL O\# $<=$ OTHERTRANSIN AND OTHERTRANSIN $<=1$ \#

THE DOORTIME AND TOTAL TRANSFER INEFFICIENCY ARE NOW COMPUTED. DRTIME = DOOrtime (DOORCHOICE)

TOTINEFF = BASTRANSIN + DOORINEFF (DOORCHOICE $)+$ OTHERTRANSIN

THE STANDING TIME REQUIRED TO FULLY LOAD AN ELEVATOR CAR IS NOW

COMPUTED AND STORED.

STNDTMEFULL = CALCSTAND\# (FULLOAD\#)

NEXT, THE ONE WAY TRIP TIMES ARE COMPUTED FOR EACH FLOOR. CALL TRIPTIME

NOW THE START UP TIME IS COMPUTED OR INPUT. THIS IS THE TIME REQUIRED

TO PREPARE FOR THE ACTUAL EGRESS BY ELEVATOR AFTER THE SIGNAL FOR

EVACUATION IS GIVEN.

TOPTOEXIT = ELEVATION(TOTFLRS) - ELEVATION(EXITFLR) 


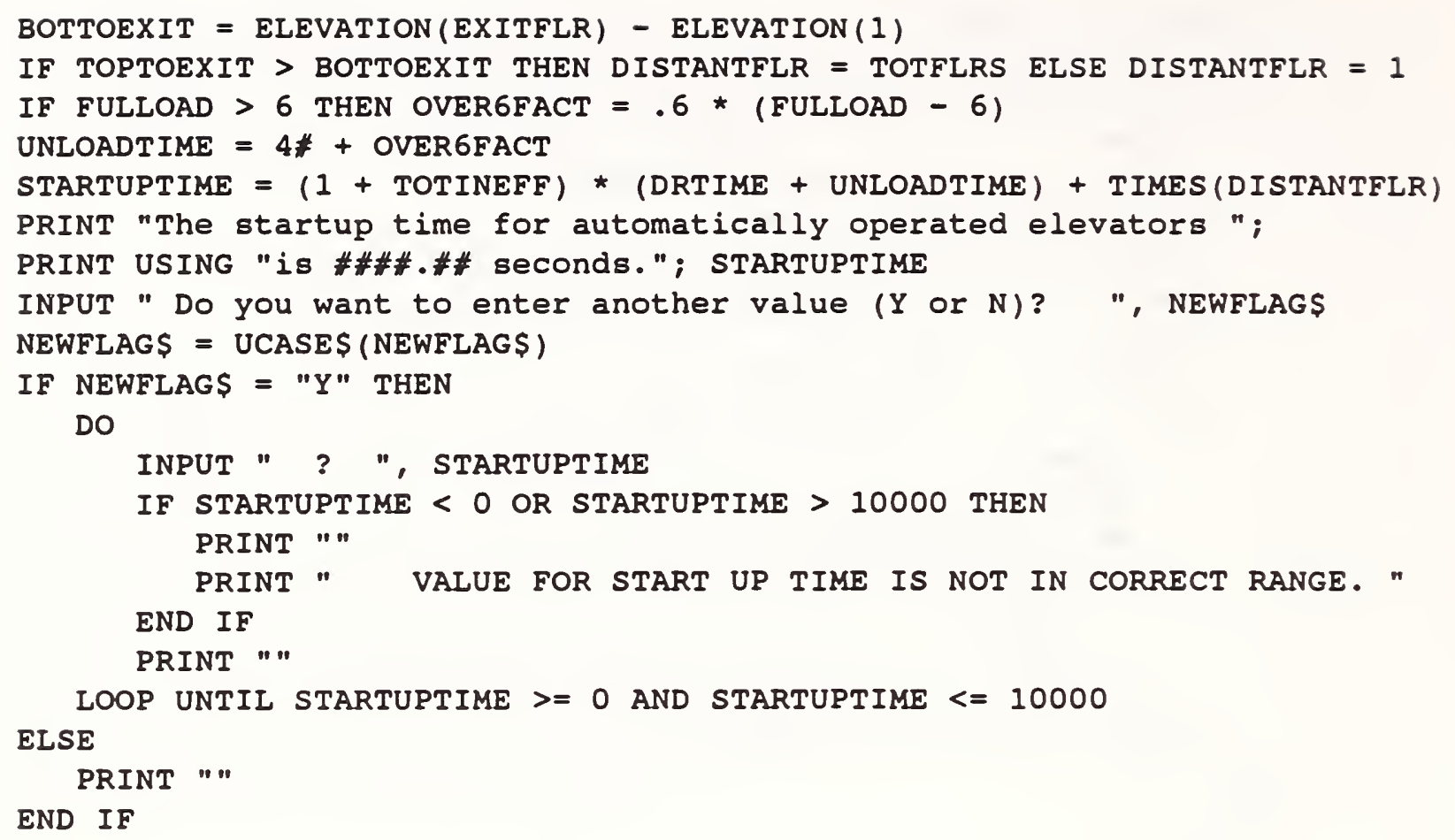

* REAds IN A NEW SET of ELEVATOR USE PERCENTAGES. THIS LOOP 
IS RERUN UNTIL THE CURRENT INPUT VALUES TOGETHER WITH THE NEW PERCENTAGE VALUES PRODUCE SATISFACTORY RESULTS.

Do

THE TYPICAL ELEVATOR USAGE IS NOW KEYED IN. THIS IS THE PERCENT OF PEOPLE ON EACH FLOOR WHO USE ELEVATOR CARS TO EGRESS. IT MUST BE A VALUE BETWEEN O AND 100.

Do

PRINT " "

INPUT "Percent of people on typical floor using elevator"; TYPPERCNT

IF TYPPERCNT < O\# OR TYPPERCNT > 100\# THEN

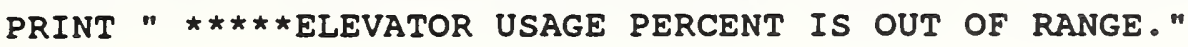

END IF

LOOP UNTIL O\# <= TYPPERCNT AND TYPPERCNT <= 100\#

FOR I $=1$ TO TOTFLRS: PERCNT $(I)=$ TYPPERCNT: NEXT I

NEXT, EXCEPTIONS TO THE TYPICAL ELEVATOR USAGE PERCENT ARE ENTERED. THESE OVERRIDE THE TYPICAL PERCENT.

FOR $I=1$ TO 1000

PRINT " Percent usage exceptions:"

PRINT " Floor Range, Percent (enter END to stop)"

LINE INPUT STORE\$

CALL PARSE (STORE\$, NUMTOKS\#)

CALL CHECK(NUMTOKS\#, O\#, 100\#, 3\#)

IF TOKENS $\$(1)=$ "STOP" THEN EXIT FOR

NEXT I

$\star \star \star \star \star \star \star \star \star \star \star \star ~$
$\star$ MAIN OUTPUT LOOP

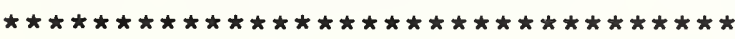

FIRST, CLEAR THE SCREEN. NEXT, EXECUTE THE OUTPUT LOOP UNTIL THE VALUE OF RERUNOUTPUTS IS Y. THE VALUE OF THIS VARIABLE IS 1 ONLY WHEN THE USER WANTS TO PRINT OR STORE THE OUTPUT RESULTS. CLS

Do

IMPORTANT PROGRAM PARAMETERS ARE NOW PRINTED. THESE APPEAR BEFORE THE TABLE OF FLOOR INFORMATION.

PRINT \#1, " "

PRINT \#1, TITLE\$

PRINT \#1, " "

PRINT \#1, USING "People per floor is \#\#\#\#\#. "; PPLEFLR

PRINT \#1, USING "Distance between floors is \#\#\#.\#\#" m"; TYPDIFsi;

PRINT \#1, USING " or \#\#\#.\#\# ft. "; TYPDIF

PRINT \#1, USING "Elevator usage percent is \#\#.\#\#\#"; TYPPERCNT

PRINT \#1, USING "Normal car velocity is \#\#.\#\# $\mathrm{m} / \mathrm{s}$ "; VMAXsi;

PRINT \#1, USING "Or \#\#\#.\#\# fpm."; VMAX * 60 


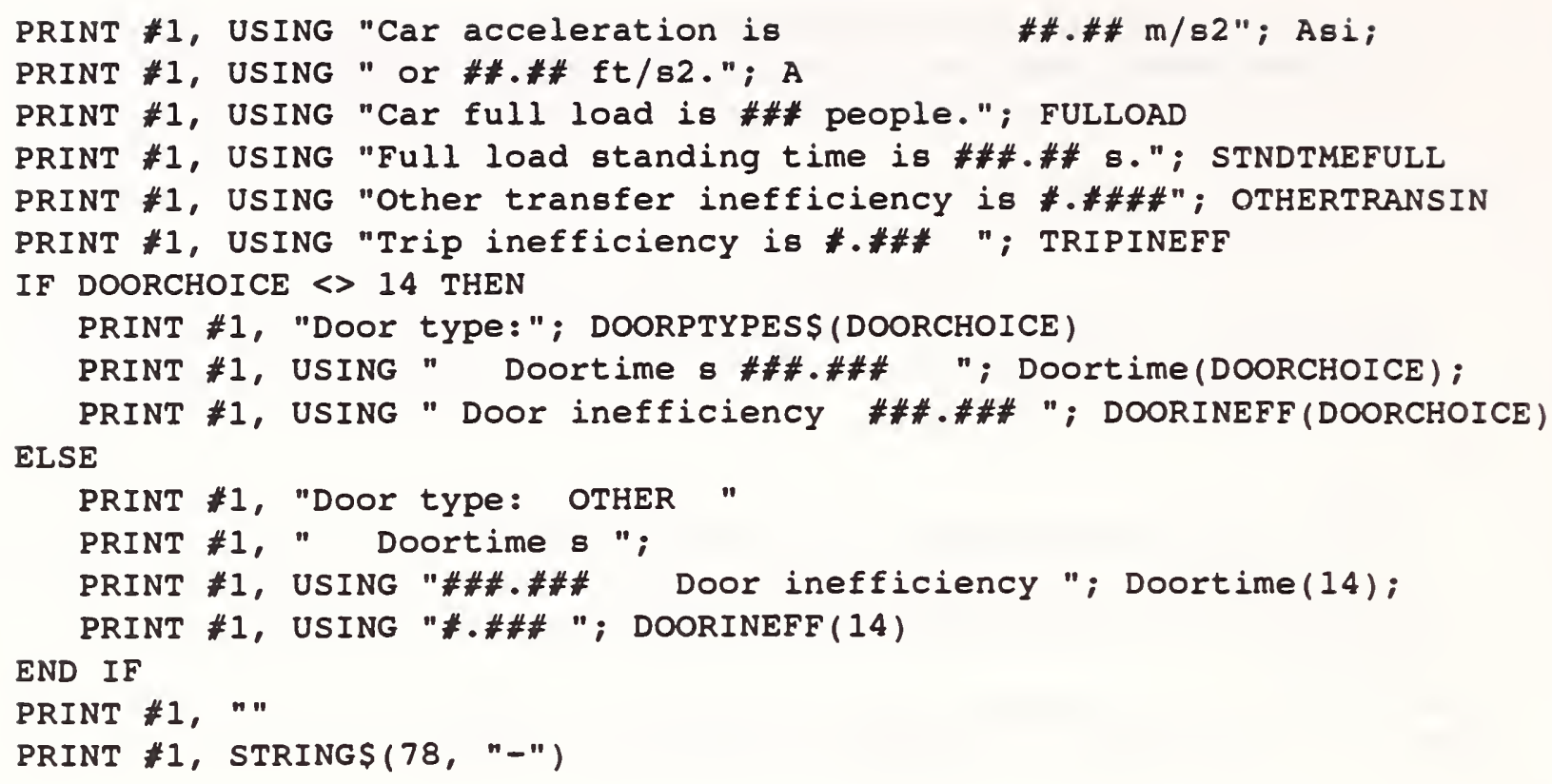

NOW THE VALUES FOR THE OUTPUT TABLE ARE COMPUTED AND PRINTED. THE FIRST ROW CORRESPONDS TO THE TOP FLOOR OF THE BUILDING, THE NEXT ROW TO THE FLOOR BENEATH THE TOP FLOOR, ETC.

PRINT \#1, MTITLE1S

PRINT \#1, MTITLE2\$

PRINT \#1, MTITLE3\$

PRINT \#1, STRING $\$(78, "-")$

TOTTIME $=0 \#$

FOR I = TOTFLRS TO 1 STEP -1

PPLEI $=$ people $(I) \star$ PERCNT(I) *.01*

IF INT(PPLEI) $>$ PPLEI THEN PPLEI = INT(PPLEI + .5\#) +1

TRIPS = PPLEI / FULLOAD

IF INT(TRIPS) $<$ TRIPS THEN TRIPS $=$ CINT $($ TRIPS + .5\#)

NTRIPSFULL = INT (PPLEI / FULLOAD)

NPPLELAST = PPLEI - NTRIPSFULL * FULLOAD

$\operatorname{RNDTIMES}(I)=2 \#$ * $\operatorname{TIMES}(I)$

IF NTRIPSFULL $=0$ \# THEN

TIMELAST = RNDTIMES $(I)+$ CALCSTAND (NPPLELAST\#)

RNDTIMES $(I)=$ TIMELAST

TIMEFULL $=0$ \#

ELSEIF NTRIPSFULL > O\# AND NPPLELAST $=0$ THEN

TIMELAST $=0 \#$

RNDTIMES $(I)=\operatorname{RNDTIMES}(I)+$ STNDTMEFULL

TIMEFULL = NTRIPSFULL * RNDTIMES(I)

ELSEIF NTRIPSFULL > O\# AND NPPLELAST > O\# THEN

TIMELAST = RNDTIMES(I) + CALCSTAND (NPPLELAST\#)

RNDTIMES(I) = RNDTIMES(I) + STNDTMEFULI

TIMEFULL = NTRIPSFULL * RNDTIMES $(I)$

END IF

IF PPLEI $=0$ \# THEN

EXITIMEFLRI $=0$ \#

ELSE

EXITIMEFLRI = TIMEFULL + TIMELAST

END IF

PRINT \#1, USING " $\backslash \backslash "$; FLRNAMES\$(I); 


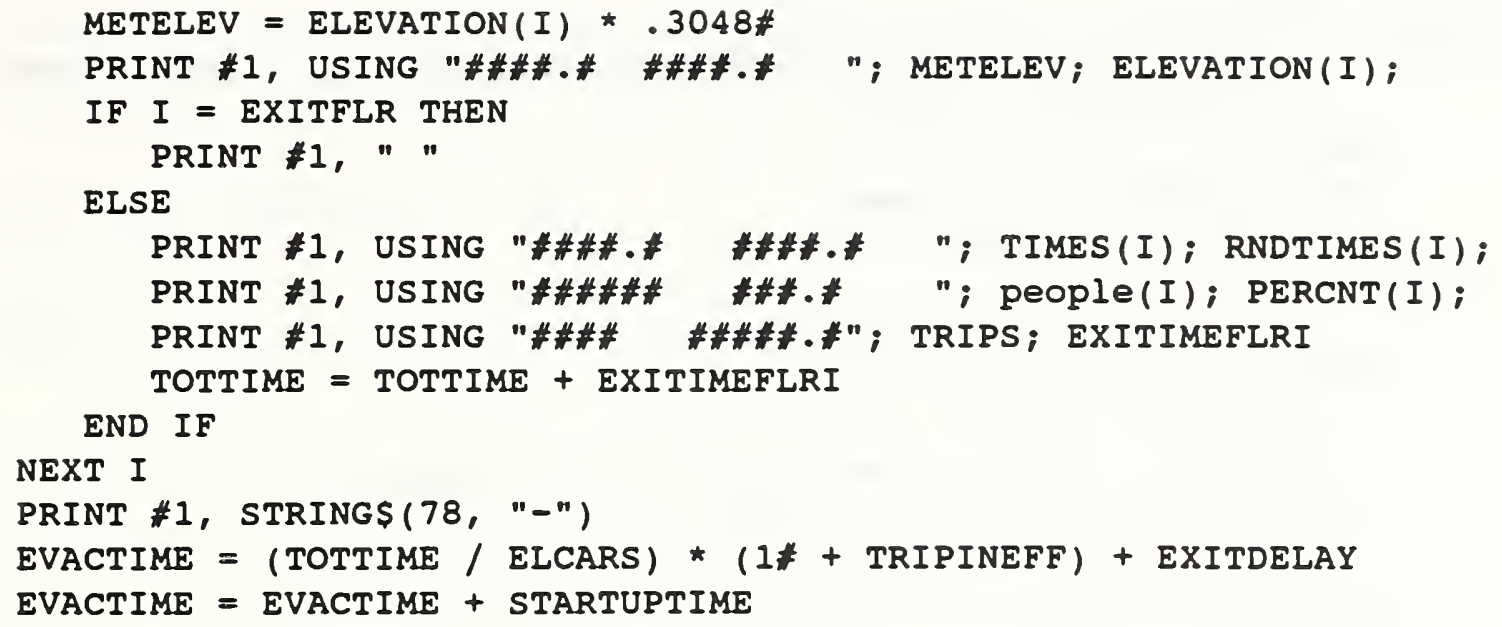

THE TOTAL BUILDING EVACUATION TIME NOW APPEARS.

PRINT \#1, STRING\$(43," ");

PRINT \#1, "Total round trip time=";

PRINT \#1, USING " \#\#\#\#\#\#."; TOTTIME

PRINT \#1, STRINGS(51, " ");

PRINT \#1, "Start up time=";

PRINT \#1, USING " \#\#\#.\#"; STARTUPTIME

PRINT \#1, STRINGS(11," ");

PRINT \#1, "Time to get to the outside after leaving the elevator=";

PRINT \#1, USING " \#\#\#"; EXITDELAY

PRINT \#1, STRING\$(30," ");

PRINT \#1, USING "Evacuation time using \# elevators="; ELCARS;

PRINT \#1, USING " \#\#\#\#\#.\#"; EVACTIME

PRINT \#1, STRING\$(53," ");

PRINT \#1, USING "(or \#\#\#\#.\# minutes)"; EVACTIME / 60

DETERMINE IF THE PROGRAM USER WISHES TO SAVE THE OUTPUT SHOWN ON THE SCREEN. IF THIS IS THE CASE, THE OUTPUT LOOP IS RERUN. THE USER MAY PRINT THE OUTPUT, SEND IT TO A FILE, OR DO BOTH.

PRINT " "

IF PATHSEL $\$$ = "SCRN:" THEN ELSE

INPUT "Do you want to save the output ( $Y$ or $N$ )? ", RERUNOUTPUTS

END IF

RERUNOUTPUTS = UCASE\$ (RERUNOUTPUT\$)

IF RERUNOUTPUTS = "Y" THEN

DO

OPTIONERRORS = "NO"

PRINT " "

PRINT " The options for saving the output now follow.

PRINT " Enter a number corresponding to one of the following:

PRINT " 1. Send the output to the printer.

PRINT " 2. Store the output in a file.

PRINT " "

INPUT "Output option? ", OUTPUTOPTION

IF OUTPUTOPTION < 1 OR OUTPUTOPTION > 2 THEN 




DETERMINE IF THE USER WISHES TO RERUN THE PROGRAM WITH NEW ELEVATOR USAGE PERCENTAGES.

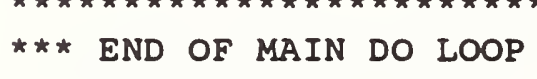


INPUT "Do you wish to rerun the entire program ( $Y$ or $N$ )? ", RERUNPROG\$ RERUNPROG\$ = UCASE\$ (RERUNPROG\$)

CLOSE \#1

LOOP UNTIL RERUNPROG $\$=" N "$

END

F U N C T I O N C A L C S T A N D

THIS FUNCTION COMPUTES THE STANDING TIME PORTION OF AN ELEVATOR'S

TRIP. IT IS DEFINED AS FOLLOWS:

STANDING TIME $=(1+$ TOTINEFF $) *(2 *$ DOORTIME+LOADING TIME+UNLOADING TIME)

LOCAI VARIABLES:

LOADTIME TIME (s) TO LOAD AN ELEVATOR CAR.

PEOP\# NUMBER OF PEOPLE FOR WHICH THE STANDING TIME IS COMPUTED.

OVER6FACT EXTRA TIME REQUIRED WHEN PEOP\# IS OVER 6.

UNLOADTIME TIME (s) TO UNLOAD AN ELEVATOR CAR AT THE EXIT FLOOR.

GLOBAL VARIABLES:

DRTIME TIME (S) REQUIRED FOR THE OPENING AND CLOSING OF THE ELEVATOR CAR DOOR.

TOTINEFF TOTAL TRANSFER INEFFICIENCY.

FUNCTION CALCSTAND\# (PEOP\#)

OVER6FACT $=0$

IF PEOP\# > 6\# THEN OVER6FACT $=.6 \# *($ PEOP\# -6 )

IF PEOP\# <= 2\# THEN LOADTIME = 2\# ELSE LOADTIME = PEOP\#

UNLOADTIME $=4 \#+$ OVER6FACT

CALCSTAND\# = $(1 \#+$ TOTINEFF $) *(2 \#$ * DRTIME + LOADTIME + UNLOADTIME $)$

END FUNCTION

$S$ U B R O U T I N E C H E C K

THIS SUBROUTINE CHECKS HEIGHT, PEOPLE PER FLOOR, AND ELEVATOR USAGE PER FLOOR EXCEPTIONS. THESE EXCEPTIONS ARE ENTERED IN THE FORM nm,val, WHERE nm IS A FLOOR NAME AND val IS AN EXCEPTION VALUE. THE STRING VALUE "END" STOPS EXCEPTION INPUT FOR EACH OF THE THREE CATEGORIES OF EXCEPTIONS.

NUMTOK\# ARGUMENTS:

NUMTOK\# NUMBER OF STRINGS FOUND ON THE CURRENT LINE BY THE PARSING ROUTINE. THIS IS PASSED TO CHECK.

LLIMIT\# LOWER LIMIT FOR THE SECOND ITEM ON THE LINE.

UPLIMIT\# UPPER LIMIT FOR THE SECOND ITEM.

ARRPTR\# EITHER 1, 2, OR 3. IT DETERMINES THE ARRAY TO WHICH THE SECOND ITEM IS PASSED. 


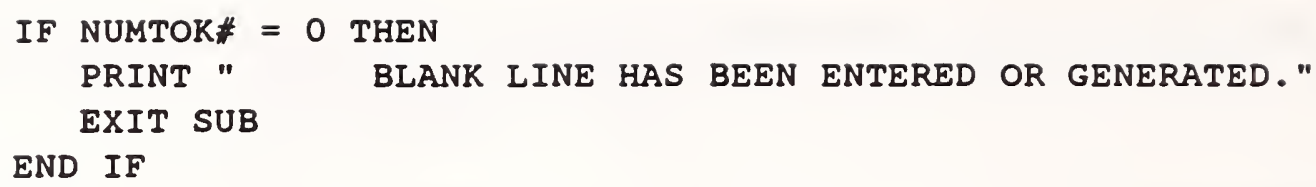

IF THE INFORMATION ON THE LINE IS SUCH THAT NO FURTHER ANALYSIS

IS POSSIBLE, EXIT THE SUBROUTINE. IF THERE IS ONE ITEM, AND IT IS

THE CORRECT END INDICATOR, SET A FLAG TO STOP SUBROUTINE CALLS

FOR THIS TYPE OF EXCEPTION.

IF NUMTOK\# $>2$ THEN

PRINT " MORE THAN TWO ITEMS ON LINE."

EXIT SUB

ELSEIF NUMTOK\# $=2$ AND UCASE $\$$ (TOKENS $\$(1))=$ "END" THEN

PRINT " TWO ITEMS ON LINE, BUT FIRST ONE IS THE END INDICATOR." EXIT SUB

ELSEIF NUMTOK\# = 1 AND UCASE $\$(T O K E N S \$(1))=" E N D "$ THEN TOKENS $\$(1)=$ "STOP"

EXIT SUB

ELSEIF NUMTOK\# = 1 AND UCASE\$(TOKENS\$(1)) <> "END" THEN

PRINT " ONE ITEM ON LINE, NOT CORRECT END INDICATOR."

EXIT SUB

END IF

THE FIRST ITEM ON THE LINE SHOULD BE THE FLOOR NAME OR RANGE. CHECK TO SEE IF IT MATCHES A NAME THAT HAS BEEN PREVIOUSLY SPECIFIED. THE RANGE EXPANSION SUBROUTINE IS CALLED TO CHECK THE FLOOR RANGE SPECIFIED. IF THE VALUE OF EXPECP IS 0 , THE RANGE WAS EXPANDED. IF 1, THE RANGE COULD NOT BE EXPANDED DUE TO CERTAIN ERRORS FOUND IN ITS COMPONENTS. IF IT IS 2, THE FLOOR NAME IS A SINGLE ITEM. CALL RANGEEXP(TOKENS\$(1), FLRSUB1, FLRSUB2, FLREXCP1\$, FLREXCP2\$, EXPECP)

PRINT OUT AN ERROR MESSAGE IF ONE OR MORE OF THE NAMES IN THE FLOOR RANGE COULD NOT BE FOUND IN THE FLOOR NAME TABLE.

IF FLRSUB $1=0$ AND EXPECP $=0$ THEN PRINT " FLOOR NAME "; FLREXCP1\$; " NOT FOUND."

PRINT " VALID NAMES- "; FLOORS\$

END IF

IF FLRSUB2 $=0$ AND EXPECP $=0$ THEN

PRINT " SECOND FLOOR NAME "; FLREXCP2\$; " NOT FOUND."

PRINT " VALID NAMES- "; FLOORS $\$$

END IF

IF FLRSUB $1=0$ AND EXPECP $=2$ THEN

PRINT " FLOOR NAME "; FLREXCP1\$; " NOT FOUND."

PRINT " VALID NAMES- "; FLOORS\$

END IF

ERRFLAG $=0$

DETERMINE IF THE SECOND ITEM IS A VALID NUMBER.

FOR I $=1$ TO LEN(TOKENS\$(2))

$\operatorname{PTR} \$=\operatorname{MID} \$(\operatorname{TOKENS} \$(2), I, 1)$

IF INSTR(".0123456789", PTR\$) = 0 THEN

PRINT " INVALID NUMBER AFTER FLOOR NAME."

ERRFLAG $=1$ 


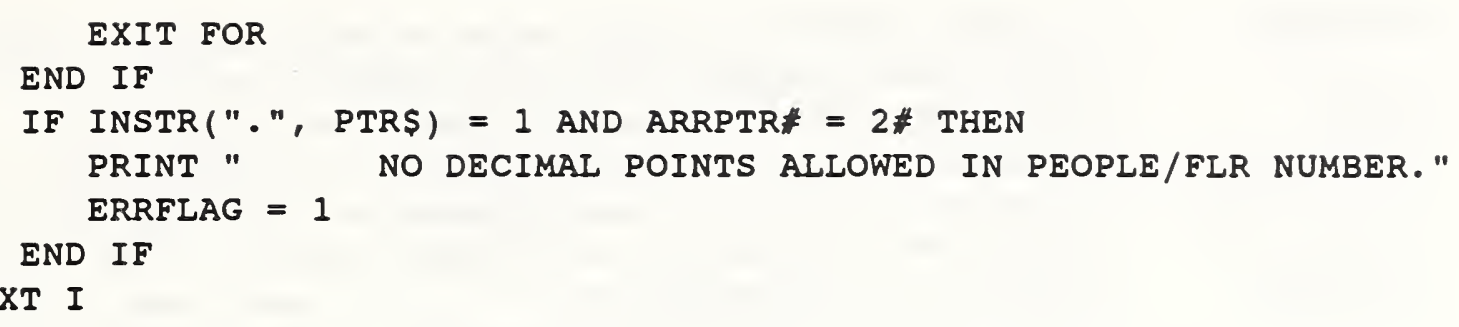

IF THE ITEM IS A VAIID NUMBER, DETERMINE IF IT IIES BETWEEN THE LOWER AND UPPER LIMITS.

IF ERRFLAG $=0$ THEN

NUMB $=$ VAL $($ TOKENS $\$(2))$

IF NUMB < LLIMIT\# OR NUMB > UPLIMIT\# THEN

PRINT " NUMBER AFTER FLOOR NAME IS OUT OF RANGE."

ERRFLAG $=1$

END IF

END IF

IF ANY ERRORS HAVE BEEN DETECTED, LEAVE THE SUBROUTINE.

IF ERRFLAG $=1$ THEN EXIT SUB

SET THE APPROPRIATE ARRAY ROW(S) TO THE VALUE OF THE EXCEPTION. FOR I = FLRSUB1 TO FLRSUB2

IF ARRPTR\# $=1 \#$ AND UNITS $=1 \operatorname{THEN~HGTDIF(I)~}=\operatorname{NUMB} *(1 / .3048 \#)$

IF ARRPTR\# = 1\# AND UNITS $=2 \operatorname{THEN~} \operatorname{HGTDIF}(I)=$ NUMB

IF ARRPTR\# $=2$ \# THEN people(I) $=$ NUMB

IF ARRPTR\# = 3\# THEN PERCNT(I) $=$ NUMB

NEXT I

END SUB

$S$ U B R O U T I N E HE I G H T S

THIS SUBROUTINE FIRST CALLS THE PARSING ROUTINE TO ISOLATE ALL FLOOR NAMES IN THE FLOOR NAME LINE INPUT BY THE USER. IT CHECKS FOR SITUATIONS WHICH MAKE FURTHER ANALYSIS IMPOSSIBLE. IT THEN EXAMINES ALL FLOOR NAMES WHICH CONTAIN THE CHARACTER "-". THESE ARE TERMED RANGES (such as $2-10$ is the range of floors from 2 through 10). ANY RANGES FOUND ARE EXAMINED CAREFULIY FOR POSSIBLE AMBIGUITIES, INVALID NUMBERS, ETC. IF NO ERRORS ARE DETECTED, ANY RANGES THAT HAVE BEEN FOUND ARE EXPANDED. NEXT, THE SUBROUTINE PROMPTS THE USER FOR HEIGHT EXCEPTIONS. AFTER THESE HAVE BEEN ENTERED THE ELEVATIONS ARE COMPUTED AND THE SUBROUTINE IS EXITTED.

LOCAL VARIABLES, AND GLOBAL VARIABLES CHANGED HERE:

CURTOKS CONTAINS STRING VALUE BEING TESTED AS A POSSIBLE RANGE.

ELEMENT NUMBER OF SUBSTRINGS FOUND ON THE FLOOR NAME LINE.

ELEVATION(I) ELEVATION OF Ith FLOOR ABOVE LOWEST FLOOR.

FLOORS\$ INITIALLY CONTAINS THE FLOOR NAME LINE INPUT BY THE USER, THEN IT IS COMPRESSED TO REMOVE EXTRA BLANKS.

FLRNAMESS(I) ARRAY CONTAINING THE FLOOR NAMES AFTER RANGE EXPANSION. HGTDIF(I) ARRAY WHOSE Ith ROW IS THE HEIGHT DIFFERENCE BETWEEN FLOOR I AND FLOOR I+1, WHERE THE LOWEST FLOOR IS 1. 
KILLEXP IF THIS IS SET TO 1, THE MAIN PROGRAM KEEPS ON PROMPTING THE USER FOR A NEW FLOOR NAME LINE.

PTR COUNTER USED WHEN FLRNAMES\$ ARRAY IS CREATED.

RANGE1\$(I) CONTAINS THE FIRST RANGE VALUE OF Ith RANGE FOUND. FOR

EXAMPLE, IF THE 4th RANGE FOUND IS 7-10, RANGE1\$(4)="7"

RANGE2\$(I) SIMILAR TO RANGE1\$(I), BUT STORES SECOND RANGE VALUES.

RANGEMK LOCATION OF THE CHARACTER "-" IN A SUBSTRING. IF IT IS NOT 0 , THE SUBSTRING IS ASSUMED TO BE A RANGE.

STORE\$ CONTAINS THE HEIGHT EXCEPTION LINE.

TOTFLRS SET EQUAL TO THE TOTAL NUMBER OF FLOORS FOUND AFTER EXPANSION .

TYPDIF TYPICAL FLOOR TO FLOOR HEIGHT. CAN BE OVERRIDDEN BY HEIGHT EXCEPTIONS FOR INDIVIDUAL FLOORS.

SUB HEIGHTS

DIM RANGE1\$(200), RANGE2\$(200)

KILLEXP $=0$

PARSE THE LINE OF FLOOR NAMES.

CALL PARSE (FLOORS\$, NUMTOK\#)

ELEMENT $=$ NUMTOK\#

IF NO ITEMS ARE FOUND ON THE FLOOR NAME LINE, PRINT ERROR MESSAGE AND EXIT SUBROUTINE.

IF ELEMENT $=0$ THEN

PRINT " "

PRINT " BLANK LINE HAS BEEN ENTERED OR GENERATED."

KILLEXP $=1$

EXIT SUB

END IF

IF ONE ITEM IS FOUND, AND IT IS NOT A RANGE, THEN ONLY ONE FLOOR NAME HAS BEEN INPUT.

IF ELEMENT $=1$ AND INSTR(TOKENS $(1), n-n)=0$ THEN

PRINT " "

PRINT " ONLY ONE FLOOR IS GIVEN."

KILLEXP $=1$

EXIT SUB

END IF

FLOORS $\$="$ "

CHECK EACH SUBSTRING TO SEE IF IT IS A RANGE. IF SO, TEST FOR COMMON ERROR SITUATIONS. PRINT " "

FOR I $=1$ TO ELEMENT

CURTOKS $=$ TOKENS $\$(I)$

CALL RANGEEXP(CURTOKS, SUBS1, SUBS2, FLRVAL1\$, FLRVAL2\$, EXPRANGE)

IF EXPRANGE $=1$ THEN

KILLEXP $=1$

ELSEIF EXPRANGE $=2$ THEN 


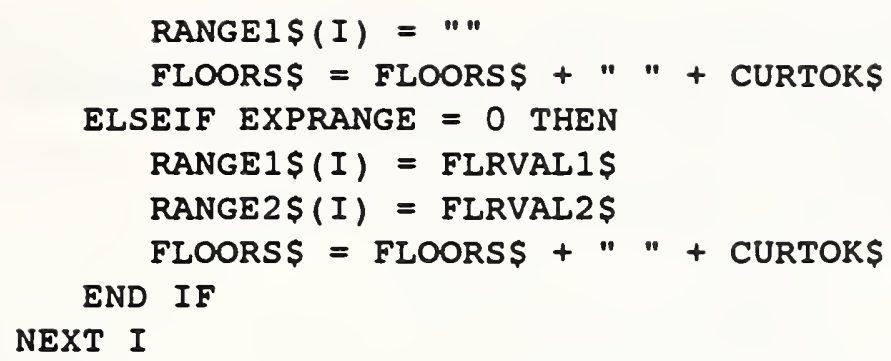

READ IN THE TYPICAL FLOOR TO FLOOR HEIGHT AND THEN THE HEIGHT EXCEPTIONS.

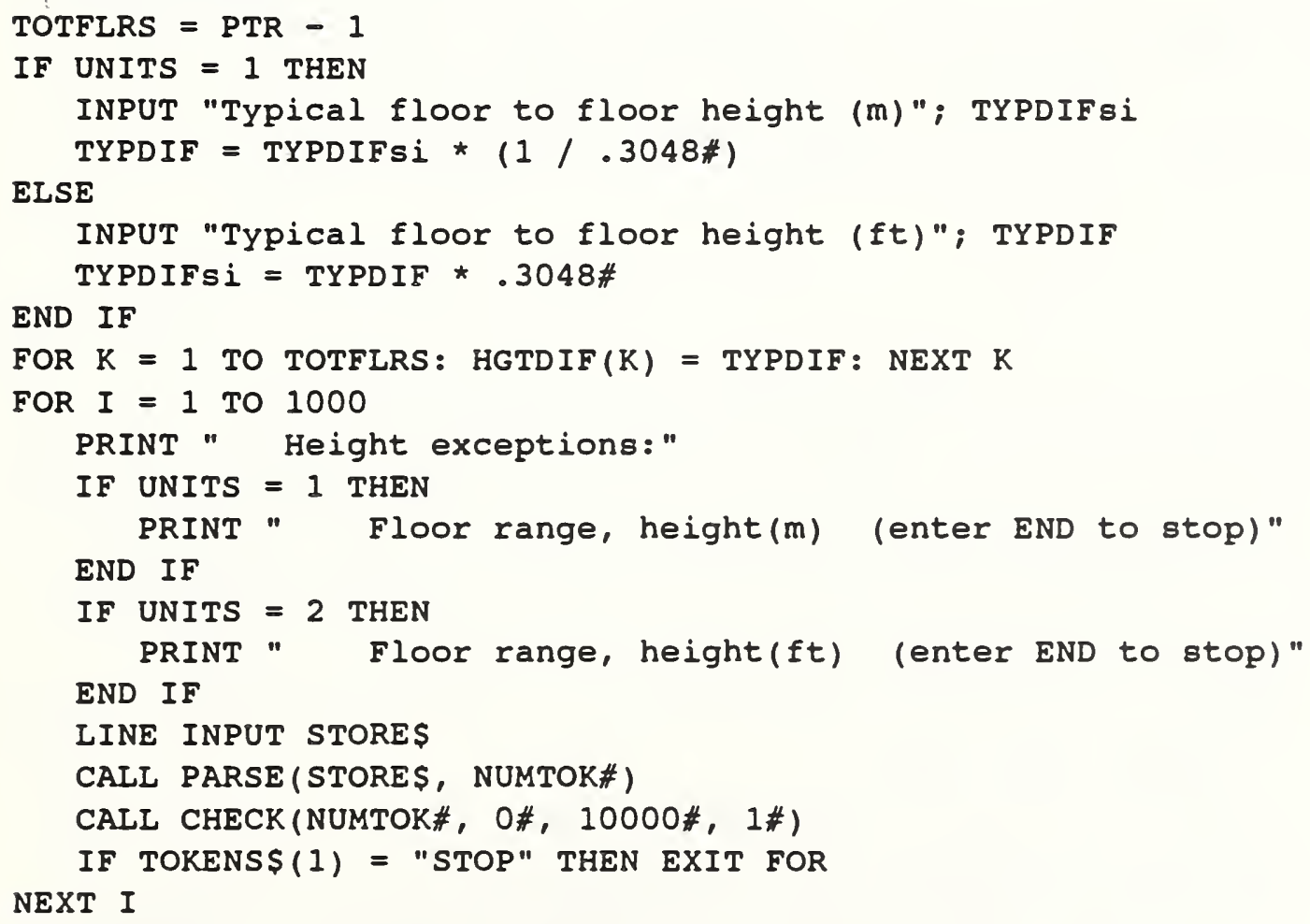


COMPUTE THE ELEVATIONS OF EACH FLOOR, STARTING FROM THE LOWEST ONE. ELEVATION (1) $=0$

FOR I $=2$ TO TOTFLRS + 1

NEXT I

ELEVATION $(I)=\operatorname{ELEVATION}(I-1)+\operatorname{HGTDIF}(I-1)$

END SUB

$S U B R O U T I N E$ P A R S E

THIS SUBROUTINE IS PASSED THE STRING STORE\$, CHANGES ANY COMMAS TO BLANKS, ISOLATES ALL SUBSTRINGS SEPARATED BY BLANKS WITHIN THE STRING, AND COUNTS THEM. THE ARGUMENT NUMTOK\# IS SET TO THE COUNTED NUMBER. THE PARSING METHOD DESTROYS ALL SUBSTRINGS WITHIN STORES EXCEPT FOR THE RIGHTMOST ONE.

SUB PARSE (STORE\$, NUMTOK\#)

FOR COL $=1$ TO LEN(STORE\$)

IF MIDS(STORE\$, COL, 1$)=", " \operatorname{THEN} \operatorname{MID} \$(\operatorname{STORE} \$, \operatorname{COL}, 1)="$ " NEXT COL

STORE\$ = RTRIMS (STORE\$)

FOR I $=1$ TO 200

STORE\$ = LTRIMS(STORE\$)

NEXTBLNK = INSTR(STORES, " ")

IF NEXTBLNK $=0$ THEN

TOKENS\$ $(I)=$ STORE $\$$

EXIT FOR

END IF

TOKENS\$(I) = MID\$(STORE\$, 1, NEXTBLNK - 1)

$\operatorname{MID}$ (STORE\$, 1, NEXTBLNK - 1) = STRING $(100, "$ ") NEXT I

IF LEN(STORE\$) $>0$ THEN NUMTOK\# = I: ELSE NUMTOK\# = 0

END SUB

$S U B R O U$ T I N E R A N G E E X P

THIS SUBROUTINE IS PASSED A FLOOR NAME OR FLOOR RANGE. IF IT IS PASSED A RANGE, IT CHECKS THE TWO PARTS OF THE RANGE FOR VARIOUS ERROR SITUATIONS, ISOLATES THE FIRST AND SECOND PART OF THE RANGE, AND FINDS THE LOCATIONS OF THE FLOOR NAMES WITHIN THE FLOOR NAME TABLE.

ARGUMENTS :

EXPEXCP AN OUTPUT PARAMETER. ITS VALUE IS O IF THE FLOOR ITEM IS A VALID RANGE, 1 IF IT IS AN INVALID RANGE, AND 2 IF THE FLOOR ITEM IS A SINGLE FLOOR NAME.

FLREXCP1\$ AN OUTPUT PARAMETER. THE VALUE OF THE FIRST ITEM IN THE RANGE, OR THE ONLY ITEM IF THERE IS NO RANGE.

FLREXCP2\$ AN OUTPUT PARAMETER. THE VALUE OF THE SECOND ITEM IN THE RANGE, OR THE ONLY ITEM IF THERE IS NO RANGE. 
FLRSTRS THE CHARACTER STRING PASSED TO THIS SUBROUTINE.

FLRSUB1 THE LOCATION OF THE FIRST FLOOR NAME WITHIN THE FLOOR NAME TABLE, OR O IF THE NAME IS NOT A VALID FLOOR NAME.

FLRSUB2 THE LOCATION OF THE SECOND FLOOR NAME WITHIN THE FLOOR NAME TABLE, OR O IF THE NAME IS NOT A VALID FLOOR NAME.

IMPORTANT VARIABLES:

CURTOKS CONTAINS THE STRING PASSED TO THE SUBROUTINE.

RANGEMK THE LOCATION OF A DASH WITHIN THE FLOOR RANGE.

TEMPRANGEIS STORES THE FIRST PART OF THE RANGE.

TEMPRANGE2\$ STORES THE SECOND PART OF THE RANGE.

SUB RANGEEXP (FLRSTR\$, FLRSUB1, FLRSUB2, FLREXCP1\$, FLREXCP $2 \$$, EXPEXCP)

INITIALIZE SOME OF THE OUTPUT PARAMETERS.

EXPEXCP $=0$

FLRSUBI $=0$

FLRSUB2 $=0$

CHECK THE SUBSTRING TO SEE IF IT IS A RANGE. IF SO, TEST FOR COMMON ERROR SITUATIONS.

IF FLRNAMESS(1) $<$ " " THEN PRINT " "

CURTOK\$ = FLRSTRS

RANGEMK = INSTR (CURTOK\$, "-")

IF RANGEMK = 0 THEN

TEMPRANGE1S = " "

ELSEIF RANGEMK = 1 OR RANGEMK = LEN (CURTOK\$) THEN

PRINT " MISPLACED DASH - NO RANGE EXPANSION PERFORMED. "; CURTOKS

EXPEXCP $=1$

ELSEIF RANGEMK $\gg 0$ THEN

TEMPRANGE $1 \$$ = MID\$ (CURTOK\$, 1, RANGEMK - 1)

TEMPRANGE2\$ = MID\$(CURTOK\$, RANGEMK + 1, LEN(CURTOK\$))

FOR $J=1$ TO LEN (TEMPRANGEI\$)

IF INSTR("0123456789", MID\$(TEMPRANGE1\$, J, 1)) = 0 THEN

PRINT " INCORRECT 1ST RANGE IN "; CURTOKS; ", POS "; J

EXPEXCP $=1$

END IF

NEXT $J$

FOR $J=1$ TO LEN (TEMPRANGE2\$)

IF INSTR("0123456789", MID\$(TEMPRANGE2\$, J, 1)) = 0 THEN

PRINT " INCORRECT 2ND RANGE IN "; CURTOKS; ", POS "; J EXPEXCP $=1$

END IF

NEXT J

IF EXPEXCP = 0 AND VAL (TEMPRANGE 1\$) >= VAL(TEMPRANGE2\$) THEN

PRINT " IST RANGE IS NOT LESS THAN 2ND RANGE IN "; CURTOKS

EXPEXCP $=1$

END IF

END IF

IF ERRORS HAVE BEEN DETECTED, EXIT SUBROUTINE

IF EXPEXCP $=1$ THEN EXIT SUB 
IF THE STRING IS A SINGLE NAME, THEN SET BOTH TEMPORARY RANGES TO IT.

IF TEMPRANGE $1 S="$ THEN

TEMPRANGE1S = CURTOKS

TEMPRANGE2 $\$=$ CURTOK\$

EXPEXCP $=2$

END IF

PERFORM THE FOLLOWING SECTION ONLY WHEN THE FLOOR NAMES ARRAY

HAS ALREADY BEN CREATED.

IF NO ERRORS HAVE BEEN FOUND, FIND THE LOCATION OF THE FLOOR NAMES

WITHIN THE FLOOR NAMES ARRAY (IF THE PASSED VALUE IS A RANGE),

IF FLRNAMES\$ $(1)<>$ " THEN

FOR $I=1$ TO TOTFLRS

IF TEMPRANGE1\$ = FLRNAMES $\$(I)$ THEN FLRSUBI = I

IF TEMPRANGE2\$ = FLRNAMES\$(I) THEN FLRSUB2 = I

NEXT I

END IF

IF NO ERRORS HAVE BEEN FOUND, AND THE PASSED VALUE IS A SINGLE NAME, THEN FIND ITS LOCATION WITHIN THE FLOOR NAMES ARRAY.

IF FLRNAMES\$(1) $<>"$ THEN

FOR I $=1$ TO TOTFLRS

IF TEMPRANGE $1 \$=$ FLRNAMES\$ $(I)$ THEN FLRSUB $1=I$

NEXT I

END IF

FLREXCP1\$ = TEMPRANGE1\$

FLREXCP2\$ = TEMPRANGE $2 \$$

END SUB

$S$ U B R O U T I N E T R I P T I M E

SUBROUTINE TRIPTIME COMPUTES THE TRAVEL TIME FROM THE DESIGNATED

EXIT FLOOR TO EACH OF THE OTHER FLOORS IN THE BUILDING. THE COMPUTED

TIME IS FOR ONE WAY TRAVEL ONLY. THERE ARE THREE MAIN SITUATIONS WHICH CAN OCCUR. THESE ARE:

CASE 1 - DISTANCE TO BE TRAVELLED IS SUCH THAT LINEAR ACCELERATION IS MAINTAINED. THIS OCCURS WHEN DISTANCE IS SMALL.

CASE 2 - DISTANCE TO BE TRAVELLED IS SLIGHTLY GREATER. NON-LINEAR, OR TRANSITIONAL, ACCELERATION IS REACHED.

CASE 3 - DISTANCE IS GREAT ENOUGH THAT MAXIMUM ELEVATOR CAR VELOCITY IS REACHED. THIS IS THE CONSTANT VELOCITY CASE.

A

LEVELTME

S1

s2

ST
VARIABLES :

ACCELERATION RATE OF ELEVATOR CAR.

LEVELING TIME ( $S$ ).

DISTANCE REQUIRED FOR ELEVATOR CAR TO REACH VELOCITY V1. DISTANCE CAR REQUIRES TO REACH VMAX (MAXIMUM VELOCITY), ACTUAL DISTANCE BETWEEN EXIT FLOOR AND FLOOR FOR WHICH THE TRIPTIME IS BEING COMPUTED. 
T1

T2

T2CASE2

T5

TIMES ( I )

TOTFLRS

TRANS

TT

V2

VCUBED

V1

VMAX
TIME (s) FOR ELEVATOR CAR TO TRAVEL A DISTANCE OF $S 1$. TIME (s) FOR CAR TO ATTAIN VMAX.

TIME (s) FOR CAR TO ATTAIN MAXIMUM VELOCITY IN CASE 2. TIME (S) FOR ELEVATOR CAR TO TRAVEL THE DISTANCE ST,

IN CASE 3, NOT INCLUDING LEVELING TIME. ONE WAY TRIP TIMES COMPUTED FOR EACH FLOOR. TOTAL NUMBER OF FLOORS.

TRANSITIONAL COEFFICIENT. VI=TRANS * VMAX. ONE WAY TRIP TIME FOR THE CURRENT FLOOR.

MAXIMUM VELOCITY OF ELEVATOR CAR ATTAINED IN CASE 2. $V * \star 3$, WHERE V IS AS DEFINED ABOVE.

MAXIMUM ELEVATOR CAR VELOCITY TIMES THE TRANSITIONAL COEFFICIENT. MAXIMUM CAR VELOCITY, SPECIFIED BY THE USER.

\section{SUB TRIPTIME}

COMPUTE V1, S1, S2, T1, T2. ONLY PERFORMED ONCE.

$\mathrm{V} 1=$ TRANS * VMAX

$S 1=V 1 \wedge 2 \# /(2 \# * A)$

$S 2=(1 \# /(3 \# * A)) *(\operatorname{VMAX} \wedge 3 \# / \mathrm{V} 1-\mathrm{V} 1 \wedge 2 \#)+S 1$

$\mathrm{T} 1=\mathrm{V} 1 / \mathrm{A}$

$\mathrm{T} 2=((\operatorname{VMAX} \wedge 2 \#-\mathrm{V} 1 * \mathrm{~V} 1) /(2 \# * A * \mathrm{~V} 1))+\mathrm{T} 1$

PRINT " "

PRINT " 2*S1="; 2 *S1

PRINT " $2 \star S 2=" ; 2$ * S2

MAIN LOOP OF THIS SUBROUTINE. FOR EACH FLOOR OF THE BUILDING, THE DISTANCE ST IS COMPUTED. NEXT, THE LOOP DETERMINES IF CASE 1, CASE

2, OR CASE 3 IS THE RELEVANT SITUATION, AND IT THEN PERFORMS THE APPROPRIATE CALCULATIONS.

FOR I $=1$ TO TOTFLRS

$S T=A B S(E L E V A T I O N(I)-\operatorname{ELEVATION}($ EXITFLR))

CASE $10<=S T<2 * S 1$

IF 0 ! $<=S T$ AND ST $<2$ * SI THEN

$T T=2 * \operatorname{SQR}(S T / A)+$ LEVELTME

$\operatorname{TIMES}(I)=T T$

END IF

PRINT " CASE 1 - FLOOR \# "; I

CASE 22 2*S1<=ST<2*S2

IF 2 * S1 <= ST AND ST $<2$ * S2 THEN

VCUBED $=V 1 \star 3+(3 * A * V 1 *((S T / 2 \#)-S 1))$

$\mathrm{V} 2$ = VCUBED $\sim(1 \# / 3 \#)$

$\mathrm{T} 2$ CASE $2=((\mathrm{V} 2 * \mathrm{~V} 2)-(\mathrm{V} 1 * \mathrm{~V} 1)) /(2 * A * \mathrm{~V} 1)+\mathrm{T} 1$

TT $=2$ * T2CASE2 + LEVELTME

$\operatorname{TIMES}(I)=T T$

PRINT " CASE 2 - FLOOR \# "; I

END IF

CASE $3 \quad 2 * S 2<=S T$

IF 2 * S2 $<=S T$ THEN 
$T 5=2 * T 2+(S T-2 * S 2) / \operatorname{VMAX}$

$T T=T 5$ + LEVELTME

$\operatorname{TIMES}(I)=\mathrm{TT}$

PRINT " CASE 3 - FLOOR \#"; I END IF

NEXT I

END SUB 


\section{Appendix D ELVAC Example of an 11 story building}

The example of this appendix was developed to illustrate many of ELVAC's features. ELVAC is an interactive computer program, and Table D. 1 is a listing of all text that appears on the screen during the ELVAC run of this example. Note that in table D. 1 bold type indicates answers typed by the user of ELVAC.

The simulated building has two basement levels, a ground floor, and ten floors above ground level. The typical floor to floor height is $3.7 \mathrm{~m}$ (approximately 12 feet). Exceptions to this are the two basement levels and the ground floor, which are somewhat higher. Also, floors 3-5 are somewhat shorter, and it should be noted that the exceptions for these three floors are input into the program in one line.

There are typically 110 people on each floor, with the exceptions being the two basement levels (with fewer), and floors G and 2-3 (with more). The percent of people on the floors that use elevators to evacuate is typically 85 , with the exception of the two basement levels and floors 2-7, where 3 percent of the people use elevators while the rest use stairways. Note again that only one statement is used to input the percent usage exceptions for floors 2-7.

If the user wants the program will list basic concepts about the model as is done in this example.

Table D.1 Listing of ELVAC Analysis of 11 story building

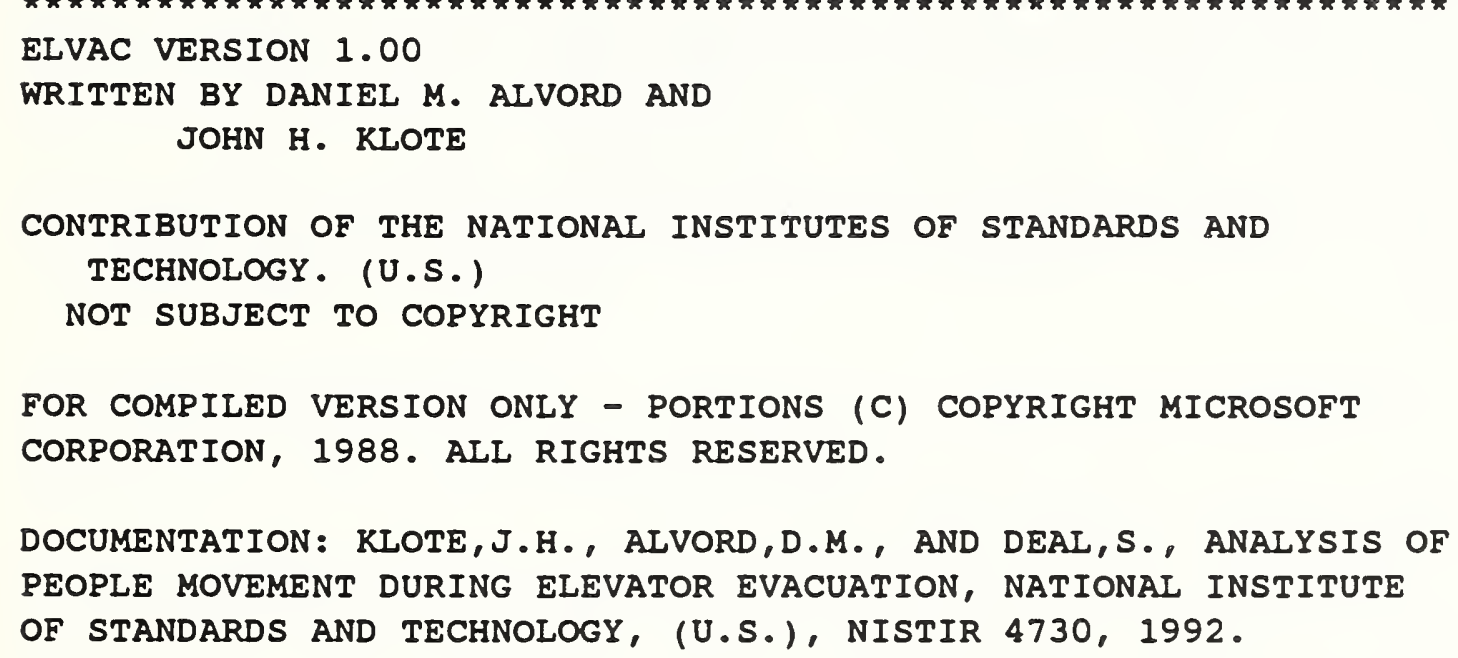




\section{Table D. 1 Cont inued}

arrangements of elevator groups.

Discharge floor- When emergency evacuation starts, elevators will take people to a discharge floor where passengers on the elevators will exit. This floor may lead to the outside or to an area of relative safety. Door inefficiency- Adjusts for any increase in transfer time over that of a $1200 \mathrm{~mm}$ (48 in) wide center opening door.

Press ENTER to continue......

Dwell time- The minimum time an elevator car door remains open. The time used in this program is 4 seconds.

Groups- Elevators are located in groups of up to eight elevators. The elevators in a group are located near each other and are controlled together to move people efficiently.

Elevator evacuation start up time- The time from activation of the alarms(for example) to the start of the round trips that evacuate people. If the elevators are operated automatically during evacuation, one starts the elevator evacuation after all of the elevators have been moved to the discharge floor and the people in them have left. In the case of manual elevator operation, the time for elevators operators to reach the cars must be included. Motion- Elevator motion starts with constant acceleration, followed by transitional acceleration until constant velocity motion at the normal operating velocity of the car is attained.

Press ENTER to continue....

Other transfer inefficiency- accounts for inefficiencies due to unusual elevator car shape or limited physical capability of passengers. In office buildings, a value of 0 is used.

Round trip- a round trip starts at the discharge floor and consists of the sequence: elevator doors close, car travels to another floor, doors open, passengers enter the car, doors close, car travels to discharge floor, doors open, and passengers leave the car. Alternatively, it may be defined as two one way trips and a standing period.

Standing time- Twice the time required to open and close the elevator doors, plus the time for people to enter the elevator, plus the time for people to leave the elevator.

Trip inefficiency- a multiplicative factor that accounts for trips to empty floors and for trips to pick up only a few stragglers. 
Table D. 1 Cont inued

Press ENTER to continue....

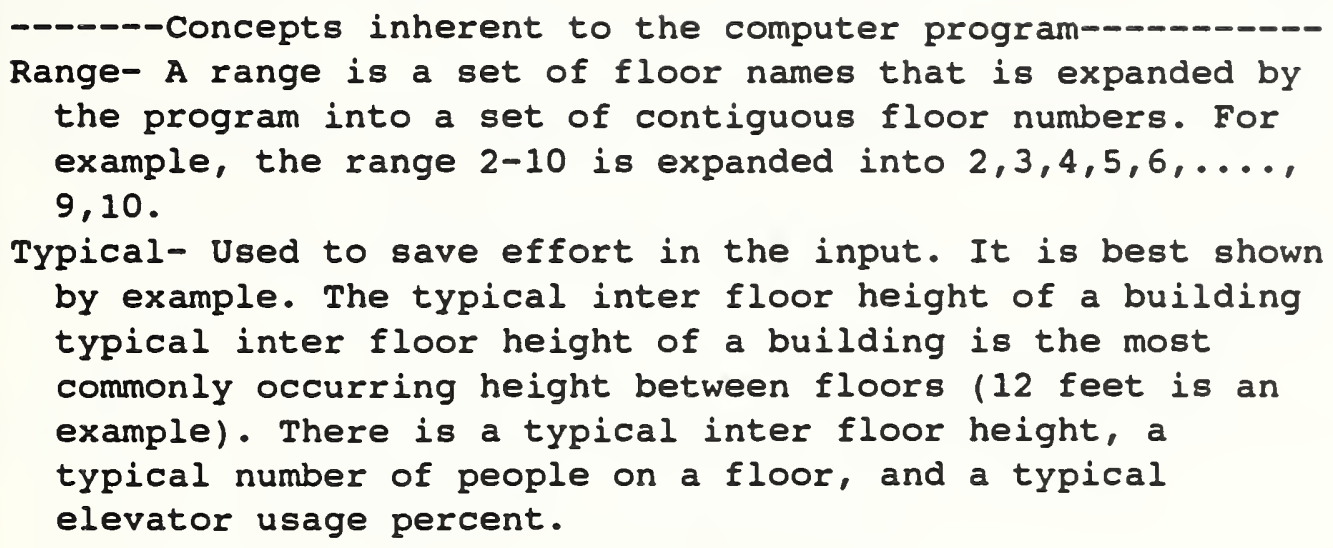

Enter the title of this run.

11 STORY EXAMPLE BUILDING.



G 5.7

Height exceptions:

Floor range, height(m) (enter END to stop)

3-5 3.5

Height exceptions:

Floor range, height(m) (enter END to stop)

END

Discharge floor? G

Time to outside after leaving elevator (s)? 30 


\section{Table D. 1 Cont inued}



\begin{tabular}{|c|c|c|c|c|}
\hline Door type & Door & width & $\begin{array}{l}\text { Time to Open } \\
\text { and close, s }\end{array}$ & $\begin{array}{l}\text { Door Transfer } \\
\text { Inefficiency }\end{array}$ \\
\hline A single-slide & $900 \mathrm{~mm}$ & $(36 \mathrm{in})$ & 6.6 & 0.10 \\
\hline B Two-Speed & $900 \mathrm{~mm}$ & (36in) & 5.9 & 0.10 \\
\hline C Center-Opening & $900 \mathrm{~mm}$ & (36in) & 4.1 & 0.08 \\
\hline D single-slide & $1100 \mathrm{~mm}$ & (42in) & 7.0 & 0.07 \\
\hline E Two-Speed & $1100 \mathrm{~mm}$ & (42 in) & 6.6 & 0.07 \\
\hline F Center-Opening & $1100 \mathrm{~mm}$ & (42 in) & 4.6 & 0.05 \\
\hline G Two-Speed & $1200 \mathrm{~mm}$ & (48in) & 7.7 & 0.02 \\
\hline H Center-Opening & $1200 \mathrm{~mm}$ & (48in) & 5.3 & 0 \\
\hline I Two-Speed & $1400 \mathrm{~mm}$ & (54in) & 8.8 & 0.02 \\
\hline $\mathrm{J}$ Center-Opening & $1400 \mathrm{~mm}$ & (54in) & 6.0 & 0 \\
\hline K Two-Speed & $1600 \mathrm{~mm}$ & (60in) & 9.9 & 0.02 \\
\hline L Center-Opening & $1600 \mathrm{~mm}$ & (60in) & 6.5 & 0 \\
\hline $\begin{array}{l}\text { M Two-speed, } \\
\text { Center-Opening }\end{array}$ & $1600 \mathrm{~mm}$ & (60in) & 6.0 & 0 \\
\hline N OTHER & & & & \\
\hline
\end{tabular}

Other transfer inefficiency? $\quad 0.0$

The startup time for automatically operated elevators is 32.68 seconds.

Do you want to enter another value ( $Y$ or $N)$ ? $N$

Typical Number of People per Floor? 110

People per floor exception:

B2 40

Floor Range, people (enter END to stop)

People per floor exception:

Floor Range, people (enter END to stop)

B1 60

People per floor exception:

Floor Range, people (enter END to stop) 


\section{Table D. 1 Cont inued}

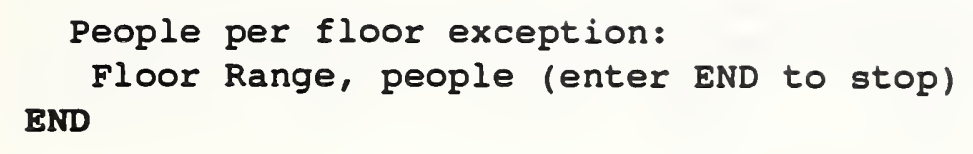

Percent usage exceptions: B2 3

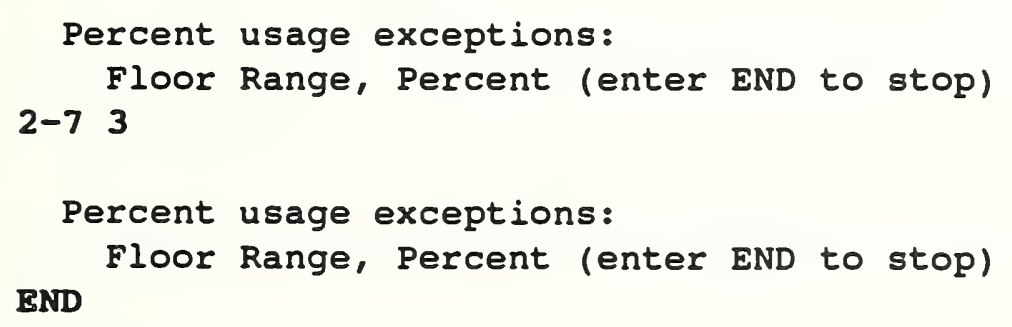

11 STORY EXAMPLE BUILDING.

People per floor is 110 .

Distance between floors is $3.70 \mathrm{~m}$ or $12.14 \mathrm{ft}$.

Elevator usage percent is 85.0008

Normal car velocity is $\quad 3.00 \mathrm{~m} / \mathrm{s}$ or $590.55 \mathrm{fpm}$.

Car acceleration is $\quad 1.20 \mathrm{~m} / \mathrm{s} 2$ or $3.94 \mathrm{ft} / \mathrm{s} 2$.

Car full load is 16 people.

Full load standing time is $40.48 \mathrm{~s}$.

Other transfer inefficiency is 0.0000

Trip inefficiency is 0.100

Door type: F Center-Opening $1100 \mathrm{~mm}$ (42in) wide

Doortimes 4.600 Door inefficiency 0.050

\begin{tabular}{|c|c|c|c|c|c|c|c|c|}
\hline $\begin{array}{l}\text { Floor } \\
\text { Name }\end{array}$ & \multicolumn{2}{|c|}{ Elevation } & $\begin{array}{l}\text { One } \\
\text { Way } \\
\text { Time } \mathrm{s}\end{array}$ & $\begin{array}{l}\text { Round } \\
\text { Trip } \\
\text { Time s }\end{array}$ & $\begin{array}{l}\text { People } \\
\text { on } \\
\text { Floor }\end{array}$ & $\begin{array}{l}\text { Percent } \\
\text { Usage }\end{array}$ & $\begin{array}{l}\text { Round } \\
\text { Trips }\end{array}$ & $\begin{array}{l}\text { Time } \\
\text { per } \\
\text { Floor } \mathbf{s}\end{array}$ \\
\hline 11 & 47.4 & 155.5 & 15.9 & 72.3 & 110 & 85.0 & 6 & 431.7 \\
\hline 10 & 43.7 & 143.4 & 14.7 & 69.8 & 110 & 85.0 & 6 & 416.9 \\
\hline 9 & 40.0 & 131.2 & 13.4 & 67.3 & 110 & 85.0 & 6 & 402.1 \\
\hline 8 & 36.3 & 119.1 & 12.2 & 64.9 & 110 & 85.0 & 6 & 387.3 \\
\hline 7 & 32.6 & 107.0 & 11.0 & 41.7 & 110 & 3.0 & 1 & 41.7 \\
\hline 6 & 28.9 & 94.8 & 9.7 & 39.2 & 110 & 3.0 & 1 & 39.2 \\
\hline 5 & 25.4 & 83.3 & 8.6 & 36.9 & 110 & 3.0 & 1 & 36.9 \\
\hline 4 & 21.9 & 71.9 & 7.4 & 36.9 & 150 & 3.0 & 1 & 36.9 \\
\hline 3 & 18.4 & 60.4 & 6.2 & 34.5 & 150 & 3.0 & 1 & 34.5 \\
\hline 2 & 14.7 & 48.2 & 4.9 & 31.8 & 150 & 3.0 & 1 & 31.8 \\
\hline
\end{tabular}




\section{Table D. 1 Cont inued}

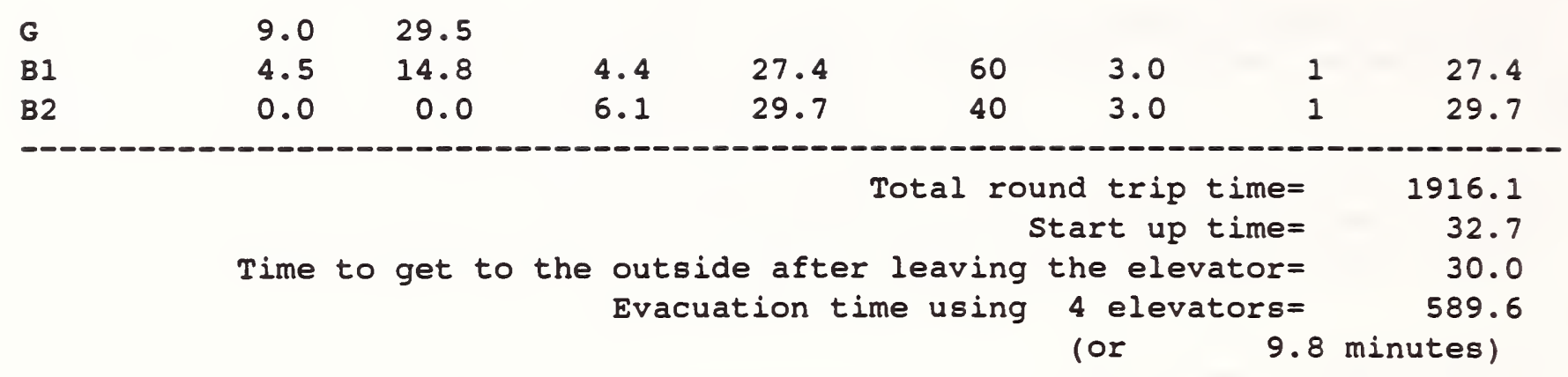

Do you want to save the output ( $Y$ or $N$ )? N

Rerun program with new usage percentages ( $Y$ or $N)$ ?

Do you wish to rerun the entire program ( $Y$ or $N)$ ? $N$ 


\section{Appendix E ELVAC Example of a 21 story building}

This appendix presents the ELVAC analysis of the 21 story example in the paper. ELVAC is an interactive computer program and Table E.1 is a listing of the computer screen during this ELVAC run. Note that in table E.1 bold type indicates answers typed by the user of ELVAC.

\section{Table E.1 Listing of ELVAC Analysis of 21 story Building}

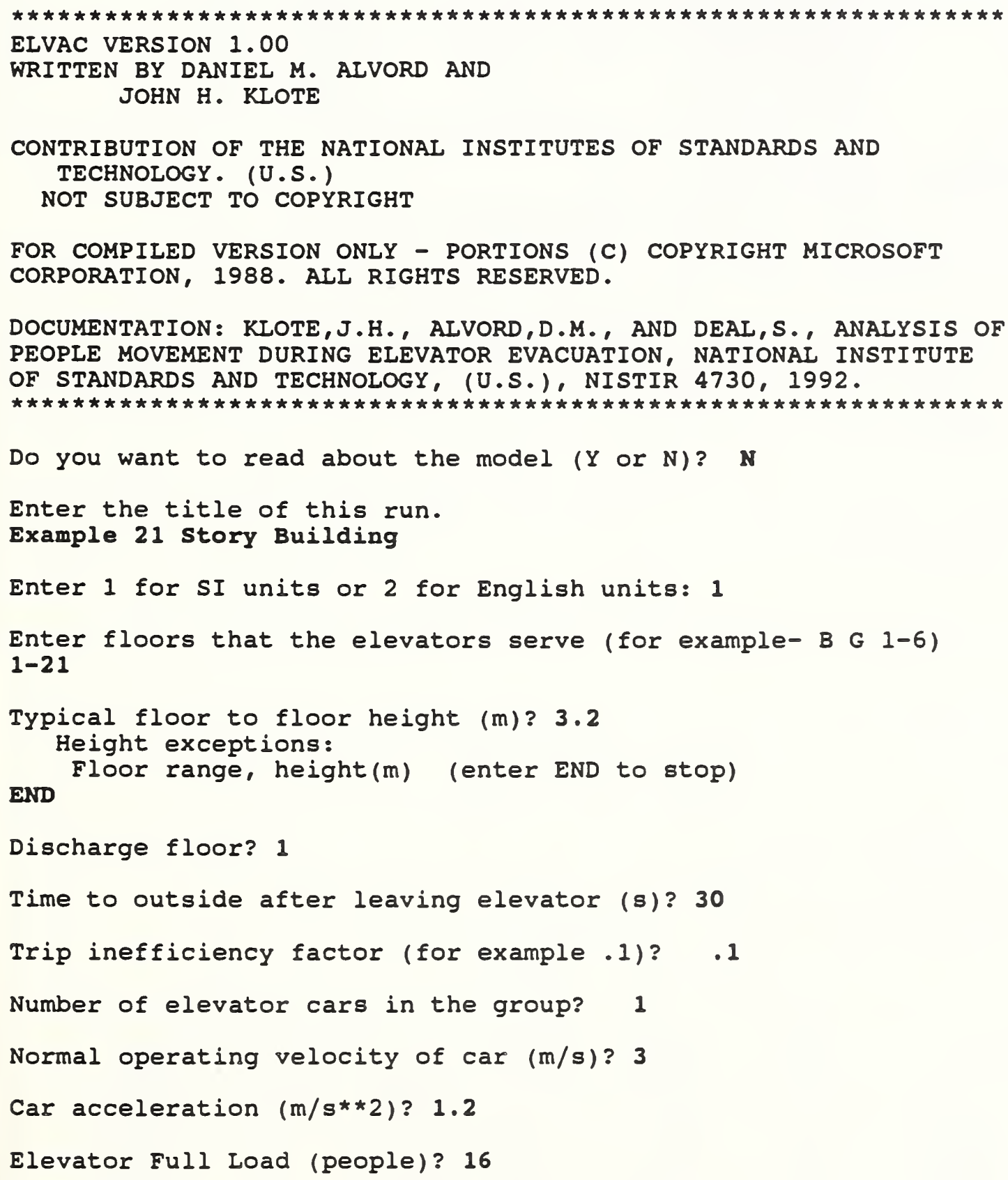


Table E.1 Continued



The startup time for automatically operated elevators is 41.25 seconds. Do you want to enter another value ( $Y$ or $N)$ ? N

Typical Number of People per Floor? 100

People per floor exception: END

Floor Range, people (enter END to stop)

Percent of people on typical floor using elevator? 100
Percent usage exceptions:
Floor Range, Percent (enter END to stop)
END

Example 21 Story Building

People per floor is 100.

Distance between floors is $3.20 \mathrm{~m}$ or $10.50 \mathrm{ft}$.

Elevator usage percent is $100.000 \%$

Normal car velocity is $\quad 3.00 \mathrm{~m} / \mathrm{s}$ or $590.55 \mathrm{fpm}$.

Car acceleration is $1.20 \mathrm{~m} / \mathrm{s} 2$ or $3.94 \mathrm{ft} / \mathrm{s} 2$.

Car full load is 16 people.

Full load standing time is $40.26 \mathrm{~s}$.

Other transfer inefficiency is 0.0000

Trip inefficiency is 0.100

Door type: H Center-opening $1200 \mathrm{~mm}$ (48in) wide

Doortime s 5.300 Door inefficiency 0.000

\begin{tabular}{|c|c|c|c|c|c|c|c|c|}
\hline $\begin{array}{l}\text { Floor } \\
\text { Name }\end{array}$ & $\begin{array}{l}\text { Ele } \\
m\end{array}$ & ion & $\begin{array}{c}\text { One } \\
\text { Way } \\
\text { Time } \mathbf{s}\end{array}$ & $\begin{array}{l}\text { Round } \\
\text { Trip } \\
\text { Time s }\end{array}$ & $\begin{array}{l}\text { People } \\
\text { on } \\
\text { Floor }\end{array}$ & $\begin{array}{l}\text { Percent } \\
\text { Usage }\end{array}$ & $\begin{array}{l}\text { Round } \\
\text { Trips }\end{array}$ & $\begin{array}{l}\text { Time } \\
\text { per } \\
\text { Floor } \mathrm{s}\end{array}$ \\
\hline $\begin{array}{l}21 \\
20 \\
19 \\
18\end{array}$ & $\begin{array}{l}64.0 \\
60.8 \\
57.6 \\
54.4\end{array}$ & $\begin{array}{l}210.0 \\
199.5 \\
189.0 \\
178.5\end{array}$ & $\begin{array}{l}24.4 \\
23.4 \\
22.3 \\
21.2\end{array}$ & $\begin{array}{l}89.1 \\
87.0 \\
84.8 \\
82.7\end{array}$ & $\begin{array}{l}100 \\
100 \\
100 \\
100\end{array}$ & $\begin{array}{l}100.0 \\
100.0 \\
100.0 \\
100.0\end{array}$ & $\begin{array}{l}7 \\
7 \\
7 \\
7\end{array}$ & $\begin{array}{l}603.9 \\
589.0 \\
574.1 \\
559.1\end{array}$ \\
\hline
\end{tabular}




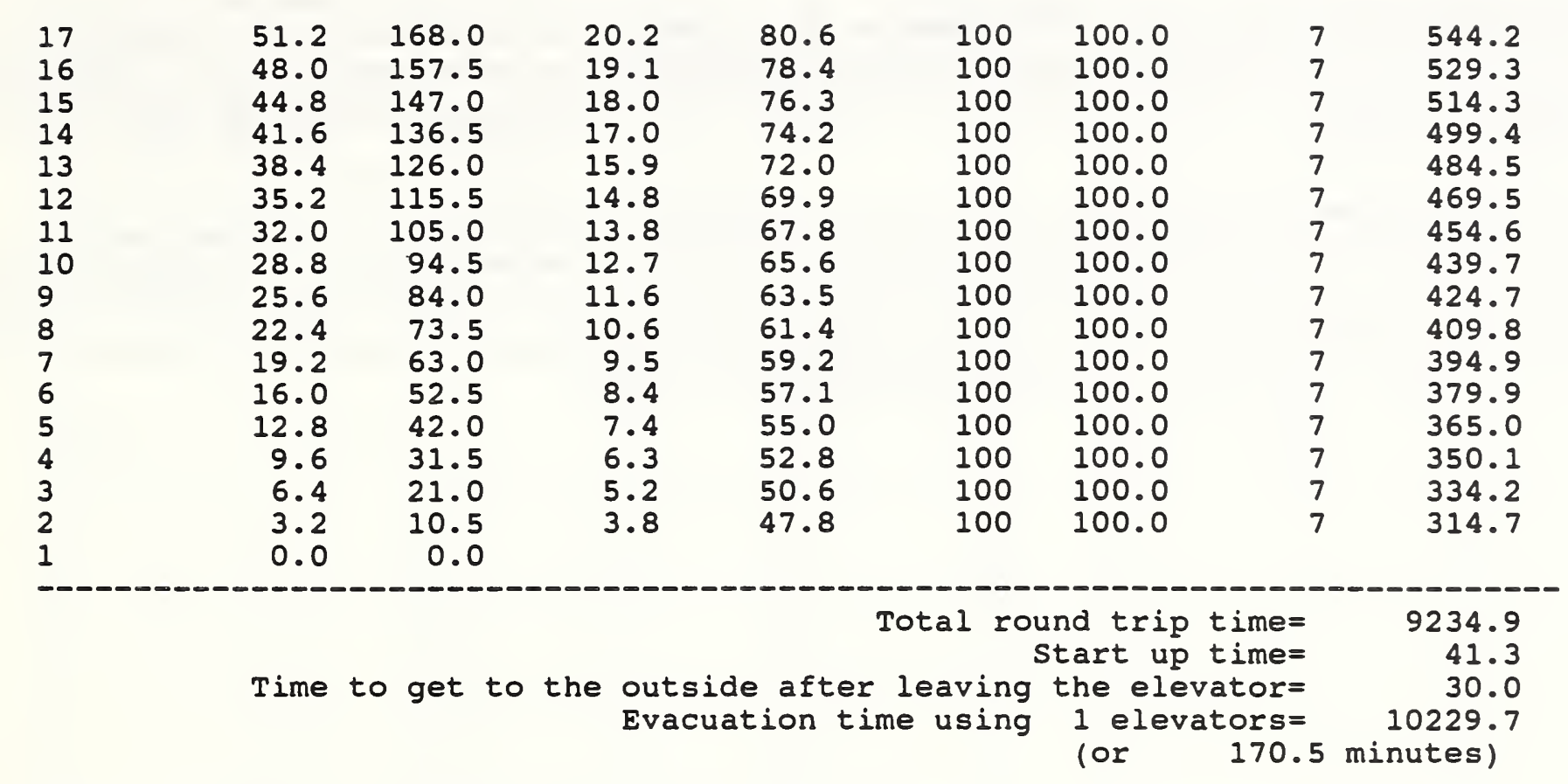

Do you want to save the output ( $Y$ or $N)$ ? $N$

Rerun program with new usage percentages ( $Y$ or $N$ )? $N$

Do you wish to rerun the entire program ( $Y$ or $N)$ ? $N$ 


\section{Appendix F ELVAC Example of a building with multiple rises}

This building has 38 floors and three rises of elevators: low rise, mid rise, and high rise. Each rise consists of a group of 6 elevators, but it is considered that only 5 of them are being used for evacuation, and one is out of service. The elevator cars in the low rise group travel at $3.10 \mathrm{~m} / \mathrm{s}(610 \mathrm{fpm})$, and the cars in the mid and high rise groups travel at $5.00 \mathrm{~m} / \mathrm{s}$ (984 fpm).

The ELVAC program was used to analyze each of the rises individually, and the computer output is listed in tables F.1, F.2, and F.3. In the case of the low rise elevators, all floors serviced by the elevators are shown. For both the mid and high rise elevators, only the floors involved in the evacuation were included in the ELVAC analyses (see tables F.2 and F.3). The evacuation times are $14.4,22.5$, and 25.0 minutes respectively for the low, mid, and high rise elevators. Since these evacuations are concurrent, the building evacuation time is 25 minutes. 


\section{Table F.1 38 Story Building: Low Rise Elevators}

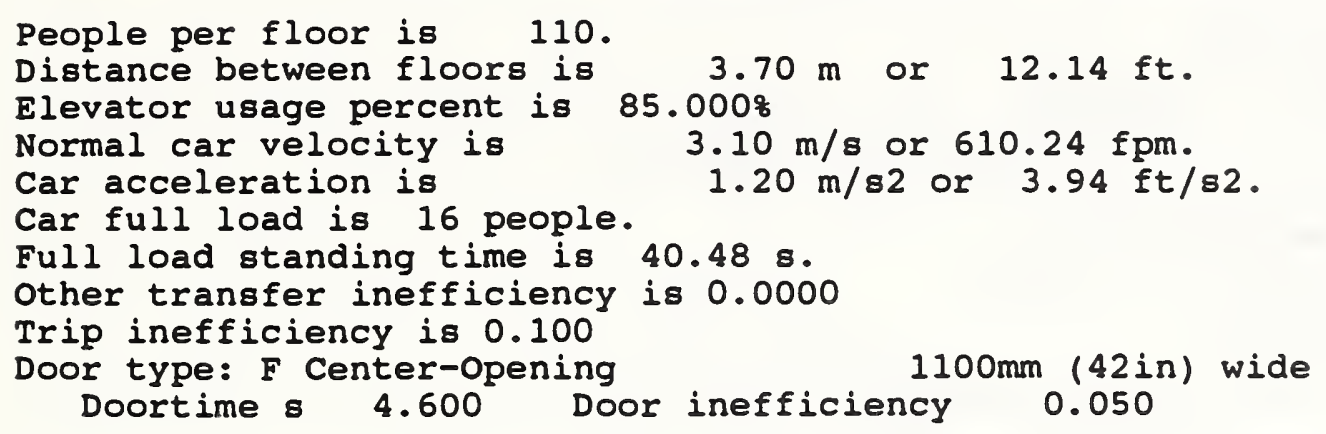

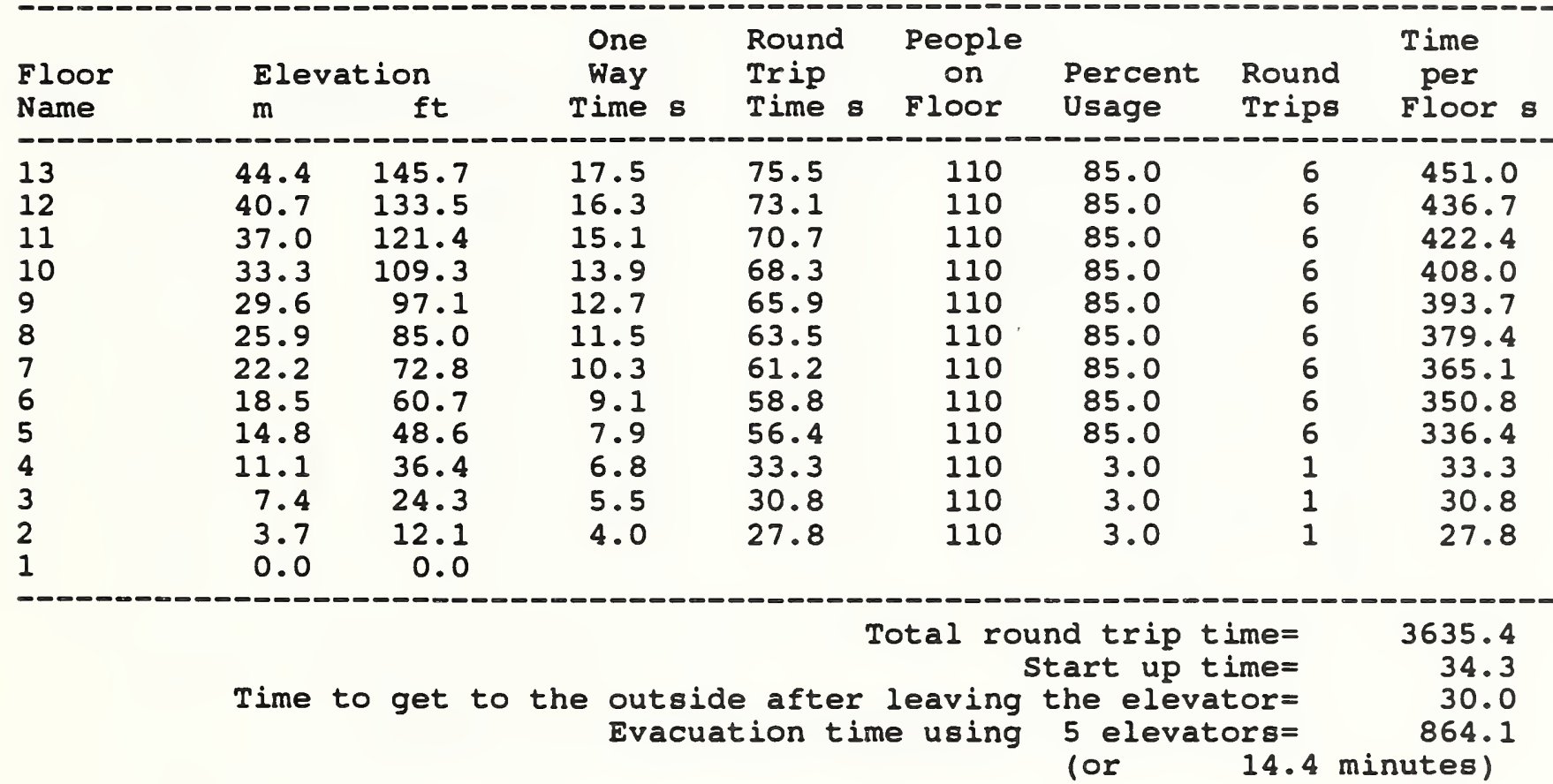




\section{Table F.2 38 story Building: Mid Rise Elevators}

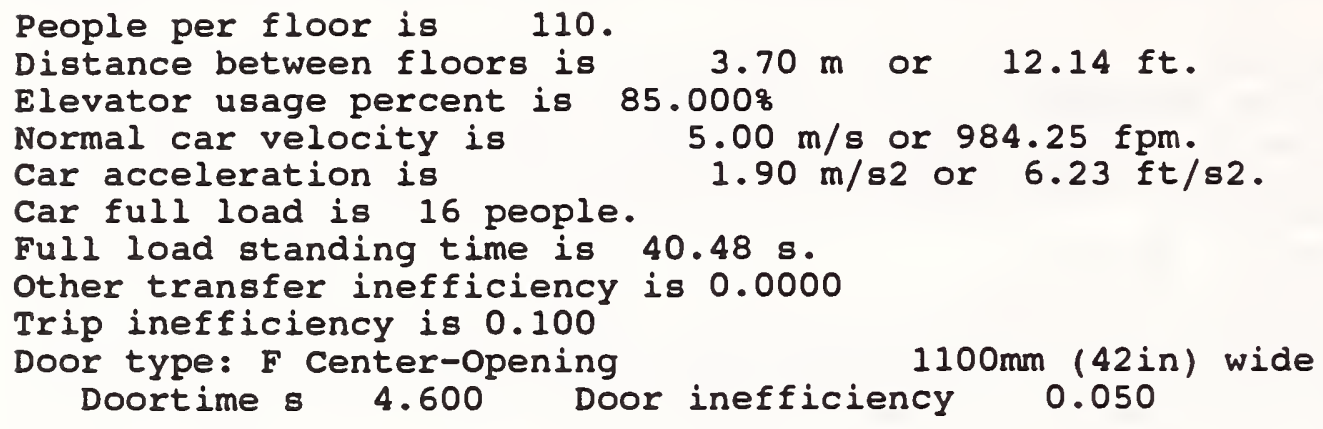

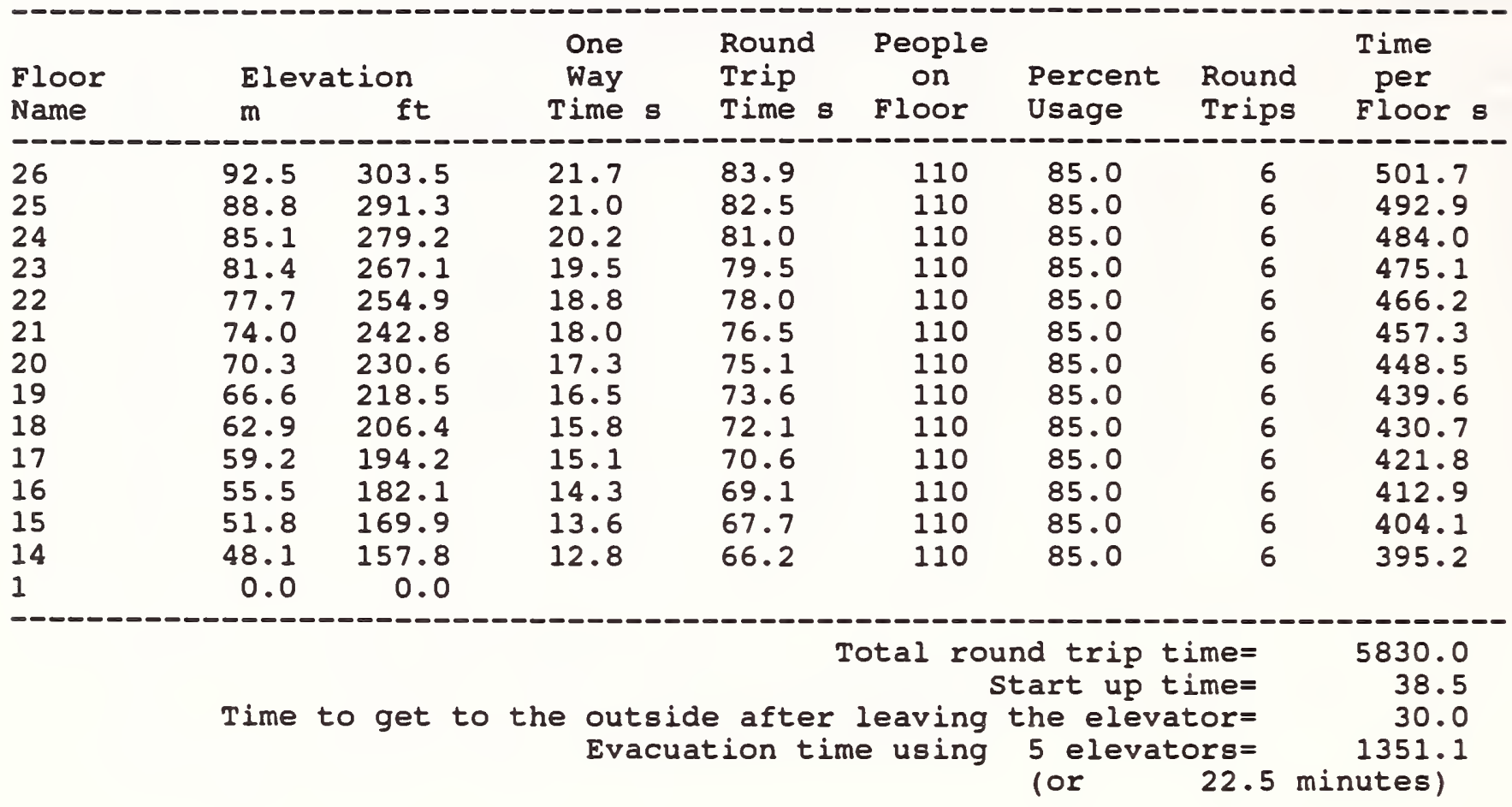




\section{Table F.3 38 Story Building: High Rise Elevators}

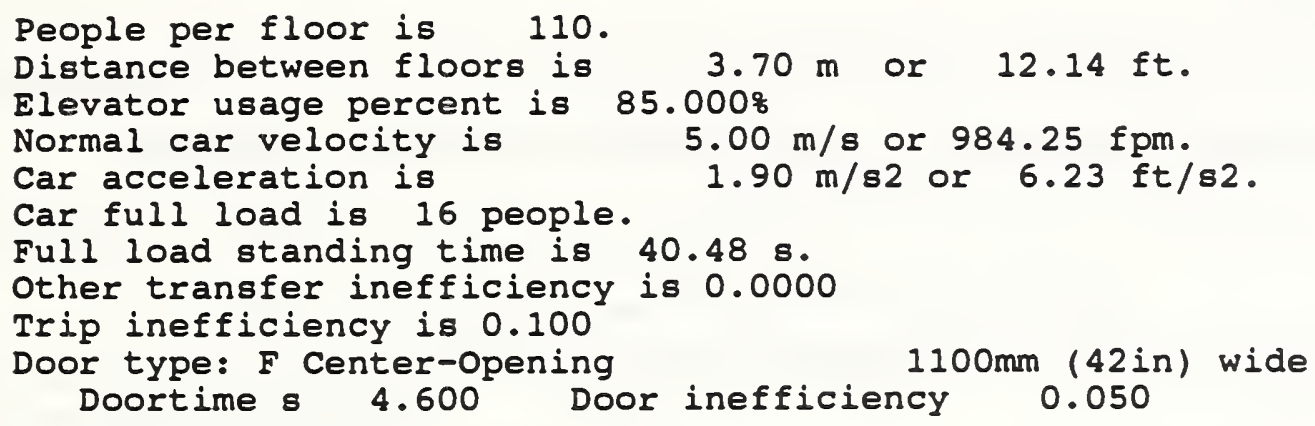

\begin{tabular}{|c|c|c|c|c|c|c|c|c|}
\hline $\begin{array}{l}\text { Floor } \\
\text { Name }\end{array}$ & $\begin{array}{l}\text { Ele } \\
\text { m }\end{array}$ & $\begin{array}{l}\text { tion } \\
\text { ft }\end{array}$ & $\begin{array}{l}\text { One } \\
\text { Way } \\
\text { Time s }\end{array}$ & $\begin{array}{l}\text { Round } \\
\text { Trip } \\
\text { Time s }\end{array}$ & $\begin{array}{l}\text { People } \\
\text { on } \\
\text { Floor }\end{array}$ & $\begin{array}{l}\text { Percent } \\
\text { Usage }\end{array}$ & $\begin{array}{l}\text { Round } \\
\text { Trips }\end{array}$ & $\begin{array}{l}\text { Time } \\
\text { per } \\
\text { Floor s }\end{array}$ \\
\hline $\begin{array}{l}38 \\
37 \\
36 \\
35 \\
34 \\
33 \\
32 \\
31 \\
30 \\
29 \\
28 \\
27 \\
1\end{array}$ & $\begin{array}{r}136.9 \\
133.2 \\
129.5 \\
125.8 \\
122.1 \\
118.4 \\
114.7 \\
111.0 \\
107.3 \\
103.6 \\
99.9 \\
96.2 \\
0.0\end{array}$ & $\begin{array}{r}449.1 \\
437.0 \\
424.9 \\
412.7 \\
400.6 \\
388.5 \\
376.3 \\
364.2 \\
352.0 \\
339.9 \\
327.8 \\
315.6 \\
0.0\end{array}$ & $\begin{array}{l}30.6 \\
29.9 \\
29.1 \\
28.4 \\
27.6 \\
26.9 \\
26.2 \\
25.4 \\
24.7 \\
23.9 \\
23.2 \\
22.5\end{array}$ & $\begin{array}{r}101.7 \\
100.2 \\
98.7 \\
97.3 \\
95.8 \\
94.3 \\
92.8 \\
91.3 \\
89.9 \\
88.4 \\
86.9 \\
85.4\end{array}$ & $\begin{array}{r}80 \\
80 \\
110 \\
110 \\
110 \\
110 \\
110 \\
110 \\
110 \\
110 \\
110 \\
110\end{array}$ & $\begin{array}{l}85.0 \\
85.0 \\
85.0 \\
85.0 \\
85.0 \\
85.0 \\
85.0 \\
85.0 \\
85.0 \\
85.0 \\
85.0 \\
85.0\end{array}$ & $\begin{array}{l}5 \\
5 \\
6 \\
6 \\
6 \\
6 \\
6 \\
6 \\
6 \\
6 \\
6 \\
6\end{array}$ & $\begin{array}{l}487.8 \\
480.4 \\
590.5 \\
581.7 \\
572.8 \\
563.9 \\
555.0 \\
546.1 \\
537.3 \\
528.4 \\
519.5 \\
510.6\end{array}$ \\
\hline
\end{tabular}

Time to get to the outside after leaving the elevator= 



